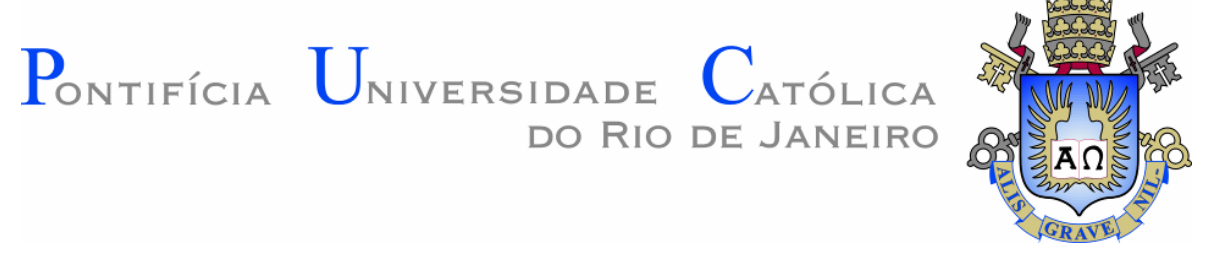

Carlos Besso

Development of laboratory methodologies for the determination of viscosity and yield stress of mass-flowing soils

Dissertação de Mestrado

Dissertation presented to the Programa de Pós-graduação em Engenharia Civil of PUC-Rio in partial fulfilment of the requirements for the degree of Mestre em Engenharia Civil.

Advisor: Prof. Tácio Mauro Pereira de Campos 


$$
\begin{array}{r}
\text { Pontifícia Universidade Católica } \\
\text { do Rio de Janeiro }
\end{array}
$$

Carlos Besso

\section{Development of laboratory methodologies for the determination of viscosity and yield stress of mass- \\ flowing soils}

Dissertation presented to the Programa de Pósgraduação em Engenharia Civil of PUC-Rio in partial fulfilment of the requirements for the degree of Mestre em Engenharia Civil. Approved by the undersigned Examination Committee.

Prof. Tácio Mauro Pereira de Campos Advisor

Departamento de Engenharia Civil e Ambiental - PUC-Rio

Prof. Celso Romanel Departamento de Engenharia Civil e Ambiental - PUC-Rio

Prof. Sérgio Tibana Departamento de Engenharia Civil e Ambiental - UENF 
All rights reserved.

\section{Carlos Besso}

Bachelor in civil engineering at Pontifícia Universidade Católica do Rio de Janeiro, in 2016. Worked with geotechnical laboratory projects and developments. His areas of interest vary in the environmental geotechnics, encompassing landslides, debris flow rheology and unsaturated soils.

Bibliographic data

Besso, Carlos

Development of Laboratory Methodologies for the Determination of Viscosity and Yield Stress of Mass-Flowing Soils / Carlos Besso; advisor: Tácio Mauro Pereira de Campos. -2018.

127 f. : il. color. ; $30 \mathrm{~cm}$

Dissertação (mestrado)-Pontifícia Universidade Católica do Rio de Janeiro, Departamento de Engenharia Civil e Ambiental, 2019.

Inclui bibliografia

1. Engenharia Civil e Ambiental - Teses. 2. Fluxo de massa.

3. Reologia. 4. Viscosidade. 5. Tensão de escoamento. I. de Campos, Tácio Mauro Pereira. II. Pontifícia Universidade Católica do Rio de Janeiro. Departamento de Engenharia Civil e Ambiental. III. Título.

CCD: 624 


\section{Acknowledgment}

First of all, I thank life for the benefit of thought, reasoning and, above all, of emotions.

I thank my parents, Isaac and Sandra, for believing in my potential since childhood and for having supported me in the decisions that have brought me here. The years in Cultura Inglesa were essential to this document writing. I appreciate your effort in keeping us updated with English vocabulary.

To my brothers, Elie and Rachel, for sharing the news, hearing my outburst and celebrating my achievements.

To my advisor, professor Tácio de Campos, who has been orientating me since 2014, in two projects of scientific initiation, in graduation final project, master and soon in the doctorate. Professor, thank you for the teachings, trust and partnership that we have developed in those 5 years!

To professor Franklin Antunes for the friendship and commitment in the teaching of engineering geology.

To professor Paulo Mendes for granting use of the Laboratory of Rheology of the Department of Mechanical Engineering of PUC-Rio.

To Professor Sidnei Paciornik, for his patience and help with ImageJ software.

The teacher Mariana Benessiuti, who first taught me to work in a geotechnical laboratory, besides the professional and academic teachings. Thank you Mariana.

To the members of the Laboratory of Geotechnics and Environment of PUC-Rio, Amauri, Edson, Josué and Carlos, for the help and partnership developed in those years.

To the personnel of the Laboratory of Rheology of PUC-Rio, mainly Priscila and Roberta, for the sympathy and aid in the appointment of schedules.

To the technicians of the Laboratory of Structures of PUC-Rio, José Nilson, Euclides, Rogério and Max, for the manual and intellectual aid in the design of the equipment. 
To Carlos Bernardi, who in life helped me to explore the paths of inner peace.

To Pedro Aires, master mountaineer with whom I learned most about discipline, concentration and self-overcoming.

To the friends of rapeize, with whom I share discussions and glasses at the bar tables.

To my academic brothers, Karl, Miguel and Vinicius, for the theoretical discussions and the good reviews on the balcony of the favelinha.

Friends who helped me in the lab. Karl, Miguel, Vinicius, Carol, Lorena, Filipe, thank you!

This study was financed in part by the Coordenação de Aperfeiçoamento de Pessoa de Nível Superior - Brasil (CAPES) - Finance Code 001. 


\section{Abstract}

Besso, Carlos; de Campos, Tácio Mauro Pereira (Advisor). Development of Laboratory Methodologies for the Determination of Viscosity and Yield Stress of Mass-Flowing Soils. Rio de Janeiro, 2019. 127p. Dissertação de Mestrado - Departamento de Engenharia Civil e Ambiental, Pontifícia Universidade Católica do Rio de Janeiro.

To evaluate debris flow downhill movements, it is necessary a rheological approach through constitutive modelling the descendent moving mass. Bingham's model is widely employed in the debris flow literature, its input parameters being plastic viscosity and yield stress. Such analysis provides understandings of the propagation of the debris motion in the field, once it provides an estimate of its velocity, thickness and range area. The present study presents a proposal for the assessment of soil yield stress and plastic viscosity, by laboratorial testing on a cylindrical tube slump test. Through the definition of shearing rates in the slump tests, yield stress and viscosity were determined on a plate-plate rheometer. Two natural soils from Rio de Janeiro, Brazil, with differing grain size distribution and plasticity, were used in the investigation. The experimental results obtained are compared with analytical and semi empirical solutions from the literature, and show that care must be taken in defining viscosities based only on data related to grain size. Correlations were obtained concerning to soil moisture and shear rates, defined in the slump tests, and also between plastic viscosity and yield stress, defined in the rheometer tests. As a result, good relationships between water content and both yield stress and viscosity were established. Comparing the obtained data with other results available in the literature it is concluded that the developed experimental methodology may provide a simple way to evaluate rheological parameters of soils for debris flow analyses.

\section{Keywords}

Debris flow rheology; yield stress; viscosity. 


\section{Resumo}

Besso Carlos; de Campos, Tácio Mauro Pereira. Desenvolvimento de Metodologias de Laboratório para a Determinação da Viscosidade e Tensão de Escoamento de Solos sob Condições de Fluxo de Massa. Rio de Janeiro, 2019. 127p. Dissertação de Mestrado - Departamento de Engenharia Civil e Ambiental, Pontifícia Universidade Católica do Rio de Janeiro.

Para avaliação de movimentos de corridas de detritos em vertentes montanhosas, é necessária uma abordagem reológica através de modalegem consitutiva da massa de solo descendente. O modelo de Bingham é amplamente empregado na literatura de corridas, sendo seus parâmetros a viscosidade plástica e tensão de escoamento. Esta análise provê o entendimento da propagação do movimento dos detritos em campo, ao fornecer uma estimativa de sua velocidade, espessura e alcance. O presente trabalho apresenta uma proposta para determinação da tensão de escoamento e viscosidade de solos, através de ensaios de abatimento de tubo cilíndrico. A tensão de escoamento e a viscosidade foram determinadas em um reômetro rotaticonal, com base nas taxas de cisalhamento definidas nos ensaio de abatimento. Foram estudados dois solos naturais do Rio de Janeiro, com diferentes granulometrias e plasticidades. Os resultados experimentais obtidos são comparados com soluções analíticas da literatura, e mostram que deve-se ter cuidado na definição destes parametros reológicos com base apenas em dados relacionados a distribuição granulométrica dos solos. Como resultado, foi estabelecida uma relação entre teor de umidade, tensão de escoamento e viscosidade. Comparando os dados obtidos com resultados disponíveis na literatura, conclui-se que a metodologia desenvolvida pode fornecer uma maneira simples de avaliar parâmetros reológicos de solos para análises de corridas.

\section{Palavras-chave}

Reologia de corridas de detritos; tensão de escoamento; viscosidade. 


\section{Table of contents}

1 Introduction $\quad 15$

1.1 Introduction $\quad 15$

1.2 Motivation of the research 15

$\begin{array}{ll}1.3 \text { Objective } & 17\end{array}$

$\begin{array}{ll}1.4 \text { Research methodology } & 17\end{array}$

$\begin{array}{ll}1.5 \text { Structure of the research } & 18\end{array}$

2 Literature Review 19

2.1 Debris flow rheology 19

2.2 Rheological models 23

2.2.1 Newtonian fluids $\quad 25$

2.2.2 Non-Newtonian fluids $\quad 25$

2.3 Slump test 29

2.3.1 Literature solutions $\quad 32$

3 Studied materials $\quad 45$

3.1 Sampling 46

3.2 Advanced campus of PUC in Tinguá 47

3.2.1 Location $\quad 47$

3.2.2 Geology and geomorphology 47

3.2.3 Climate aspects $\quad 47$

3.3 Main campus of PUC-Rio 49

3.3.1 Location 49

3.3.2 Geology and geomorphology 49

3.3.3 Climatic aspects $\quad 50$

3.4 Physical, chemical and mineralogical characterization 51

3.4.1 Physical characterization 51

3.4.2 Chemical characterization 55

3.4.3 Mineralogical characterization $\quad 57$

4 Equipment and methodologies $\quad 59$

4.1 Cylindrical tube slump test $\quad 59$

4.1.1 Modified slump test set-up $\quad 60$

$\begin{array}{ll}4.1 .2 \text { Tubes design } & 62\end{array}$ 
4.1.3 Displacements measurement $\quad 64$

4.1.4 Shear rate interpretation $\quad 69$

$\begin{array}{ll}4.1 .5 \text { Experimental procedure } & 71\end{array}$

$\begin{array}{ll}4.2 \text { Rheometer } & 74\end{array}$

$\begin{array}{ll}4.2 .1 \text { Geometry } & 74\end{array}$

4.2.2 Flow tests 76

4.2.3 Interpretation methodology 76

4.2.4 Experimental procedure $\quad 78$

5 Results and discussions $\quad 80$

5.1 Cylindrical tube slump test $\quad 80$

5.1.1 Tubes analysis $\quad 80$

5.1.2 Physical indexes $\quad 82$

5.1.3 Geometrical analyses 83

5.1.4 Kinematical analyses $\quad 84$

5.1.5 Shear rates determination $\quad 91$

5.1.6 Literature solutions 95

$\begin{array}{ll}5.2 \text { Rheometer } & 97\end{array}$

5.2.1 Shear stress analyses $\quad 97$

5.2.2 Viscosity analyses 101

5.3 Combined analyses 103

5.4 Final discussions 104

6 Conclusions and further investigations 110

6.1 Summary and Conclusions $\quad 110$

6.1.1 Cylindrical tube slump test 110

6.1.2 Rheological behavior: viscosity and yield stress analyses 111

6.2 Suggestions for Future Research 112 


\section{List of Figures}

Figure 2.1 - Flow behaviour of fine-grained sediments (adapted from Jeong, 2014)

Figure 2.2 - Parallel plate model proposed by Newton to explain the concept of viscosity (Barnes et al., 1969). 23

Figure 2.3 - Real fluids classification (Adapted from Galindo, 2013). 25

Figure 2.4 - Rheological behaviour of time indepent fluids (Adapted from Fox \& McDonald, 1998).

Figure 2.5 - Shear stress flow curve of a Carbopol ${ }^{\circledR}$ with yield stress $\tau_{0}=$ $62 \mathrm{~Pa}$ (Pierre et al., 2013).

Figure 2.6 - Schematic diagram of the slump test with reference axis (Pashias, et al., 1996).

Figure 2.7 - Schematic diagram of the initial and final shear stress distribution (Pashias, et al., 1996).

Figure 2.8 - Initial cylinder shape and cylindrical coordinates (Pierre et al., 2013).

Figure 2.9 - Axis coordinates in the Abrams Cone geometry.

Figure 2.10 - Cylindrical tube slump test, prior to and after testing (Baudez and Coussot, 2004).

Figure 2.11 - Calibration parameters for scaling laws between yield stress and plastic viscosity (Staron et al., 2004).

Figure 3.1

Figure 3.2 - Natural slope within the advanced campus of PUC in Tinguá (ACP).

Figure 3.3 - Superficial excavation in the natural slope within the main campus of PUC-Rio (MCP).

Figure 3.4 - Geological map of Tinguá (Adapted from de Campos, 2012) 48

Figure 3.5 - Map location of the main campus of PUC-Rio, where MCP soil was collected

Figure 3.6 - Geotechnical profile of the Experimental Station II of PUC-

Rio (Dylac, 1994)

Figure 3.7 - Grain size distribution of the two soils. Curves shown for sedimentation tests performed with both sodium hexametaphosphate $(\mathrm{H})$ and water (W) as deflocculant. 
Figure 3.8 - ACP soil sedimentation tests after 21 hours of start: (A) With sodium hexametaphosphate as deflocculant. (B) With water was deflocculant. (Adapted from Galindo, 2013).

Figure 3.9 - DTA results for the ACP and MCP soils.

Figure 4.1 - Modified slump test set-up. (A) Before testing. (B) After testing.

Figure 4.2 - Sketch of the modified slump test set-up. (A) Before testing. (B) After testing.

Figure 4.3 - Series of tested tubes with different heights $\mathrm{H}_{0}$, and same internal and external diameters: 10 and $13 \mathrm{~cm}$, respectively. (A) $\mathrm{H}_{0}=10$ cm. (B) $\mathrm{H}_{0}=15 \mathrm{~cm}$. (C) $\mathrm{H}_{0}=20 \mathrm{~cm}$.

Figure 4.4 - Verification of no radial deformation due to constriction. 62

Figure 4.5 - Design sketch of the tubes' apparatus.

Figure 4.6 - Vertical displacements measurement devices. (A) Left: potentiometer and data acquisition system. Centre: laptop. Right: LVDT attached to the calliper. (B) Left: MyPCLab data acquisition system. Right: Tecnolog potentiometer.

Figure 4.7 - Test filming set-up. (A) White background. (B) Led lamp. (C) Camera attached to a tripod. (D) Position marks for the tripod.

Figure 4.8 - Procedures for brightness and contrast requirements by the DIP software.

Figure 4.9 - Original frame stack obtained through test filming. Red lines assign the frames in which the soil motion is over.

Figure 4.10 - Output frame stack given by the ImageJ software.

Figure 4.11 - Shear rate interpretation by graphical analysis of a typical velocity-displacement curve.

Figure 4.12 - Typical kinematical curves, for both runout and slump movements, obtained in the cylindrical slump test. (A) Displacement-time curves. (B) Velocity-time curves. (C) Acceleration-time curves.

Figure 4.13 - Soil homogenization with the mixer. (A) Frontal view. (B) Lateral view.

Figure 4.14 - Cylindrical tube filling with soil. (A) Soil mass in the mixer prior to filling the tube. (B and C) Tube filling. (D) Soil mass in the mixer after filling the tube.

Figure 4.15 - procedures taken after the end of the test. (A) Sub-sample collecting for moisture verification. $(B)$ Final diameter $\left(D_{f}\right)$ measuring. $(C$ and D) Final height $\left(\mathrm{H}_{\mathrm{f}}\right)$ measuring. 
Figure 4.16 - Discovery rotational rheometer and its coupled computer for data acquisition.

Figure 4.17 - Cross hatch plates used in the rheometer. Left: bottom plate. Right: upper plate (Galindo, 2013). 75

Figure 4.18 - Rheometer sample with a 2.0 mm gap (Galindo, 2013). 75

Figure 4.19 - Typical shear stress flow curve obtained in the sweep tests performed in the rheometer.

Figure 4.20 - Typical viscosity flow curve obtained in the sweep tests performed in the rheometer.

Figure 4.21 - Rheometric tests' experimental procedures (adapted from Galindo, 2013). (A) Temperature adjustment. (B) Soil homogenization in a mixer. (C) Material filling with a syringe. (D) Gap adjustment down to $2.0 \mathrm{~mm}$. (E) Excess of material removal. (F) Test execution.

Figure 5.1 - Comparisons between yield stresses obtained in the rheometer and in the analytical solution for cylindrical slump test. The latter performed with tubes $\mathrm{R} 2\left(\mathrm{H}_{0}=10 \mathrm{~cm}\right), \mathrm{R} 3\left(\mathrm{H}_{0}=15 \mathrm{~cm}\right)$ and $\mathrm{R} 4\left(\mathrm{H}_{0}=20 \mathrm{~cm}\right)$. (A) ACP samples' results. (B) MCP samples' results.

Figure 5.2 - Comparisons between geometrical ratios obtained in the cylindrical slump tests. Relationships concerning to aspect, height and radius variation ratios $\left(\Delta \mathrm{R} / \Delta \mathrm{H}, \Delta \mathrm{R} / \mathrm{R}_{0}\right.$ and $\Delta \mathrm{H} / \mathrm{H}_{0}$, respectively) and water content are drawn for both ACP (squares) and MCP (circles) samples. $\quad 84$

Figure 5.3 - ACP's samples kinematics curves of the slump (vertical) movement, obtained in the cylindrical slump test. (A) Displacement-time curves. (B) Velocity-time curves. (C) Acceleration-time curves.

Figure 5.4 - ACP's samples kinematics curves of the runout (horizontal) movement, obtained in the cylindrical slump test. (A) Displacement-time curves. (B) Velocity-time curves. (C) Acceleration-time curves. $\quad 88$

Figure 5.5 - MCP's samples kinematics curves of the slump (vertical) movement, obtained in the cylindrical slump test. (A) Displacement-time curves. (B) Velocity-time curves. (C) Acceleration-time curves. 89

Figure 5.6 - MCP's samples kinematics curves of the runout (horizontal) movement, obtained in the cylindrical slump test. (A) Displacement-time curves. (B) Velocity-time curves. (C) Acceleration-time curves. 90

Figure 5.7 - Shear rates variation with water content, obtained in the cylindrical slump tests performed with both ACP and MCP samples. $\quad 92$

Figure 5.8 - Shear rate interpretation of the ACP samples tested in the cylindrical slump tests. (A) $\mathrm{w}=1,4 \mathrm{LL}$. (B) $\mathrm{w}=1,6 \mathrm{LL}$. (C) $\mathrm{w}=1,7 \mathrm{LL}$. (D) $\mathrm{w}=1,8 \mathrm{LL}$. 
Figure 5.9 - Shear rate interpretation of the MCP samples tested in the cylindrical slump tests. (A) $\mathrm{w}=1,5 \mathrm{LL}$. (B) $\mathrm{w}=1,6 \mathrm{LL}$. (C) $\mathrm{w}=1,7 \mathrm{LL}$. (D) $\mathrm{w}=1,8 \mathrm{LL}$.

Figure 5.10 - Shear stress flow curves obtained in the rheometer. (A) ACP soil. (B) MCP soil.

Figure 5.11 - Comparison between yield stresses determined in both acceleration and deceleration ramps of the flow tests performed, with the two soils, in the rheometer. Linear 1:1 relation highlights the concordant and the discordant points.

Figure 5.12 - Viscosity flow curve obtained in the rheometer within the MCP sample with $\mathrm{w}=1,8 \mathrm{LL}$.

Figure 5.13 - Viscosity flow curves obtained in the rheometer. (A) ACP soil. (B) MCP soil.

Figure 5.14 - Linear axis viscosity - shear stress - shear rate relationships obtained in the rheometer within the MCP sample with $\mathrm{w}=1,8 \mathrm{LL}$. Dotted lines assign the slump test shear rate interval.

Figure 5.15 - Plastic viscosities, found in the rheometer, corresponding to the shearing rates obtained in the cylindrical slump tests performed with the two soils.

Figure 5.16 - Comparison between analytical and experimental results, where linear 1:1 relation outlines the concordant points. (A) Viscosity results. (B) Yield stress results.

Figure 5.17 - Yield stress variation with physical indexes. (A) Water content. (B) Solid concentration.

Figure 5.18 - Plastic viscosity variation with physical indexes. (A) Water content. (B) Solid concentration.

Figure 5.19 - Comparison between results from this research and other studies. 


\section{List of Tables}

Table 2.1 - Models, equation and parameters of non-Newtonian time indepent fluids. (Adapted from Machado, 2002).

Table 3.1 - Specific gravity values obtained for the two soils

Table 3.2 - Grain size distribution of the two soils, referred to sedimentation tests performed both with sodium hexametaphosphate $(\mathrm{H})$ and water (W) as deflocculant.

Table 3.3 - Results of limits of consistency and activity of clays for the two soils.

Table 3.4 - Chemical composition of the both soils.

Table 4.1 - Design of the tubes' apparatus. Dead weights' diameters were set to result in equal total masses of the apparatus. All tubes have the same internal and external diameters: 10 and $13 \mathrm{~cm}$, respectively. All dead weights have the same height: $14.3 \mathrm{~cm}$.

Table 5.1 - Yield stresses obtained in the rheometer and in the analytical solution for the cylindrical slump test. The latter performed with tubes R2 $\left(\mathrm{H}_{0}=10 \mathrm{~cm}\right), \mathrm{R} 3\left(\mathrm{H}_{0}=15 \mathrm{~cm}\right)$ and $\mathrm{R} 4\left(\mathrm{H}_{0}=20 \mathrm{~cm}\right)$. All the tubes have the same initial radius $\mathrm{R}_{0}=5 \mathrm{~cm}$.

Table 5.2 - ACP and MCP soils' physical indexes, obtained in the cylindrical slump test samples.

Table 5.3 - ACP and MCP soils' geometrical parameters, related to both initial and final conditions of the cylindrical slump tests. All the tubes have the same initial height $\mathrm{H}_{0}=20 \mathrm{~cm}$, and the same initial radius $\mathrm{R}_{0}=5 \mathrm{~cm} . \quad 83$

Table 5.4 - Polynomial fitting of the displacement-time curves, obtained with Excel trendline tool.

Table 5.5 - Parameters related to the adopted methodology for graphical interpretation of the shear rates, for both ACP and MCP samples used in the cylindrical slump tests.

Table 5.6 - Calculation routine employed to the analytical determination of yield stresses, through Baudez \& Coussot (2004) solution.

Table 5.7 - Calculation routine employed to the analytical determination of plastic viscosities, through Staron et. al (2004) solution.

Table 5.8 - Yield stress determined in both acceleration and deceleration ramps of the flow tests performed in the rheometer with the two soils. 100

Table 5.9-General results concerning to physical indexes and rheological parameters obtained by both analytical and experimental methodologies. 104 


\section{1 \\ Introduction}

\section{1}

\section{Introduction}

Natural disasters are a great socioeconomic problem as they cause extensive material damage and are usually associated with loss of life. Among the phenomena that stand out the most are: earthquakes, floods and mass movements (Gomes, 2006).

Intensely studied by several researchers, although considered important in relief modeling processes, mass movements are, according to the UN (1993), the natural phenomena that cause the most financial losses and deaths in the world.

According to Augusto Filho and Virgili (1998), the first studies on landslides go back more than 2000 years, in countries such as China and Japan. Especially in Brazil, the beginning of these studies is due to the slides occurred in Morro de Santos, São Paulo, in 1928 and 1956, and in the city of Rio de Janeiro and surrounding regions, in 1966 and 1967 (de Campos, 1984).

Located between the sea and the mountains, the city of Rio de Janeiro has suffered numerous tragedies during periods of heavy rainfall, particularly in the summer (Soares, 1999). It is estimated that the last great tragedy that occurred in January 2011, in the mountainous region of Serra dos Órgãos, more than 3000 landslides have occurred, involving the death of approximately one thousand people. Such event involved, among others, debris flow movements.

\section{2 \\ Motivation of the research}

Debris flow comprises one of the most damaging movements among landslides (de Campos \& Galindo, 2015). Its propagation along drainage channels is associated with high velocities and wide areas of deposition. (e.g. Hutchinson, 1988; Hungr et 
al., 2001). Few researches have been taken to provide rheological parameters to such phenomena analyses and appropriate design of contentions, such as the flexible barriers widely employed nowadays.

According to Hassiotis et al. (1997), to ensure the stability of natural or artificial slopes a fundamental problem remains for the geotechnical engineer, and in order to solve it, it is necessary to understand the mechanisms of rupture as well as factors associated with instability.

In the case of mass-flow events, Macias et al (1997) point out the existence of two procedures to understand their mechanical behavior:

- empirical relationships: based on observation data and field measurements at various events;

- analytical relations by retro analysis: based on the geometric characteristics and rheological behavior, the latter represented by the parameters of yield stress and viscosity.

In terms of the ease of obtaining the fundamental parameters, analytical relations have a great advantage over the empirical relations approach (Hungr et al, 1984). However, in the case of soils, the lack of a laboratory test, to directly determine such rheological parameters, stands out.

Macias et al. (1997) also point out that the mechanical behavior of the races is both macro viscous (occurring when the dispersion resistance is controlled by the viscosity of the fluid) and transitory (in this case, the resistance is provided by both the dispersive pressure, collision between the particles of the debris particles, and the viscosity of the fluid).

This fact confirms the marked influence of viscosity on the resistance of these materials to the flow, and its extreme importance for the determination of the velocity values of flow events to be adopted in the projects of containment or correction of affected areas.

Within the frame of a fluid mechanics treatment, the rheological characteristics of the flowing material would be useful for a better understanding of the flow characteristics of such events. Rheological models thus obtained may indeed be input to numerical simulations to predict the characteristics of debris flow 
events, and to map hazard areas (e.g. Laigle et al., 2003; Rickenmann et al., 2006). Here we assume that we can get interesting information in that field by studying the rheological characteristics of two tropical soils remixed with different amounts of water.

\section{3 \\ Objective}

In this context, the present work proposes the development of a methodology for the experimental determination of the Bingham's model parameters (soil viscosity and yield stress), aiming to subsidize studies associated to the development of flow events. Among the specific objectives are:

- to develop an equipment based on adaptations of the cylindrical tube slump test;

- to establish a standard methodology of shear rate interpretation to be used in the tests to determine soil viscosity and yield stress;

- to obtain soil's rheological parameters from other tests, adapting devices used for fluids testing, such as rotational rheometer;

- to analyse the existence of a correlation between the rheological parameters and physical indexes, such as water content and solids volumetric concentration.

\section{4}

\section{Research methodology}

Two natural soils from Rio de Janeiro were studied. Firstly, cylindrical slump tests were performed aiming the determination of the shear rate developed by the materials in this test. For this, a methodology is proposed to define these rates, throughout a kinematical analysis of the test. Secondly, rheometric tests were taken within samples with the same moistures as in the slump tests, and then yield stress and viscosity were interpreted in the flow curves provided by the rheometer. Finally, the experimental results are compared with analytical solutions for the cylindrical slump test problem, which provide both yield stress and viscosity values. 


\section{5}

\section{Structure of the research}

This research is divided in six parts, which are organized as follows:

Chapter 2 introduces basic concepts and necessary background based on the existing literature to understand the overall aspects related to debris flow rheology and to gather crucial information about the classification of rheological models available.

Chapter 3 describes a characterization of the studied soils and its natural sites. For this, a description is given about the geological-geotechnical aspects of the chosen areas, as well as its climate and geomorphology. Finally, physical, chemical and mineralogical characterization of the studied soils are presented.

Chapter 4 sets out a complete description of the equipment used in this research, as well as the methodologies involved in the interpretation of the Bingham's rheological parameters.

In the chapter 5, results are presented and discussed. Finally, chapter 6 reports conclusions and suggestions for further investigations. 


\section{2 \\ Literature Review}

\section{1}

\section{Debris flow rheology}

Debris flow comprises one of the most damaging movements among landslides (de Campos \& Galindo, 2015). Its propagation along drainage channels is associated with high velocities and wide areas of deposition. (e.g. Hutchinson, 1988; Hungr et al., 2001). Jakob \& Hungr (2005) state that debris flow also comprises granular materials, eventually with fines of low plasticity, and classify flow slides encompassing debris, with high-plasticity fines, as mud flows. Though, mud flows do not necessarily follow natural drainage channels. Also, in the southern part of Brazil, initialisation of debris flow may be associated with the onset of shallow landslides under heavy rainfall conditions (Fernandes et al., 2004; Gomes et al., 2008). The saturated, finer portion of the soil in these landslides usually comprises clusters formed by clay-sized particles, with silt and sand sizes. Depending on the mineralogy and the evolution stage of laterization processes, these tropical soils may have low to high plasticity. Thus, in the present work, it is considered that the soils tested, regardless of their plasticity, compose the fine soil-matrix of debris flow.

To evaluate debris flow's effects and the associated risks, it is necessary to understand the mechanics of its evolution down the slope (e.g. Jakob \& Hungr, 2005; Takahashi, 2007). A number of models or procedures for evaluating or backanalysing debris flow development are available, including both empirical relationships and analytical- numerical proposals (e.g. Hungr et al., 1984; Macias et al., 1997; Chen \& Lee, 2000; Rickenmann et al., 2006; Pastor et al., 2009; Iverson, 2010; Redaelli et al., 2015). In any case, without an estimate of the viscosity of the flowing mass, it is not possible to arrive at a sound conclusion in relation to the velocity that the flowing mass may develop within variable flow- 
channel geometry, or in relation to the flowing mass spread out downstream under conditions of smoother ground levelling.

Soil viscosity, $\eta$, is a rheological parameter (e.g. Gupta \& Pandya, 1966; Vyalov, 1986) that reflects a viscoplastic soil behaviour (e.g. Komamura \& Huang, 1974; Abdullah, 2011). Viscoplastic fluids under shearing behave as high-viscosity solid materials until they reach a given yield stress, $\tau_{0}$. Thus, they represent a nonNewtonian type of fluid (e.g. Vliet \& Lyklema, 2005). When this stress is exceeded, the structure of the material collapses and it behaves as a liquid.

Studying polymeric fluids, Bird et al. (1987) observed a linear relationship between shear stress and rate of shear after reaching $\tau_{0}$. Drawing a parallel between polymeric liquids and clay soils under high water content (for example, with liquidity index above 1.5), it could be said that clay slurries may behave as Bingham fluids. Investigations related to debris flow indicate that $\eta$ and $\tau_{0}$ increase exponentially with sediment concentration (e.g. O'Brien \& Julien, 1988; Julien \& León, 2000; Boniello et al., 2010), confirming that soils behave as non-Newtonian fluids, but not necessarily as Bingham fluids. Fakher et al. (1999), studying soils with natural water contents well above their liquidity limits, showed that the occurrence of a Bingham fluid behaviour would depend on the rate of shearing employed in rotary viscometer tests. Considering a modified Bingham model (Imran et al., 2001) and fine-grained sediments, Jeong (2014) summarised such behaviour as comprising three flow regimes (refer to Fig. 2.1):

(a) pseudo-Newtonian viscosity, $\eta_{\mathrm{pN}}$ (the slope of the flow curve in regime I);

(b) apparent yield stress (the shaded rectangular zone, shown as regime II);

(c) Bingham viscosity, also known as plastic viscosity, $\eta_{\mathrm{h}}$ (the slope of the flow curve in regime III). From Figure 2.1 it can be observed that the pseudo-Newtonian viscosity, $\eta_{\mathrm{pN}}$, is higher than the plastic viscosity, $\eta_{\mathrm{h}}$. Data from Jeong (2014) on fine-grained sediments indicate such a difference on the order of 103.

Rotary viscometers were developed to evaluate the viscosity of fluids. They have, however, also been used to evaluate the yield stress of soils (e.g. Komamura 
\& Huang, 1974; Torrance, 1987) and standards are available to do so (ASTM, 1987; BSI, 1994). Rheometers are more modern devices used to measure $\eta$ and $\tau_{0}$ of fluids (e.g. Klein, 1992; Pipe et al., 2008) as well as further viscoelastic properties of solids, semi-solids and liquids (e.g. Van Wazer et al., 1966; Macosko, 1994). Jeong (2014) suggests that, depending on the range of shearing rates, different types of viscometers are better suited for determination of the viscosity of fine-grained soils.

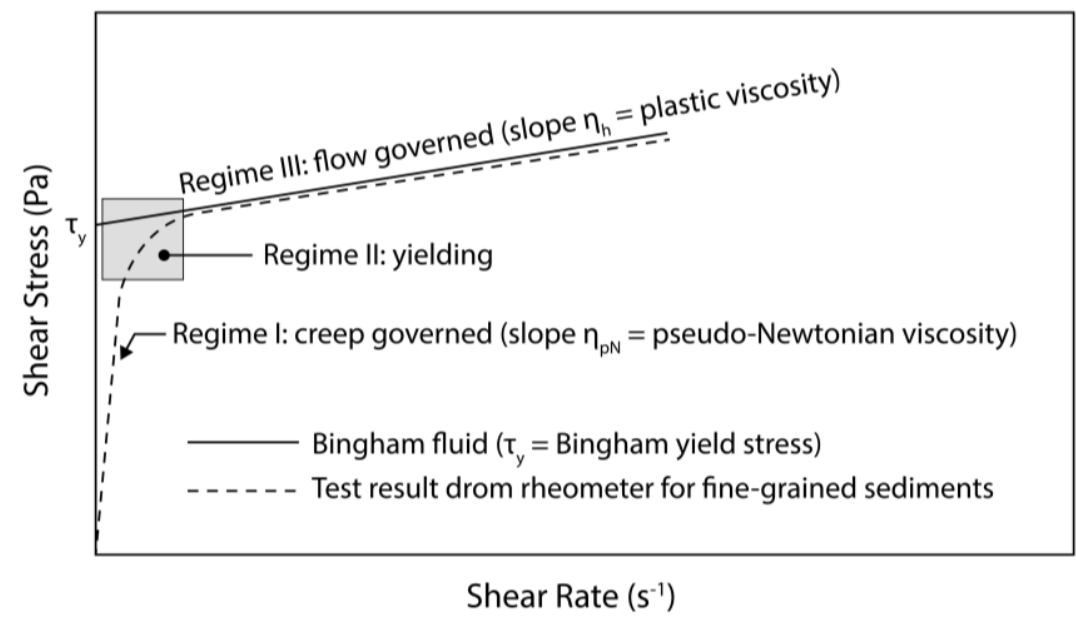

Figure 2.1 - Flow behaviour of fine-grained sediments (adapted from Jeong, 2014)

No standards are available to evaluate rheological soil parameters from single geotechnical tests. Nguyen \& Boger $(1983,1985)$ used the mini-vane laboratory test to evaluate yield stresses of concentrated soil suspensions, showing that this simple type of geotechnical test may provide a reliable direct measure of $\tau_{0}$. Mahajan \& Budhu (2009) proposed the use of the laboratory fall cone test to estimate the viscosity of soils at low liquidity indexes (LI $<1.5)$, finding that, for kaolin samples, shear viscosity decreases exponentially with LI. These authors assumed a theoretical simulation of the fall cone test (Houlsby, 1982) to backanalyse the shear viscosity while taking into account a given rheological model and a modified cone factor, K (Koumoto \& Houlsby, 2001).

Nevertheless, determination of the rheological properties of debris flow material remains a difficult subject. Specific rheometers have been developed (Phillips \& Davies, 1991; Major \& Pierson, 1992; Coussot \& Piau, 1995; Schatzmann et al., 2009), but measurements on large volumes of suspensions including coarse, dense particles implies many experimental artefacts, such as 
migration, sedimentation, wall slip and heterogeneities. (The same problem exists in the field of concrete rheology.)

In addition, there is still some difficulty in deducing the behaviour of the complete material, sometimes containing particles up to a few metres in size, from measurements on particles smaller than a few millimetres. In addition, Iverson (1997) showed the possible role of interstitial pressure within flowing granular suspensions. This indicates that there might be a need for different models associated with different material types.

The problem of identifying the appropriate model, and of determining its parameters for natural flows, led some people to consider that empirical approaches may be more appropriate (Hungr, 1995; Coussot et al., 1998; Rickenmann, 1999; Scotto di Santolo \& Evangelista, 2009). There was some attempt at clarification and classification in Coussot \& Meunier (1996), but this was only a preliminary work. More recent works have, for example, shown that granular debris flow materials (with a low clay fraction) may be considered at first sight as simple yield stress fluids, but in fact exhibit some original flow curve with a minimum that is the hallmark of some flow instability (Sosio \& Crosta, 2009).

Actually, it may be remarked that, whatever the material type, a mixture of water and grains of different sizes is being dealth with. As a consequence, it is relevant to overview our current knowledge of the behaviour of such materials in the field of physics and, in particular, recent progress in that field. In the absence of sedimentation, suspensions of non-colloidal particles in a Newtonian liquid are Newtonian as long as the concentration is not close to the maximum packing fraction with a viscosity increasing with the solid concentration. Around the maximum packing concentration the rheological behaviour is much more complex, owing to the possibility of lubrication, frictional and migration effects (Ancey \& Coussot, 1999; Huang et al., 2005; Ovarlez et al., 2006). Roughly speaking, this is a material that may behave like a simple yield stress fluid at low shear rates (when interparticle contacts dominate) and like a simple liquid if the particles have just been well dispersed. With very small particles another effect may occur, namely shear thickening, in which the material behaves like a Newtonian fluid up to a critical shear rate, at which the viscosity diverges (Fall et al., 2009). This effect seems to find its origin in that, at a sufficiently high shear rate, the particles have 
insufficient time to rearrange and facilitate the flow, so that the structure tends to jam.

On the other side there are colloidal suspensions, for which particles develop interactions at distance within the liquid. Clay suspensions are typical examples of such materials. When the interactions are relatively low, the suspension behaves as a simple yield stress fluid without significant thixotropic effect (e.g. kaolin suspensions). When there are strong attractive colloidal attractions, the suspension is significantly thixotropic, so that its apparent yield stress increases with time at rest (Mewis \& Wagner, 2009).

\section{2}

\section{Rheological models}

The viscosity concept, defined as the slip resistance of fluid molecules due to internal friction, was introduced by Isaac Newton in 1687 through the flow of fluids placed between two parallel plates of area A separated by a distance h, by force F, as shown in Figure 2.2.

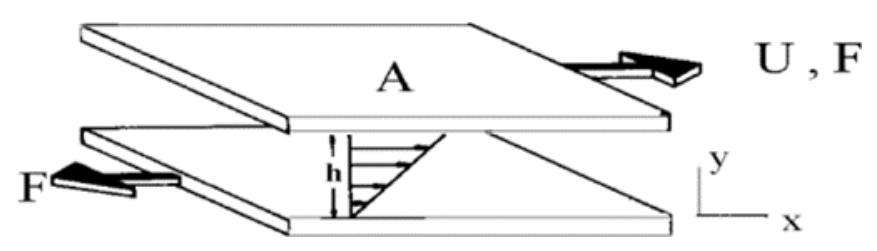

Figure 2.2 - Parallel plate model proposed by Newton to explain the concept of viscosity (Barnes et al., 1969).

According to the model proposed by Newton, the force $(F)$ required per unit area $(A)$ to maintain a speed difference between the plates is known as shear stress, mathematically expressed by Equation 1 .

$$
\tau=\frac{F}{A}
$$


The shear rate $(\dot{\gamma})$, in turn, is determined by a mathematical expression, Equation 2, which denotes, for a determined instant, the derivative of the vertical profile of horizontal velocities.

$$
\dot{\gamma}=\frac{d v}{d y}
$$

For ideal viscous fluids, the shear stress is directly proportional to the shear rate, where the proportionality constant is, by definition, the fluid viscosity $(\mu)$, as explained in Equation 3, also known as Newton's Law for viscosity.

$$
\tau=\mu \frac{d v}{d y}=\mu \dot{\gamma}
$$

For Barnes et al. (1969), viscosity can be considered the main rheological property of a fluid, since it indicates its ease of continuous flow under the action of an external shear stress. The lower the viscosity of a fluid, the lower the stress required to undergo a constant shear rate.

Van Wazer et al. (1966) divide the viscosity into differential and apparent. Both terms are applied to the non-linear "shear stress versus shear rate" curves. While the differential viscosity is determined by the slope of a given curve point, the apparent viscosity is obtained from the slope of a line connecting a particular point of the curve with the origin.

The viscosity may depend on six independent parameters: temperature, pressure, shear rate, physicochemical nature of the substance, electric field and shear time. When defining the viscosity as a function of one of these parameters, the other five must be kept constant and well defined (Schramm, 1998).

The fluids are divided into ideals and reals. The ideals are those with viscosity equal to zero and are hypothetical. In an ideal flow there are no shear stresses (e.g. Correia (2006); Mothé (2007)). The real fluids are divided into Newtonian and nonNewtonian, the latter being divided into three classes: time independent, time dependent, and viscoelastic, as summarized in Figure 2.3. 


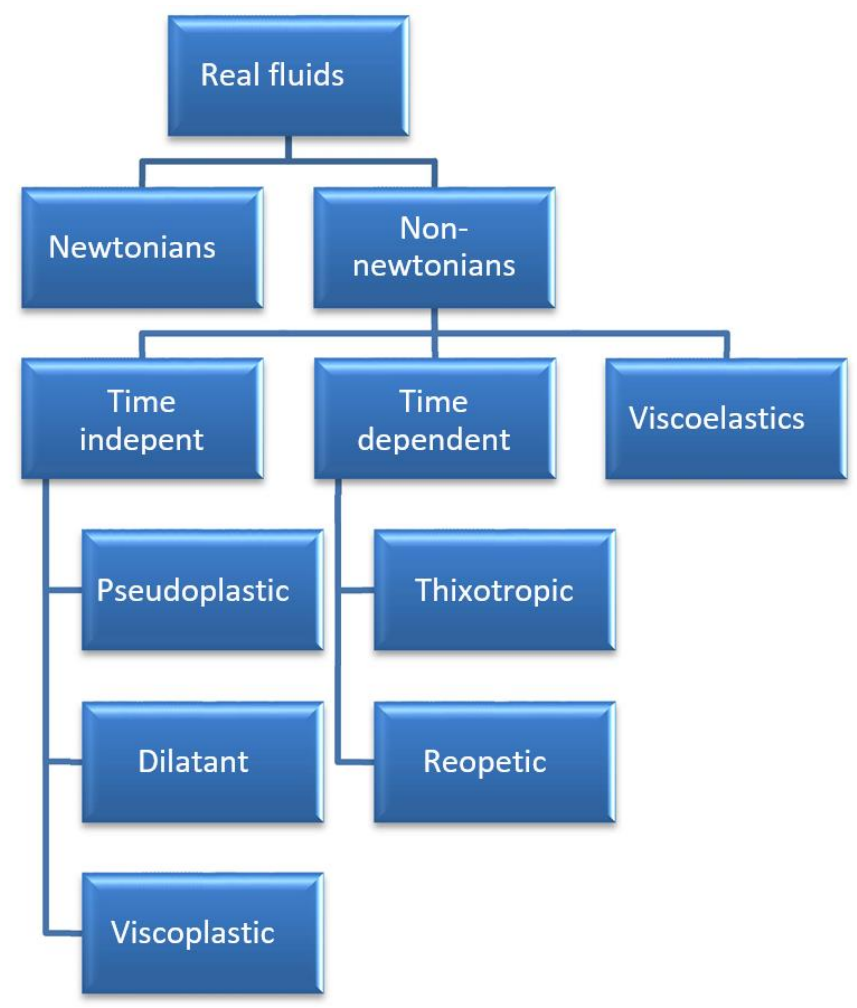

Figure 2.3 - Real fluids classification (Adapted from Galindo, 2013).

\subsection{1 \\ Newtonian fluids}

According to Tanner (1988), the Newtonian fluids are those whose viscosity, denominated absolute viscosity, is affected only by temperature and pressure, not showing variations with increase of the shear rate or stress.

The flow curve of a Newtonian fluid is a straight line that passes through the origin and has a slope whose inverse is equal to the coefficient of viscosity. Thus, for a Newtonian fluid, a simple experimental determination, that is, an assay measuring only one of the rheological parameters is sufficient for the characterization of its rheological behavior (Vliet \& Lyklema, 2005).

\subsection{2}

\section{Non-Newtonian fluids}

The Newton's Law for viscosity, expressed by Equation 3, is restricted to a certain number of fluids, since there are materials that, under shear-directed flow, exhibit behavior different from that predicted by Newton. 
According to Vliet \& Lyklema (2005), a fluid is said to be non-Newtonian when the relationship between stress and shear rate is not linear. In this case, a viscosity, called apparent viscosity, is obtained for each shear rate considered. These fluids, in general, are divided into three groups, classified according to their behavior:

- time independent fluids: are those whose viscosity depends only on the shear rate;

- time-dependent fluids: the viscosity depends not only on the rate, but also on the shear time;

- Viscoelastic fluids: exhibit both solid (elasticity) and liquid (viscosity) characteristics and exhibit partial elastic recovery after deformation.

Time-independent fluids are subdivided into: pseudoplastics, dilatants, and binghamians (e.g.Van Wazer et al. (1966); Tanner (1988); Fox \& McDonald (1998); Machado (2002); Vliet \& Lyklema (2005)), as shown in Figure 2.4.

- Pseudoplastic fluids: are characterized by the decrease of the apparent viscosity with the increase of the deformation rate. Generally, they begin to flow under the action of infinitesimal shear stresses, without the presence of a residual stress. However, some fluids may present an initial stress, from which the rheological behavior becomes similar to that of pseudoplastics (Toneli et al, 2005). According to Vidal-Bezerra (2000), this behavior can be explained by the modification of the structure of long chains of molecules. As the velocity gradient increases, these chains tend to align parallel to the current lines, reducing the resistance to flow.

- Dilatating fluids: exhibit behavior contrary to pseudoplastic fluids. In this case, the apparent viscosity increases with increasing strain rate. As described by Machado (2002), dilatation in liquids is very rare, however, this type of behavior can be evidenced in highly concentrated suspensions, whose constituent particles are irregular and do not orient easily.

- Viscoplastic or Binghamian fluids: fluids that behave as solid until a minimum rate is exceeded; then the relationship between the stress and the shear rate becomes linear. Most of the time these fluids are dispersions that 
can form an interparticle network maintained by binding forces at rest. These forces restrict changes of position of the elements, resulting in a material of solid character with high viscosity. External forces, if smaller than those forming the lattice, deform elastically the solid material. Only when the external forces are large enough to overcome the binding forces between the particles does the structure collapse. When this happens, the elements can irreversibly change position, that is, the solid becomes a liquid (Bird et al, 1983).
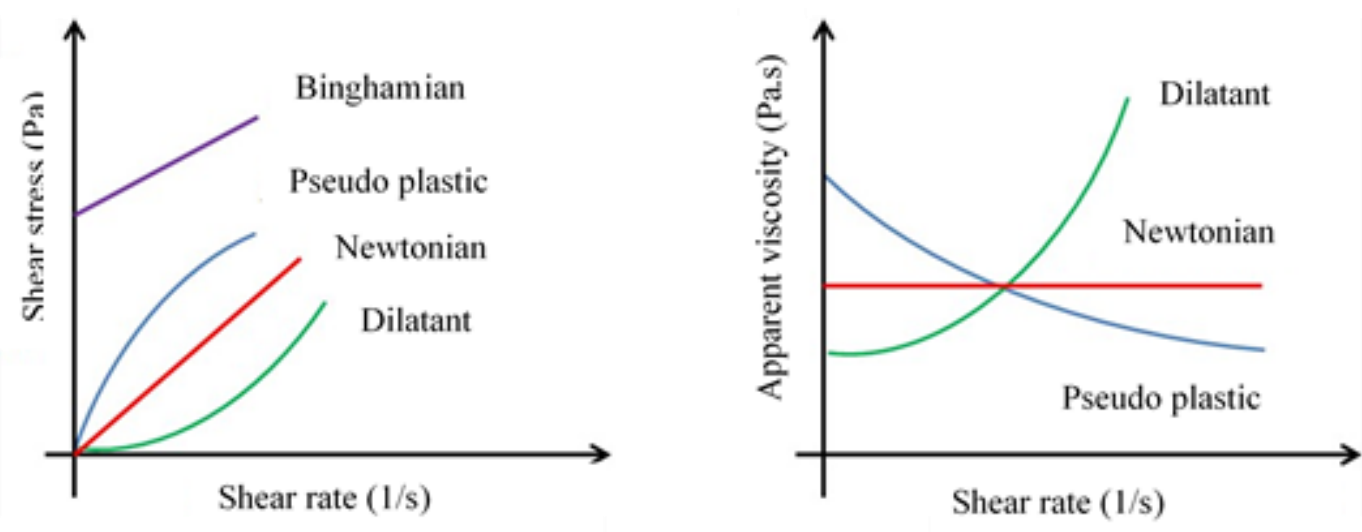

Figure 2.4 - Rheological behaviour of time indepent fluids (Adapted from Fox \& McDonald, 1998).

Some empirical relationships have been developed to establish a mathematical model that best represents the observed relationships between shear stress and rate for time independent fluids. Some of these equations are shown in Table 2.1.

Time-dependent fluids are subdivided into: rheopectic and thixotropic (e.g. Van Wazer et al. (1966); Tanner (1988); Fox \& McDonald (1998); Machado (2002); Vliet \& Lyklema (2005)).

- Thixotropic fluids: the shear stress, or viscosity decreases with the time of application of a shear rate due to the occurrence of reversible changes in the microstructure of the fluid. Generally, in the absence of shear, the structure is rebuilt and the system returns to its initial viscosity (Coussot et al, 2002a). According to Correia (2006), the thixotropy curve is similar to that of pseudoplasticity since the apparent viscosity decreases as the rate of 
deformation increases. It differs from it, however, when the apparent viscosity depends not only on the shear rate, but also on time.

- Rheopectic fluids: are similar to dilating fluids, characterized by an increase in viscosity related to the shear time. When left to stand they reach low levels of viscosity. According to Mothé (2009), rheopexy is a timedependent thickening.

Table 2.1 - Models, equation and parameters of non-Newtonian time indepent fluids. (Adapted from Machado, 2002).

\begin{tabular}{|c|c|l|}
\hline Model & Equation & \multicolumn{1}{c|}{ Parameters } \\
\hline Newton & $\tau=\mu \dot{\gamma}$ & $\begin{array}{l}\mu \text { - absolute viscosity } \\
\dot{\gamma} \text { - shear rate }\end{array}$ \\
\hline Bingham & $\tau=\tau_{0}+\eta \dot{\gamma}$ & $\begin{array}{l}\eta \text { - apparent viscosity } \\
\tau_{0} \text { - yield stress } \\
\dot{\gamma} \text { - shear rate }\end{array}$ \\
\hline Ostwald & \multirow{2}{*}{$\begin{array}{l}K \text { - consistency index } \\
\end{array}$} & $\begin{array}{l}n \text { - behavior index } \\
\dot{\gamma} \text { - shear rate }\end{array}$ \\
\hline Herschell-Buckley & $\tau=\dot{\gamma}_{0}+K \dot{\gamma}^{n}$ & $\begin{array}{l}K \text { - consistency index } \\
n-\text { behavior index } \\
\dot{\gamma} \text { - shear rate } \\
\tau_{0} \text { - yield stress }\end{array}$ \\
\hline
\end{tabular}

According to Van Wazer et al. (1966) the pseudoplastic flow (without flow limit) results from an immediately completed thixotropic behavior (exhibiting an infinitely short time interval from the initial viscosity value to a final limit viscosity value), while the dilating flow results from the rheopectic behavior also immediately completed.

In an initial analysis, the viscoplastic fluids could be considered with a thixotropic behavior, since they have an "infinite viscosity" until the flow voltage is exceeded, when that viscosity decreases and the material begins to flow (Coussot et al., 2002b).

However, Tanner (1988) clearly distinguishes both behaviors by introducing the term "false body". According to this author, the true thixotropic material breaks completely under the influence of high shear stresses and behaves like a liquid, even 
after the applied tension is withdrawn, until the time necessary for the restructuring of the material is reached. On the other hand, "false body" materials do not lose their full solid properties and may still exhibit a flow stress, although it can be reduced.

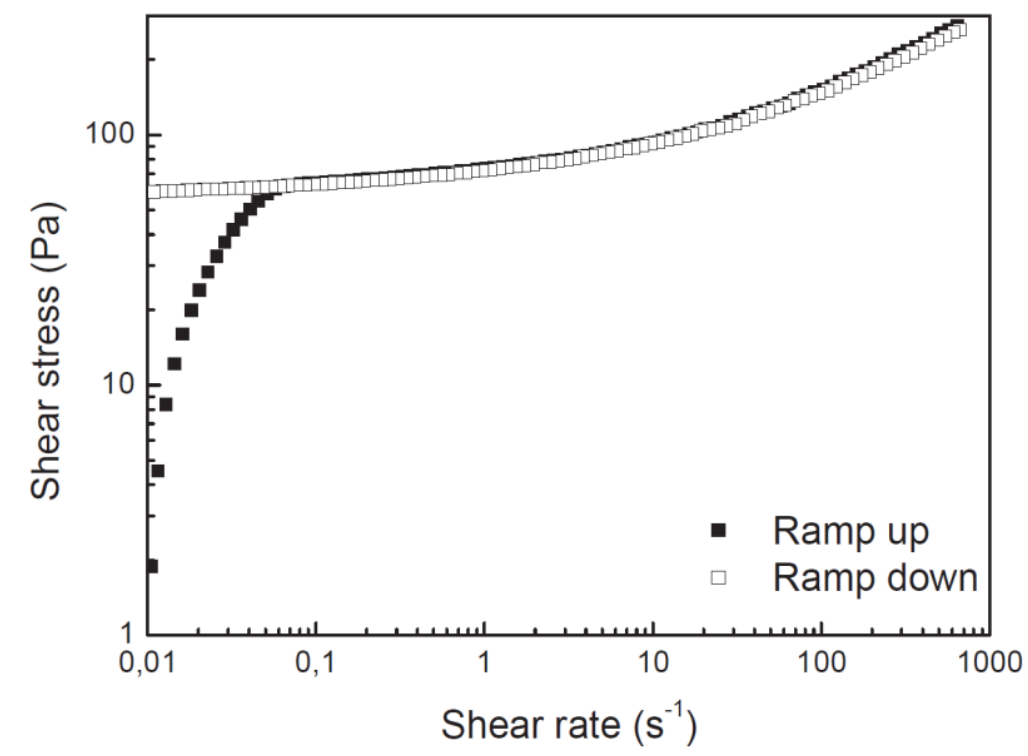

Figure 2.5 - Shear stress flow curve of a Carbopol ${ }^{\circledR}$ with yield stress $\tau_{0}=62 \mathrm{~Pa}$ (Pierre et al., 2013).

\section{3 \\ Slump test}

The slump test, originally used to determine the "workability" of fresh concrete, has since been used in many industrial fields (e.g., mining and food industries). It offers a quick and easy way to measure the yield stress of suspensions or pasty materials. The model used for estimating the yield stress from the measured conical slump was first written by Murata (1984), corrected by Schowalter and Christensen (1988) and adapted for a cylindrical geometry by Pashias et al. (1996).

Many materials in industry or nature behave as fluids with a yield stress, which is the minimum stress for irreversible deformation and flow to occur. While the yield stress can be considered as a unique material property it may, of course, be measured using conventional rheological tools. However, this is not easy for many civil engineering materials containing coarse particles, and several specific large-scale apparatuses have been developed: Couette rheometers (e.g., Coussot 
and Piau (1995); Geiker et al. (2002)), parallel plates rheometers (de Larrard and $\mathrm{Hu}, 1996)$.

These tests nevertheless often remain expensive and time consuming when only the yield stress is needed for the industrial application. In situ, simpler and cheaper tests are still preferred which cannot be readily interpreted in rheological terms, i.e., they do not provide an intrinsic physical parameter of the material, but these tests have proved through the years to be able to class different materials in terms of their ability to be cast. One interesting category of in situ tests includes the so called "slump tests."

Typically, in a slump test a sample of a given shape is filled with the tested fluid. The device is lifted and the material flows. If inertia effects can be neglected it is generally admitted that the flow stops when the shear stress in the tested sample becomes equal to or smaller than the yield stress (Schowalter and Christensen, 1998). Consequently, the shape at stoppage in the yielding region is directly linked to the material yield stress. From a practical point of view two geometrical quantities may be measured: the "slump" and/or the "runout."
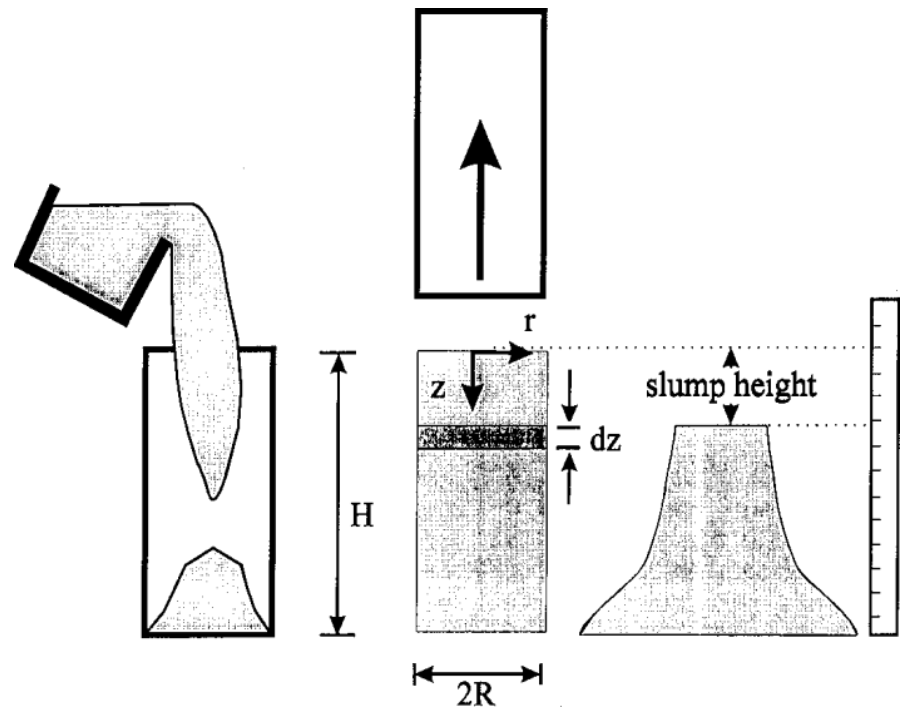

Figure 2.6 - Schematic diagram of the slump test with reference axis (Pashias, et al., 1996).

The slump $(S)$ is the difference between the height of the sample at the beginning of the test $\left(H_{0}\right)$ and after flow stoppage (Fig 2.6). The runout is the final diameter of the collapsed sample. In most applications of the ASTM (1996) Abrams 
cone technique, the initial height of which is $30 \mathrm{~cm}$, the slump is measured if it is smaller than $25 \mathrm{~cm}$, otherwise the spread is measured. In the case of cement pastes, the yield stress of which is low compared to that of concrete, a smaller cone is used, namely the ASTM (2004) minicone technique.

In that case the slump is typically of the same order as the initial height and only the spread is measured. Following such approach, Murata (1984) wrote a relation between the final height of the cone and the yield stress that does not depend on the mold geometry. Subsequent works established analogous relationships either for conical (Schowalter and Christensen, 1998) or cylindrical shape (Pashias et al., 1996) with similar assumptions. These results were successfully validated by Clayton et al. (2003) and Saak et al. (2004) in the case of cylindrical molds. However, in the case of some conical shape or in the case of high-yield stress values (i.e., low slumps) with cylindrical molds, a discrepancy between predicted and measured slumps was systematically observed.

Figure 2.7 illustrates schematically the slumping behavior and the corresponding stress profile throughout the material, in the Pashias et al. (1996) solution for a cylindrical geometry. At some point along the height of the undeformed cylinder (Fig. 2.7 A), the material will experience a stress that is larger than the yield stress (Fig. $2.7 \mathrm{~B}$ ), while above this point the stress experienced by the material is less than the yield stress. Once the slumping is complete (Fig. $2.7 \mathrm{c}$ ), the stress distribution is as shown in (Fig. 2.7 D). In the upper, unyielded section the stress distribution is identical to that of the undeformed material, while flow occurs in the remaining material until the stress is reduced to the yield stress.

Initial State

Final State

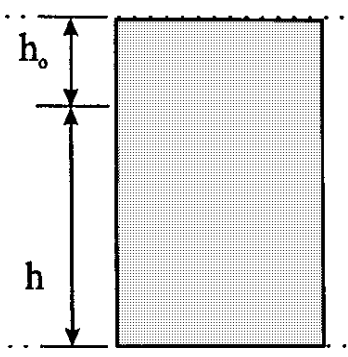

(a)

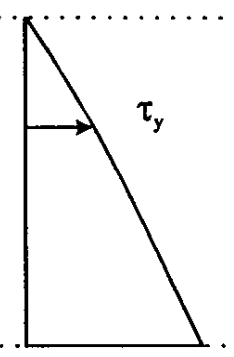

(b)

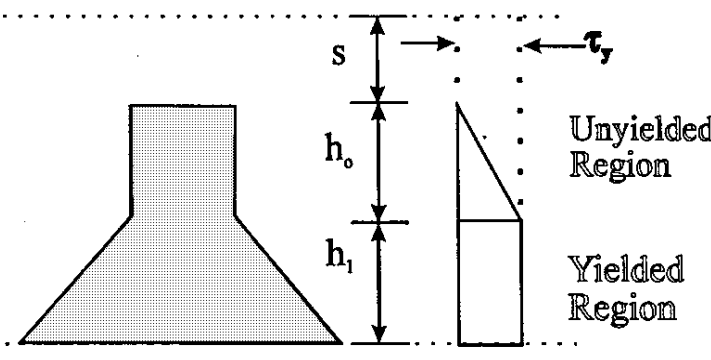

(c)

(d)

Figure 2.7 - Schematic diagram of the initial and final shear stress distribution (Pashias, et al., 1996). 


\subsection{1}

\section{Literature solutions}

For Pascalian liquids, meaning incompressible fluids, it holds for the fluid velocity vector $u$ that:

$$
\nabla \cdot \boldsymbol{u}=0
$$

The governing equation for non-Newtonian fluids called Cauchy's equation of motion (Malvern, 1969) is given by:

$$
\begin{gathered}
\rho \frac{\boldsymbol{D} \boldsymbol{u}}{d t}=\nabla \cdot \mathrm{T}+\rho g \\
T=-p I+T^{\prime}
\end{gathered}
$$

where $g$ is the gravitational acceleration vector acting on the system, $\rho$ is the material density. $T$ is the stress tensor whereas $T^{\prime}$ is the extra stress tensor associated with the viscosity of the fluid. $p$ denotes pressure and $I$ the identity tensor.

For a viscoplastic material, the relation used for $T^{\prime}$ is, (Mase, 1970):

$$
T^{\prime}=2 \eta \boldsymbol{D u}
$$

with $D_{u}$ being the tensor of rate of deformation as can be found in (Goldstein, 1996):

$$
\boldsymbol{D u}=\frac{1}{2}\left[\nabla \cdot \mathbf{u}+(\nabla \cdot \mathrm{u})^{T}\right]
$$

It was shown by (Wallevik, 2003) that Equation 5 is not only applicable for homogeneous fluids, but from a fundamental physical point of view also can be applied on coarse granular systems like soils. Such system are often modelled as a Bingham material. It is a viscoplastic material, showing little or no deformation up to a certain level of stress. For stress levels above the so called yield stress, $\tau_{0}$, the material flows. In order to fit the Cauchy equation, the apparent viscosity $\eta$ is written as:

$$
\eta=\eta_{p l}+\frac{\tau_{0}}{\sqrt{2 \boldsymbol{D u}: \mathbf{D u}}}
$$


where $\sqrt{2 \boldsymbol{D u}: \boldsymbol{D u}}$ is the shear rate.

Generically, the mechanical laws of an incompressible material with a yield stress flowing on a plane surface will be now explored. The flow is described in cylindrical coordinates attached to the horizontal solid surface $(r, \theta, z)$. The cylindrical geometry used for the spreading flow is shown in Figure 2.8. The axissymmetry of the problem implies that there is no tangential motion in a specific direction $\left(V_{\theta}\right)$ and that the variables do not depend on $\theta$. It is also assumed that the material flow stoppage occurs when the shear stress in the material is equal to or lower than the yield stress. As reported in the introduction, the viscosity of the material, inertia and surface tension effects at stoppage, are also neglected (Coussot and Roussel, 2004).

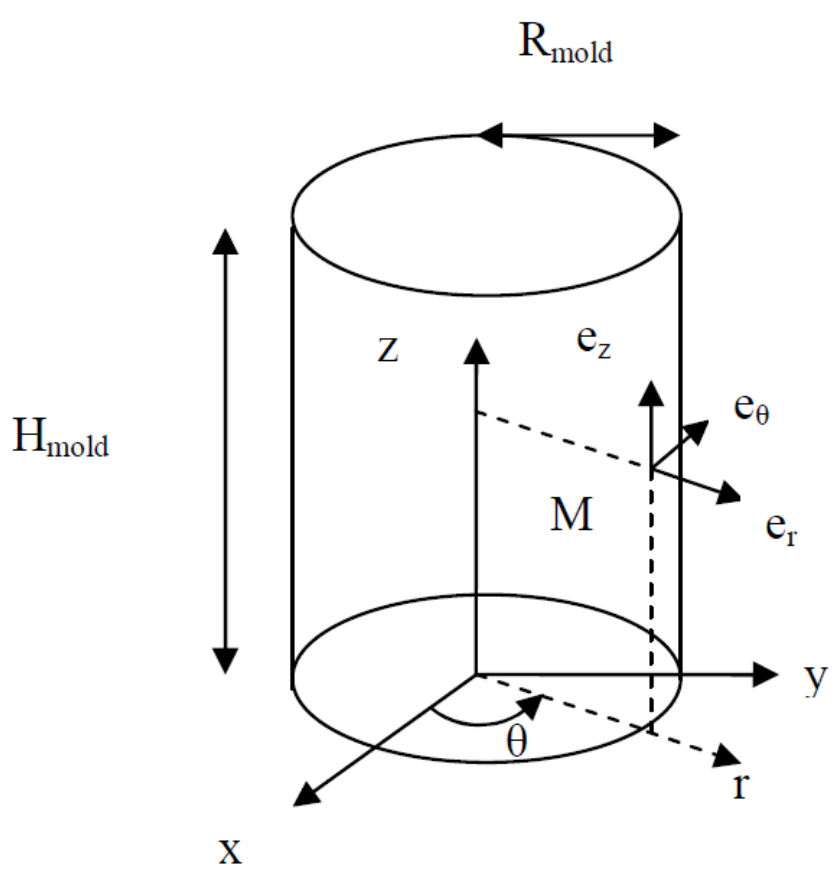

Figure 2.8 - Initial cylinder shape and cylindrical coordinates (Pierre et al., 2013).

The strain rate tensor is:

$$
\boldsymbol{D u}=\left[\begin{array}{ccc}
\frac{\partial v_{r}}{\partial r} & 0 & \frac{1}{2}\left(\frac{\partial v_{z}}{\partial r}+\frac{\partial v_{r}}{\partial z}\right) \\
0 & \frac{v_{r}}{r} & 0 \\
\frac{1}{2}\left(\frac{\partial v_{z}}{\partial r}+\frac{\partial v_{r}}{\partial z}\right) & 0 & \frac{\partial v_{z}}{\partial z}
\end{array}\right]
$$


Equation 9 is the three-dimensional von Mises yielding criterion.

$$
\boldsymbol{D u}=0 \leftrightarrow \sqrt{-T^{\prime}{ }_{I I}}<\tau_{0}
$$

where $T^{\prime}{ }_{I I}$ is the second invariant of the extra stress tensor and $\tau_{0}$ is the yield stress.

It is assumed that the constitutive equation beyond yielding can be expressed in the general form (Wallevik, 2006):

$$
\begin{gathered}
\boldsymbol{T}=-p \boldsymbol{I}+\boldsymbol{T}^{\prime}=-p \boldsymbol{I}+\frac{\tau_{0}}{\sqrt{-D u_{I I}}} \boldsymbol{D} \boldsymbol{u} \\
D u_{I I}=\frac{1}{2}\left[(\operatorname{tr} D)^{2}-\operatorname{tr}\left(D^{2}\right)\right]
\end{gathered}
$$

where $T$ is the stress tensor, which can vary with the flow regime and $D u_{I I}$ is the second invariant of the strain rate tensor.

\subsubsection{1 \\ Conical geometry}

Kokado et al. (1997) analysed the conical shape slump test problem, concluding that by assuming that material density and sample volume are known, the final flow spread at flow stoppage is directly correlated to the yield stress of the material. Also assuming that inertia effects of the spreading flow are neglected for this theory. The slump flow may be treated as a one-dimensional problem, since the threedimensional Abrams cone will reshape into a one-dimensional flow problem with a propagation of much smaller height than its radial spread. This allows one to evaluate it analytically. Also, surface tension effects are disregarded since they are much smaller than the apparent viscosity of materials.

The governing equations for this particular case are based on the physical principles stating that within the system, mass is conserved (the continuity equation) and Newton's second law $F=m a$ (the momentum equation). So starting out with the equation of continuity and the equation of motion for incompressible fluids in cylindrical coordinates $(r, \theta, z)$ according to Figure 2.9, (Kokado et al., 1997) state the equation of continuity: 


$$
\frac{1}{r}\left[\frac{\partial}{\partial r}\left(r \cdot v_{r}\right)+\frac{\partial v_{\theta}}{\partial \theta}\right]=0
$$

As well as the equation of motion (radial direction $r$ ):

$$
\begin{aligned}
\frac{\partial v_{r}}{\partial t}+v_{r} \frac{\partial v_{r}}{\partial r}+ & \frac{v_{\theta}}{r} \frac{\partial v_{r}}{\partial \theta}+v_{z} \frac{\partial v_{r}}{\partial \theta}-\frac{v_{\theta}^{2}}{r} \\
& =\frac{1}{\rho}\left\{-\frac{\partial p}{\partial r}+\left[\frac{1}{r} \frac{\partial}{\partial r}\left(r \cdot \tau_{r r}\right)+\frac{1}{r} \frac{\partial \tau_{\theta r}}{\partial \theta}-\frac{\tau_{\theta \theta}}{r}+\frac{\partial \tau_{z r}}{\partial z}\right]\right\}
\end{aligned}
$$

where, $v_{r}, v_{\theta}, v_{z}$ are the velocity vector components, $\tau_{i j}$ is the stress tensor.

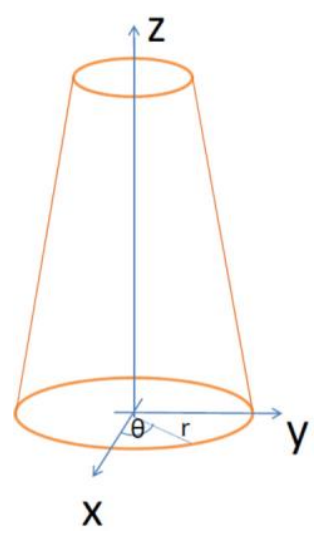

Figure 2.9 - Axis coordinates in the Abrams Cone geometry.

The stress variations in the radial variation are negligible compared with those in the vertical direction (Coussot and Roussel, 2005), this follows from the assumption that the flow is mainly elongational and thus, in the vertical direction, the stress results from the weight of the material above and, at a height $z$ is equal to:

$$
p=-\rho g\left[h_{0}+h\left(R_{0}\right)-z\right]
$$

The pressure $p$, at $z=0$, is defined as follows:

$$
p=-\frac{\operatorname{tr}(\boldsymbol{T})}{3}=-\frac{\rho g\left[h_{0}+h\left(R_{0}\right)\right]}{3}
$$

The extra stress tensor is: 


$$
\boldsymbol{T}^{\prime}=-\frac{1}{3} \operatorname{tr}(\boldsymbol{T}) \boldsymbol{I}
$$

Equations 15 and 16 yield Equation 17:

$$
\boldsymbol{T}^{\prime}=\left[\begin{array}{ccc}
\frac{1}{3} \rho g\left[h_{0}+h\left(R_{0}\right)\right] & 0 & 0 \\
0 & \frac{1}{3} \rho g\left[h_{0}+h\left(R_{0}\right)\right] & 0 \\
0 & 0 & -\frac{2}{3} \rho g\left[h_{0}+h\left(R_{0}\right)\right]
\end{array}\right]
$$

In tangential and radial directions, the stress is equal to zero. By considering Equation 11, the stress tensor is expressed as:

$$
\boldsymbol{T}=-\frac{\rho g\left[h_{0}+h\left(R_{0}\right)\right]}{3} \boldsymbol{I}+\frac{\rho g\left[h_{0}+h\left(R_{0}\right)\right]}{3}\left[\begin{array}{ccc}
1 & 0 & 0 \\
0 & 1 & 0 \\
0 & 0 & -2
\end{array}\right]
$$

The second invariant of the extra stress tensor $T_{I I}$ is calculated as:

$$
T^{\prime}{ }_{I I}=-\frac{1}{3}\left\{\rho g\left[h_{0}+h\left(R_{0}\right)\right]\right\}^{2}
$$

Consequently, for small deformation, and considering that flow stoppage results in the height $h_{0}+h\left(R_{0}\right)$ at which the von Mises criterion is exactly reached, the yield stress is finally obtained from Equation 20 (Roussel and Coussot, 2004):

$$
\tau_{0}=\frac{\rho g\left[h_{0}+h\left(R_{0}\right)\right]}{\sqrt{3}}
$$

Differently, in the spread regime, the flowing sample is mainly submitted to a pure shear flow (Roussel and Coussot, 2004). As the height of the sample is smaller compared to its radius $(h<R)$, it is to be expected that the radial velocity is much larger to the vertical velocity $\left(v_{z} \ll v_{r}\right)$. Thus, based on the lubrication approximation, the strain tensor reduces to Equation 21: 


$$
\boldsymbol{D u}=\left[\begin{array}{ccc}
0 & 0 & \frac{1}{2} \frac{\partial v_{r}}{\partial z} \\
0 & 0 & 0 \\
\frac{1}{2} \frac{\partial v_{r}}{\partial z} & 0 & 0
\end{array}\right]
$$

If the material is in spread regime and neglecting inertia effect, only the tangential stress component $\tau_{r z}$ is significant at $z=0$ in the extra stress tensor. Considering Equations 11 and 21, the momentum equations reduce to Equation 22:

$$
0=-\frac{\partial p}{\partial r}+\frac{\partial \tau_{r z}}{\partial z}=-\rho g-\frac{\partial p}{\partial z}
$$

Considering that at material stoppage the stress tensor component is equal to the yield stress, the latter can be derived from the momentum equation and expressed as follows:

$$
\begin{gathered}
\tau_{r z}(0) \rightarrow \tau_{0} \\
\tau_{0}=\rho g h \frac{d h}{d r}
\end{gathered}
$$

With the boundary conditions $h(R)=0$, the sample height as a function of the distance $r$ from the sample center can be obtained from the previous equation:

$$
h(r)=\sqrt{\frac{2 \tau_{0}(R-r)}{\rho g}}
$$

The volume of the sample $V_{0}$ is:

$$
V_{0}=\int_{0}^{R} 2 \pi r \cdot h(r) d r
$$

Combining Equations 24 and 25 leads to Equation 26:

$$
V_{0}=2 \pi \sqrt{\frac{2 \tau_{0} R^{5}}{\rho g}} \frac{4}{15}
$$


Finally for the spread regime, the yield stress is expressed by Equation 27 which was initially obtained by Kokado et al. (1997) and also by Roussel and Coussot (2004):

$$
\tau_{0}=\frac{225 \rho g}{128 \pi^{2} R^{5}} V_{0}^{2}
$$

For Gram and Lagerbard (2013) Once the flow spread can be determined analytically, the dynamics of the cone spread motion may only be captured numerically, using e.g. finite element or the like. Nevertheless, in order to grasp the problem and to create a plausible picture of the motion, one will here just scratch the surface of the problem by taking a few steps into it in a simplified way. The following can be said about the moving fluid propagating circular flow:

- The value of the plastic viscosity $\left(\eta_{p l}\right)$ approaches the measured apparent viscosity $\left(\eta_{a p}\right)$ as shear rates are increasing, which can be seen in Equation 28 ;

- The height of the flowing radial part of flow is averaged to $h$;

- The shear rate is then approximated as velocity divided by sample thickness, $v / h$;

- The measured viscosity can be approximated as stress $\tau$ divided by the shear rate;

- The stress $\tau$ is given by $\rho g h$.

This renders the following relation for plastic viscosity analyses:

$$
\eta_{p l}=\frac{\tau}{\dot{\gamma}}+\eta_{a p}=A \frac{\rho g h}{v / h}+B
$$

with $A(X)$ and $B(X)$ being geometrical parameters, depending on the geometry of the cone and the location of the measuring point $X$. Since we are interested in measuring the frictional (no slippage) flow over most of the flow domain in order to average the flow time over the full spread to obtain higher accuracy, one might be tempted to measure the flow time from cone lifting time $t=0$ until flow 
stoppage. However, since it is quite difficult to exactly determine the very moment of motion cease, we will choose a different approach. The flow duration will always be timed at a certain given radius $X$ of the flow, e.g. $X=250 \mathrm{~mm}$, (measuring $t_{500}$ ). The flow velocity $v$ is now:

$$
v=\frac{X}{t_{x}}
$$

However, point $X$ is to be normalized with respect to the total flow radius (travelling length $R$ ), which gives us the dimensionless measuring point $X / R$. Always using the same measuring point $X$ also ensures the same averaged measuring height $\mathrm{h}$ (slump flow thickness) of the same sample volume. Using Equations 28 and 29 with the dimensionless measuring point we can now obtain for a normalized plastic viscosity:

$$
\frac{\eta_{p l}}{\rho}=A \frac{g h^{2} t_{x}}{X / R}+B
$$

Since the measuring point $x$ and $h^{2}(X)$ are chosen beforehand and always kept constant, they may be treated as constants when comparing obtained values. This is true also for the gravitational acceleration parameter $g$. Plastic viscosity normalized with respect to specific gravity of the material is $\rho_{\text {water }} / \rho$. The flow spread diameter $(2 R)$ is employed instead of the radius $R$, aiming at facilitating parameter measurement. Values of interest are now:

$$
\frac{\eta_{p l}}{\rho} \cdot \rho_{w}=M \cdot 2 R \cdot t_{x}+N
$$

Where e.g. parameter M now incorporates $A / 2, g, h^{2}, \rho_{\text {water }}$ and $1 / X$.

\subsubsection{2}

\section{Cylindrical geometry}

The analytical model devised by Murata (1984) relating yield stress to the slump height has been adopted for a cylindrical geometry, as pioneered by Chandler, (1986). Figure 2.7 schematically represents the undeformed material. At any given height, $z$, the pressure, $p$, can be approximated as 


$$
\left.p\right|_{z}=\rho g z
$$

For an ideal elastic solid the maximum shear stress that can act on a body when a pressure $(p)$ is applied to it in a normal direction is equal to half the pressure (Hibbeler, 1991). Hence, the maximum shear stress $(\tau)$ at a height $z$ can be expressed as

$$
\left.\tau\right|_{z}=\frac{1}{2} \rho g z
$$

Scaling the stress with initial normal stress $\rho g h$, Eq. 32 in dimensionless form becomes

$$
\left.\bar{\tau}\right|_{z}=\frac{1}{2} \bar{z}
$$

where $\left.\tau^{\prime}\right|_{z}$ and $z^{\prime}$ are the scaled variables.

Equation 33 illustrates that there is a linearly increasing stress distribution along the height of the cylinder, ranging from zero at the top to a maximum at the base. Figure 2.7 illustrates schematically the slumping behavior and the corresponding stress profile throughout the material. At some point along the height of the undeformed cylinder (Fig. 2.7 A), the material will experience a stress that is larger than the yield stress (Fig. $2.7 \mathrm{~B}$ ), while above this point the stress experienced by the material is less than the yield stress. Once the slumping is complete (Fig. 2.7 C), the stress distribution is as shown in Figure 2.7 D. In the upper, unyielded section the stress distribution is identical to that of the undeformed material, while flow occurs in the remaining material until the stress is reduced to the yield stress. The height of the unyielded material, denoted by the symbol $h_{0}$, or $h_{0}^{\prime}$ in dimensionless form, can be calculated by substituting $\tau_{0}^{\prime}$ in place of $\tau_{z}^{\prime}$ into Equation 34.

The interface layer between the yielded and unyielded material is assumed to be a flat surface that moves down as the material beneath it flows. The initial height is reduced to a total final height $(h)$ that is made up of two components, the height of the yielded region $\left(h_{1}\right)$ and the remaining non yielded region $\left(h_{0}\right)$. In the portion of the material that undergoes yielding, the height can be divided into elements of 
thickness $d z$, which reduce to a thickness dz1 once yielding is complete. During the deformation stage it is assumed that all horizontal sections remain horizontal, and slumping is only due to radial flow.

By assuming incompressibility, Pashias et al. (1996) state that the thickness $d z_{1}$ can be related to $d z$ by:

$$
d z_{1}=\left(\frac{\left.r\right|_{z}}{\left.r\right|_{z_{1}}}\right)^{2} d z
$$

The height h1 can then be evaluated by integrating $d z_{1}$ :

$$
h_{1}=\int_{h_{0}}^{H} d z_{1}
$$

Since it is assumed that there is no flow between horizontal planes, the amount of material above any given plane will be the same before and after the slump. Flow occurs until the cross-sectional area increases so that the stress required to support the weight is reduced to the yield stress. Thus, another relationship between the original and final elements is that the product of stress times the cross-sectional area is proportional to the weight of material above the plane resulting in the following expression:

$$
\left.\left(\left.r\right|_{z}\right)^{2} \tau\right|_{z}=\left(\left.r\right|_{z_{1}}\right)^{2} \tau_{0}
$$

By substituting Equations 34, 35, and 37 into Eq. 38, the following expression in dimensionless form is obtained:

$$
\overline{h_{1}}=\int_{h^{\prime} 0}^{1} \frac{\overline{\tau_{0}}}{\bar{z} / 2} d z_{1}
$$

Integrating Eq. 38 yields:

$$
\overline{h_{1}}=-2 \overline{\tau_{0}} \cdot \ln \left(\overline{h_{0}}\right)
$$

The value of $h_{0}^{\prime}$ to be used in Eq. 39 can be evaluated from Eq. 33 as: 


$$
\overline{\tau_{0}}=\frac{1}{2} \overline{h_{0}}
$$

The dimensionless slump value can then be calculated via:

$$
\overline{\Delta H}=\bar{s}=1-\left(\overline{h_{0}}+\overline{h_{1}}\right)
$$

Solving Eqs. 39 to 41 results in Equation 42:

$$
\frac{\Delta H}{H_{0}}=1-2 \overline{\tau_{0}}\left[1-\ln \left(2 \overline{\tau_{0}}\right)\right]
$$

Baudez and Coussot (2004) improved such analytical solution by considering the overweight due to an object placed on the top of the sample (ref. to Figure 2.10), which is the case of the present students as it will be seen forward in Item 4.1. To consider such overweight, the authors add to the initial height of the sample $\left(H_{0}\right)$, a virtual height $\left(\mathrm{z}_{0}\right)$ associated to the object mass, as it follows.

$$
\begin{gathered}
q=1-2 \overline{\tau_{0}}\left[1-\ln \left(2 \overline{\tau_{0}}\right)\right] \\
p=\frac{\Delta H}{H_{0}+z_{0}} \\
z_{0}=\frac{m_{0}}{\rho \cdot \pi \cdot R^{2}} \\
\overline{\tau_{0}}=\frac{\tau_{0}}{\sigma_{0}} \\
\sigma_{0}=\rho \cdot g \cdot\left(H_{0}+z_{0}\right) \\
p=q(\text { verication condition })
\end{gathered}
$$

Where $\overline{\tau_{0}}$ is the dimensionless yield stress of the fluid; $\Delta H$ is the fluid height variation observed in the test; $H_{0}$ is the initial height of the sample; $z_{0}=$ virtual mass due to overweight; $m_{0}=$ the overweight mass; $\rho$ is the fluids specific mass; $\rho_{0}$ is the object specific mass; $R$ is the overweight radius; $\tau_{0}$ is the yield stress of the fluid; $\sigma_{0}$ is the initial stress at the bottom of the sample; $g$ is the gravity acceleration; $p=q$ is the convergence verification condition. 

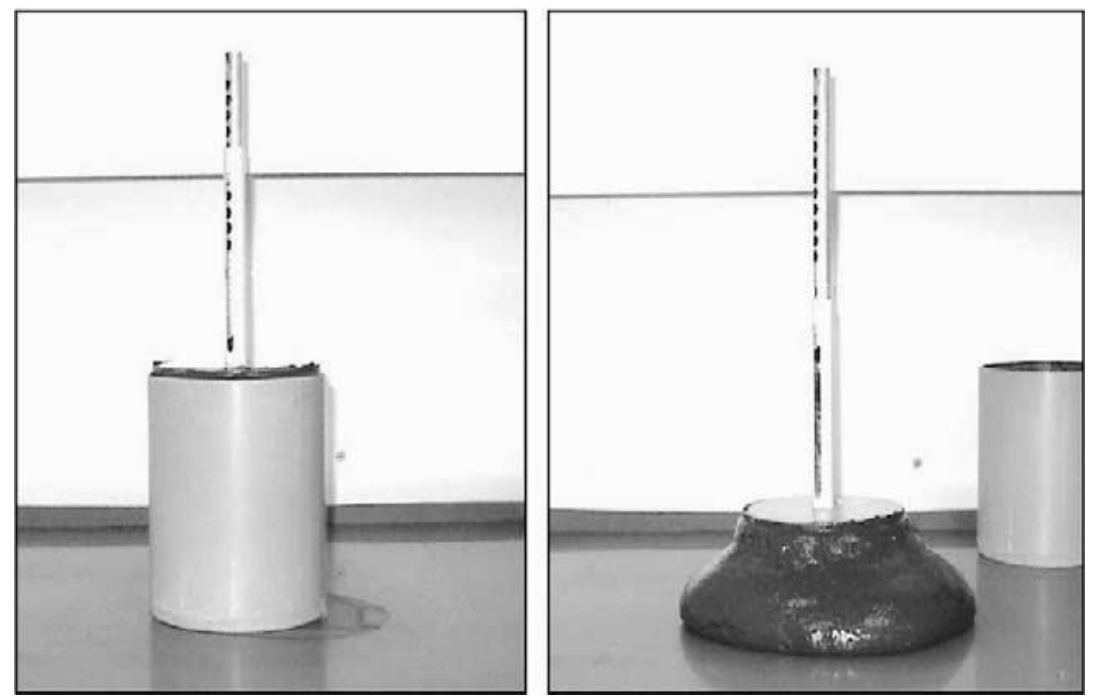

Figure 2.10 - Cylindrical tube slump test, prior to and after testing (Baudez and Coussot, 2004).

Staron et al. (2004) performed a series of numerical experiments to determine a relationship between critical stress and viscosity. They scaled laws between yield stress and plastic viscosity through calibrations parameters $a_{0}, \lambda_{1}$ and $\lambda_{2}$ (see Figure 2.11), which equality assigns the convergence of a verification condition.

$$
\begin{gathered}
\lambda_{1}=\frac{\Delta R}{R_{0}\left(a-a_{0}\right)} \\
\lambda_{2}=0,40\left(\frac{1}{\bar{\eta}} \cdot \frac{1}{\overline{\tau_{0}}}\right)^{0,3} \\
a=\frac{H_{0}}{R_{0}} \\
a_{0}=2,25 \cdot \overline{\tau_{0}}\left(\frac{1}{\bar{\eta}}\right)^{0,2} \\
\overline{\tau_{0}}=\frac{\tau_{0}}{\sigma_{0}} \\
\sigma_{0}=\rho \cdot g \cdot R_{0} \\
\bar{\eta}=\frac{\eta}{\rho \cdot R_{0} \sqrt{g \cdot R_{0}}}
\end{gathered}
$$

$\lambda_{1}=\lambda_{2}$ (verification condition) 
Where $\lambda_{1}$ and $\lambda_{2}$ are convergence verification parameters; $\Delta R$ is the fluid radius variation observed in the test; $\overline{\tau_{0}}$ is the dimensionless yield stress of the fluid; $\bar{\eta}$ is the dimensionless plastic viscosity of the fluid; $a$ is the initial aspect ratio; $a_{0}$ is a calculation parameter; $H_{0}$ is the initial height of the sample; $R_{0}$ is the initial radius of the sample; $\tau_{0}$ is the yield stress of the fluid; $\sigma_{0}$ is the initial stress at the bottom of the sample; $\eta$ is the plastic viscosity of the fluid; $\rho$ is the fluids specific mass; $g$ is the gravity acceleration; $\lambda_{1}=\lambda_{2}$ is the verification condition.
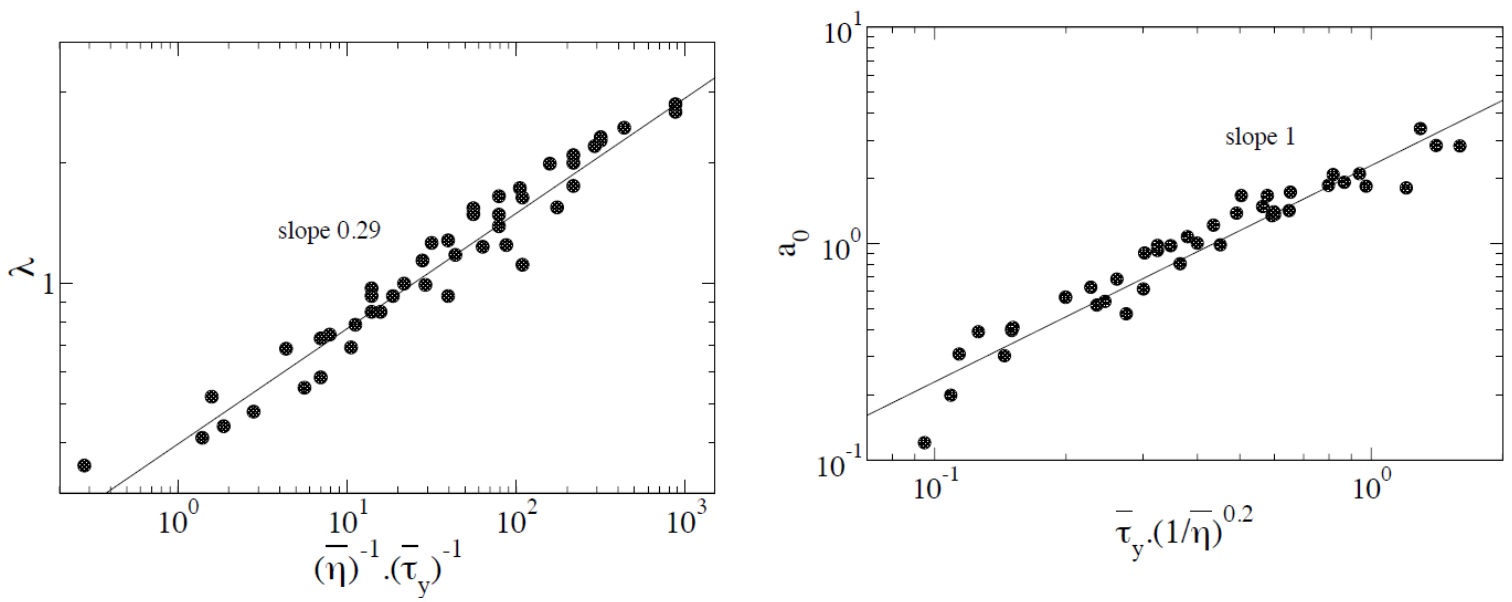

Figure 2.11 - Calibration parameters for scaling laws between yield stress and plastic viscosity (Staron et al., 2004). 


\section{3 \\ Studied materials}

This chapter presents geological-geotechnical aspects concerning to the herein studied soils and its natural sites. For the accomplishment of the tests, two materials were analysed. The first consists of a clay soil from a natural slope at the main campus of PUC-Rio, with no history of relevant mass movement. The second comprises a clayey soil from a natural slope, from the Advanced Campus of PUCRio, located at Tinguá, in the municipality of Nova Iguaçu - Rio de Janeiro, with a history of debris flow (de Campos \& Galindo, 2015). To facilitate identification, the following symbols are used herein forth:

- ACP - Advanced campus of PUC in Tinguá;

- $\mathrm{MCP}$ - Main campus of PUC-Rio.

The first place was chosen as to contribute to studies related to the Tinguá Project, part of a PRONEX Project, under development at the Nucleus of Environmental Geotechnics of PUC-Rio, in which this dissertation is inserted.

The second material was chosen because its ease of access and the large amount of information already available on it (e.g. Marinho (1986), Lins (1991), Daylac (1994), Beneveli (2002), Duarte (2004), Soares (2005)).

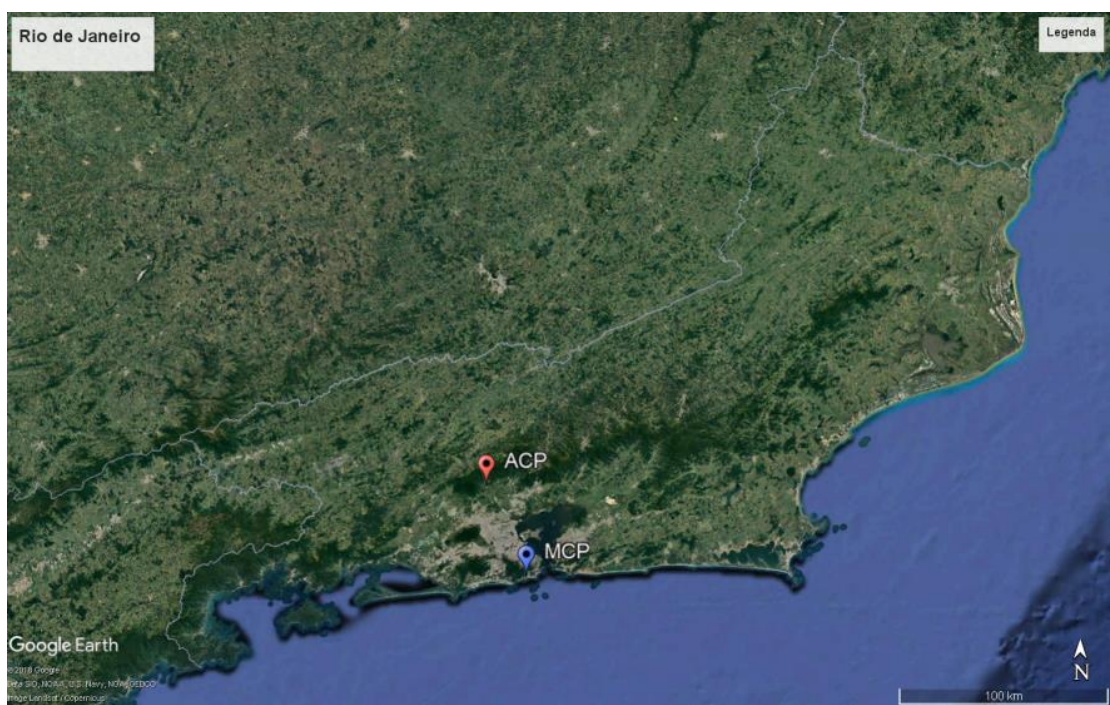

Figure 3.1 


\section{1 \\ Sampling}

For laboratorial proceedings, remolded soil samples were taken from superficial excavations executed on the natural slopes of both sites (Figures 3.2 and 3.3).

Approximately $8 \mathrm{~kg}$ of material was collected from each location. Care was taken to avoid the presence of vegetation roots of the sampled mature soils. As expected, it was observed that both slopes were unsaturated under their original condition.

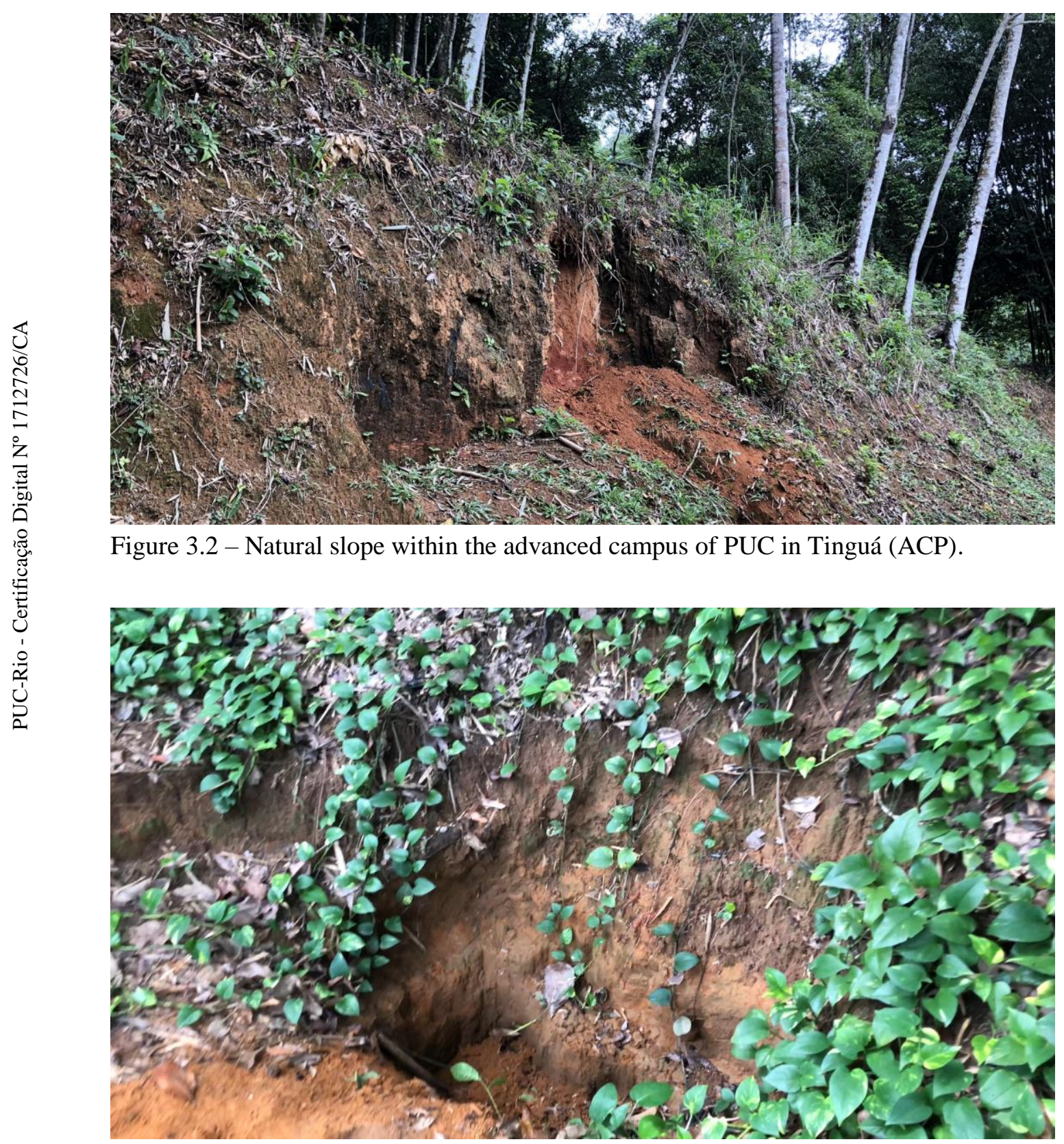

Figure 3.3 - Superficial excavation in the natural slope within the main campus of PUCRio (MCP). 


\section{2}

\section{Advanced campus of PUC in Tinguá}

\subsection{1}

\section{Location}

The Tinguá Biological Reserve covers an area of 26 thousand hectares and covers six municipalities, mainly located in Nova Iguaçu. Due to its size and variety in terms of geological units, it was decided to collect samples from two distinct points: one located inside the reserve and the other at the PUC-Rio advanced campus in Tinguá.

\subsection{2}

\section{Geology and geomorphology}

According to de Campos (2012), four lithological units occur in the region of Tinguá Massif, namely: Biotite Gnaisse (Migmatito) and Foliated Granite (Gnaisse Granite), both of the Rio Negro Unit; the Leucognaisse, the Batolite Serra dos Órgãos, and the alkaline ones. It was also possible to observe that almost all the outcrops are related to the gneiss rocks.

As observed in the geological map shown in Figure 3.4, the sampling points belong to the Serra's Batolith of the organs, being characterized by leucognais.

\subsection{3}

\section{Climate aspects}

According to the classification of Köppen, Tingua region's climate is of the type CWB, corresponding to the Tropical Climate of Altitude, possessing mild summers and typical showers of the station, that is, of great intensity, but with low duration, being little pronounced in the highest points of the dry season.

The annual average temperature of the entire region varies between $13^{\circ} \mathrm{C}$ and $23^{\circ} \mathrm{C}$, with an average rainfall between $1500 \mathrm{~mm}$ and $2600 \mathrm{~mm}$, distributed in a heterogeneous way between the seasons. Summer and spring are the rainiest seasons to the detriment of winter and fall, which in turn have the lowest averages of precipitation. 


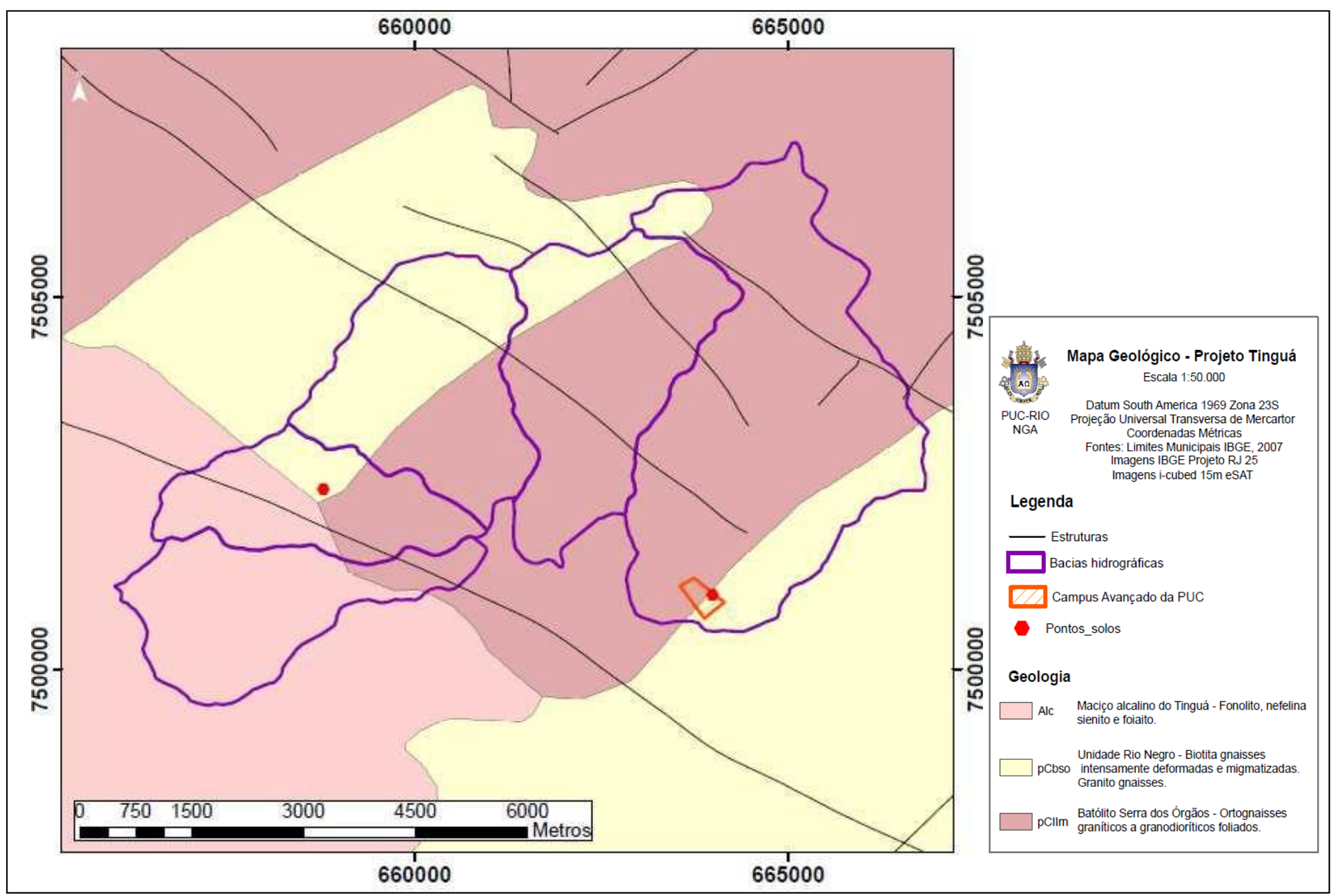

Figure 3.4 - Geological map of Tinguá (Adapted from de Campos, 2012) 


\section{3 \\ Main campus of PUC-Rio}

\subsection{1}

Location

The main campus of PUC-Rio is located within the south hillside of the Tijuca massif, Rio de Janeiro, Brazil. The soil samples were collected from the Experimental Station II, situated inside the main campus of PUC-Rio (Figure 3.5).

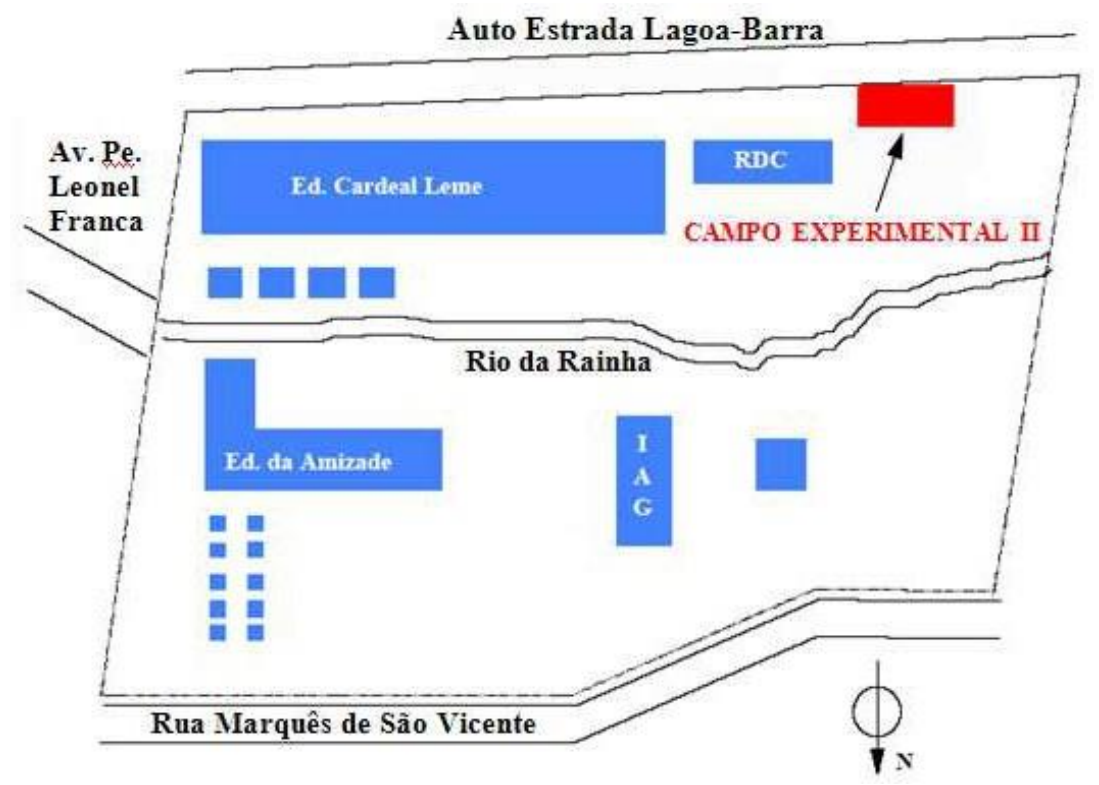

Figure 3.5 - Map location of the main campus of PUC-Rio, where MCP soil was collected

\subsection{2 \\ Geology and geomorphology}

Tijuca's massif comprises biotite-plagioclase-gneisses, microcline-gneisses, liptinites / granites and granodiorites rock formations (Brito, 1981). With respect to the geomorphological aspects, Brito (1981) highlights the presence of hills that rise abruptly, almost without the transition of the plain, as main characteristic of the landscape of the municipality of Rio de Janeiro. The abrupt feature and high slope presented on the PUC-Rio slope confirm these characteristics.

Sertã (1986) mention on the absence of an apparent rock outcrop at the Experimental Station II site. However, it is pointed out that the local base is 
constituted by a granade-biotiteplagioclásio-gnaisse, with granulolepidoblastic texture, referred to the Pre-Cambrian, of uncertain age.

According to Lins (1991), the Experimental Station II presents a well developed residual soil mantle, derived from weathering of a clastic gneiss, a high grade metamorphism rock, composed mainly by quartz, feldspar and biotite. As accessory minerals, muscovite and pomegranate are present.

Pedologically, the soil is classified as red-yellow podzolic. Over the young residual soil there is a layer of mature residual soil, which can be described as a redyellowish clayey matrix with many fractured quartz grains and pomegranate alteration grains. In the young residual soil, the existence of fractures and quartzfeldspathic fractions of variable granulation is verified (Beneveli, 2002). A morphological description is shown in Figure 3.6, representative of the residual soil profile at the Experimental Station II of PUC-Rio, obtained by Daylac (1994) from inspection of an open pit of approximately $13.5 \mathrm{~m}$ deep.

\subsection{3 \\ Climatic aspects}

According to Brito (1981), the municipality of Rio de Janeiro is subject to five different types of climate. The region under study was defined as belonging to a Mega thermal Zone with a hot and rainy tropical climate, having in the driest month a precipitation higher than $60 \mathrm{~mm}$ and in the coldest month a temperature higher than $18^{\circ} \mathrm{C}$. The region's average rainfall ranges from 1,800 to $2,000 \mathrm{~mm}$ per year.

The climatic analysis of this region indicates conditions for the occurrence of deep soils, well developed, with a marked tendency for acidity and a well characterized weathering process (Brito, 1981). 


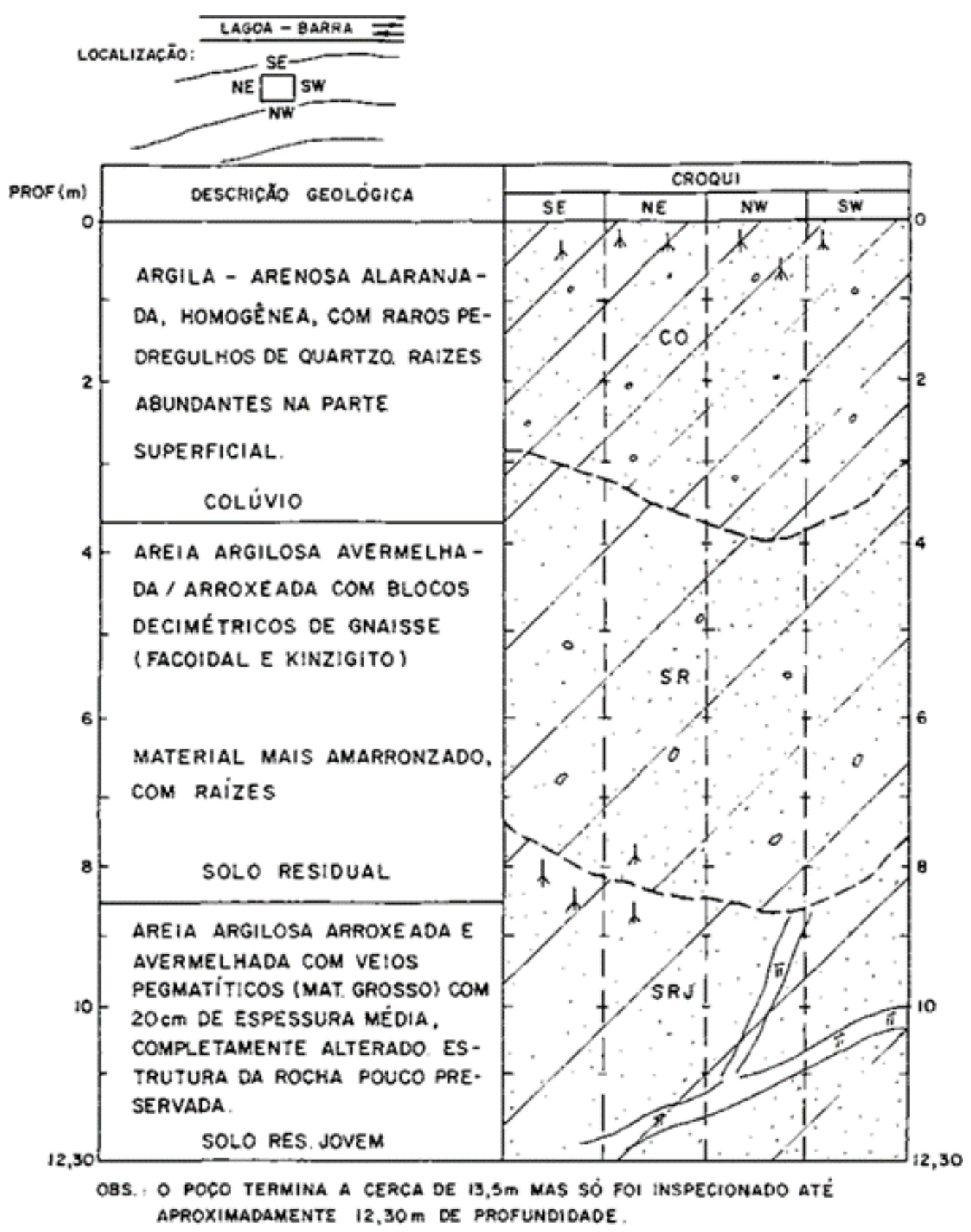

Figure 3.6 - Geotechnical profile of the Experimental Station II of PUC- Rio (Dylac, 1994)

\section{4}

\section{Physical, chemical and mineralogical characterization}

\subsection{1}

\section{Physical characterization}

For the physical characterization of the soils, specific gravity tests (Gs), particle size analysis and consistency limits tests were performed. The samples were prepared after air drying, according to NBR 6457/86 (ABNT). 


\subsubsection{1 \\ Specific gravity $\left(G_{s}\right)$}

The specific mass of the grains was determined in accordance with standard NBR 6508/1984. In total, $100 \mathrm{~g}$ of material dried at $105{ }^{\circ} \mathrm{C}$, were distributed equally among four $250 \mathrm{~mL}$ pycnometers. Subsequently, the air contained within the particles was extracted using a vacuum pump for 15 minutes or until the total absence of air bubbles was detected.

This procedure was adopted for all soils and the values obtained from the arithmetic means of each of the four determinations were divided by the specific mass of the water to determine the relative density of the grains, Gs.

Table 3.1 - Specific gravity values obtained for the two soils

\begin{tabular}{|c|c|}
\hline Sample & Gs \\
\hline ACP & 2,661 \\
\hline MCP & 2,723 \\
\hline
\end{tabular}

\subsubsection{2 \\ Grain size analysis}

The coupled sieving-sedimentation tests performed in this work followed the NBR 7181 / 84a (ABNT) with a few adaptations. The Brazilian Association of Technical Standards $(\mathrm{ABNT})$ recommends that sedimentation tests should be performed with material passing through the $2 \mathrm{~mm}$ sieve (\# 10). The tests, however, were done according to the method used in the Geotechnical and Environmental Laboratory of PUC-Rio, with the material passing through the sieve of $0.42 \mathrm{~mm}(\# 40)$.

Initially, the material retained in the $0.42 \mathrm{~mm}$ sieve was washed in order to eliminate any fine particles adhered to the coarser fraction of the soil. This sample was then oven dried and taken to sieving. The sedimentation tests consisted of mixing $50 \mathrm{~g}$ of air-dried soil, passing through the \# 40 sieve with $125 \mathrm{~mL}$ of water or hexametaphosphate. After a 24 hours rest, the mechanical dispersion was performed and the mixture was placed in a $1000 \mathrm{~mL}$ beaker whose volume was filled with distilled water. The beaker was shaken for one minute and the densimeter readings were followed for 24 hours. 
After the readings, the material was placed in the $0.075 \mathrm{~mm}$ sieve (\# 200) and subjected to the washing process, and then taken to the stove. After drying, fine sieving was performed, thus completing the grain size curve of the material analysed.

The grain size results are shown in Table 3.2, which summarizes the percentage of each soil fraction, followed by grain size distribution curves presented in Figure 3.7. It is important to state that sedimentation tests were performed with two different deflocculants: sodium hexametaphosphate $(\mathrm{H})$ and water $(\mathrm{W})$.
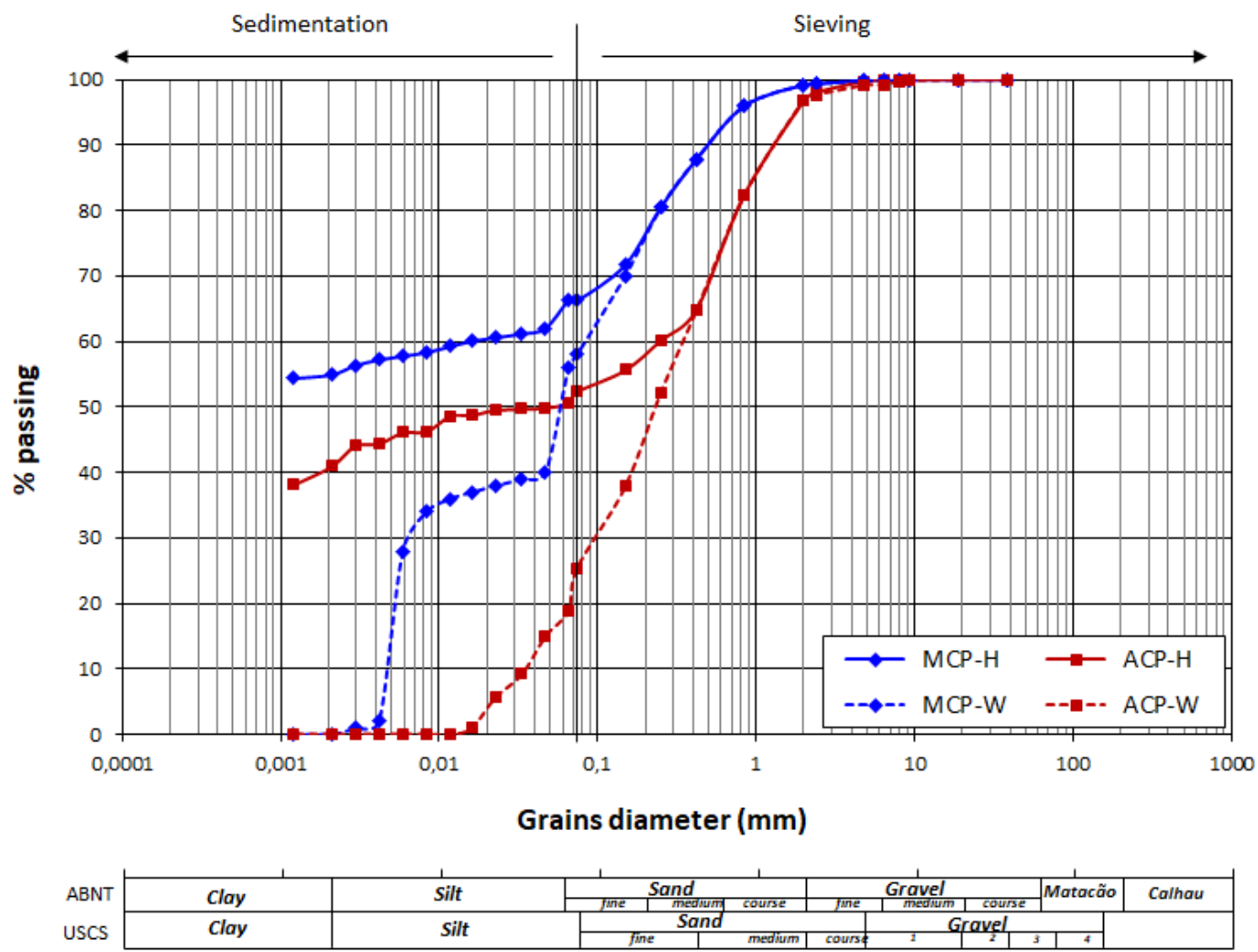

Figure 3.7 - Grain size distribution of the two soils. Curves shown for sedimentation tests performed with both sodium hexametaphosphate $(\mathrm{H})$ and water $(\mathrm{W})$ as deflocculant.

The results of the grain size tests performed with sodium hexametaphosphate as a deflocculant indicate that both ACP and MCP soils are clayey. The use of just water as a sedimentation fluid showed that all the soils tested agglomerated, forming flakes when in their natural state. This state is evidenced in Figure 3.8, where the water has a lighter shade and the soil forms a homogeneous mass in the bottom of the beaker. 

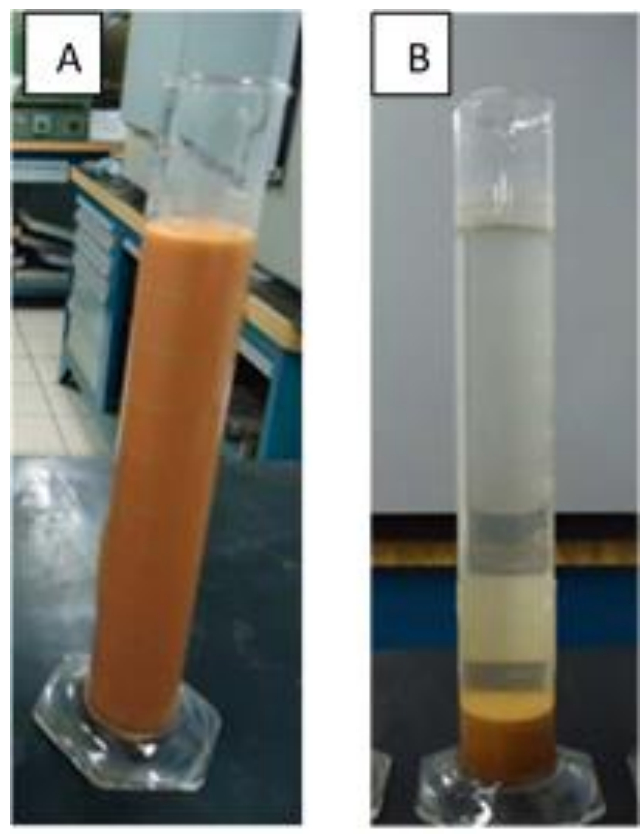

Figure 3.8 - ACP soil sedimentation tests after 21 hours of start: (A) With sodium hexametaphosphate as deflocculant. (B) With water was deflocculant. (Adapted from Galindo, 2013).

Table 3.2 - Grain size distribution of the two soils, referred to sedimentation tests performed both with sodium hexametaphosphate $(\mathrm{H})$ and water $(\mathrm{W})$ as deflocculant.

\begin{tabular}{|c|c|c|c|c|c|c|}
\hline \multirow{2}{*}{ Sample } & \multirow{2}{*}{ Gravel } & \multicolumn{3}{|c|}{ Sand } & \multicolumn{2}{c|}{ Fines } \\
\cline { 3 - 7 } & & Coarse & Medium & Fine & Silt & Clay \\
\hline ACP-H & 2,9 & 24,6 & 14,2 & 7,7 & 10,1 & 40,5 \\
\hline ACP-W & 2,9 & 24,6 & 27,3 & 29 & 16,0 & 0,1 \\
\hline MCP-H & 0,8 & 7,9 & 15,2 & 11,1 & 10,2 & 54,9 \\
\hline MCP-W & 0,8 & 7,9 & 15,2 & 21,3 & 55,4 & 0,1 \\
\hline
\end{tabular}

It is important to note here that the changes in the grain size distribution, when using water in the sedimentation tests, may affect debris flow analyses. The clay fraction disappears for the two soils and its particles form silt to fine sand sized clusters. A striking variation occurs in soil ACP, which changes its classification from a high-plasticity clay to a poorly graded sand. The MCP soil change its initial clayey classification to silty-sand soil. This finding is relevant in the sense that all mechanical tests in this study were realized with water as a fluid, and debris flow mechanisms may change depending on the grain size of the moving mass (e.g. Scotto di Santolo et al., 2012; Zhou et al., 2013). 


\subsubsection{3}

\section{Limits of consistency and activity of clays}

The tests of liquidity limit and plasticity limit followed the determinations of standards NBR 6459 / 84b and NBR 7180 / 84c, respectively. All the tests were performed with dewatering samples, air dried and passers in the \# 40 sieve. The activity index of the clays $\left(A_{c}\right)$ determined by using the Skempton expression, presented in Equation 44, serves as an indication of the influence of the clay fraction in soil behavior.

$$
A_{c}=\frac{P I}{\%<0.002 \mathrm{~mm}}
$$

Table 3.3 - Results of limits of consistency and activity of clays for the two soils.

\begin{tabular}{|c|c|c|c|c|}
\hline Sample & LL (\%) & PL (\%) & PI (\%) & $\mathrm{A}_{\mathrm{c}}$ \\
\hline $\mathrm{ACP}$ & 64,5 & 35,9 & 28,8 & 0,71 \\
\hline $\mathrm{MCP}$ & 68,3 & 28,2 & 40,1 & 0,73 \\
\hline
\end{tabular}

\subsubsection{4 \\ Soil classification}

Based on the referred standard geotechnical tests, the soils ACP and MCP comprise clayey-sand materials. According to the unified soil classification system (USCS), the both materials are classified as high-plasticity clays. The occurrence of gibbsite in the fine fraction of the ACP soil (as it will be shown in Item 3.4.3) indicates a more advanced process of laterization in this soil than in the MCP soil. Thus, a higher plasticity would be expected for soil MCP than for soil ACP.

\subsection{2}

\section{Chemical characterization}

For the chemical characterization of the soils, total chemical analysis was carried out on a Phillips / sequential PW 2400 X-ray fluorescence spectrometer, in the Department of Chemical Engineering of PUC-Rio. 


\subsubsection{1}

\section{Total chemical analysis}

The chemical elements present in each of the soils tested were determined by X-ray fluorescence on samples fused with lithium tetraborate. By means of these analyses, it was possible to obtain the contents of silica ( $\mathrm{SiO} 2)$, alumina (Al2O3), titanium oxide ( $\mathrm{TiO} 2)$, iron $(\mathrm{Fe} 2 \mathrm{O} 3)$, magnesium $(\mathrm{MgO})$ and other elements present in soils.

According to Antunes (2013), the alumina and silica contents found indicate that all soils are in an advanced stage of laterization, provided by the leaching of the alkalis and part of the silica. In this way, they could be classified as mature soils.

Table 3.4 - Chemical composition of the both soils.

\begin{tabular}{|c|c|c|c|c|c|c|c|c|}
\hline Sample & $\mathrm{SiO}_{2}$ & $\mathrm{Fe}_{2} \mathrm{O}_{3}$ & $\mathrm{Al}_{2} \mathrm{O}_{3}$ & $\mathrm{TiO}_{2}$ & $\mathrm{SO}_{3}$ & $\mathrm{~K}_{2} \mathrm{O}$ & $\mathrm{ZrO}_{2}$ & $\mathrm{P}_{2} \mathrm{O}_{5}$ \\
\hline ACP & 31,02 & 32,28 & 31,59 & 3,55 & 0,45 & 0,398 & 0,283 & 0,154 \\
\hline MCP & 41,47 & 30,47 & 23,87 & 2,84 & 0,57 & 0,31 & 0,16 & 0,15 \\
\hline
\end{tabular}

\subsubsection{2}

\section{Sulfur attack}

In order to investigate correlation between the materials' degree of laterization and rheological behavior, sulfur attack tests were performed in EMBRAPA-Solos, in Jardim Botânico/ Rio de Janeiro. In the test, the $K I$ index is measured, as it follows in Equation 45, and laterization is approached by: $K I>1.4$ states high degree of laterization; $K I<1.4$ states low degree of laterization.

$$
K I=\frac{\mathrm{SiO}_{3}}{\mathrm{Al}_{2} \mathrm{O}_{3}}
$$

The sulfuric attack test only affects the secondary minerals, such as the clay minerals, iron and aluminium oxyhydroxides present in the clay fraction of the soil, to determine the percentages of silicon oxide $\left(\mathrm{SiO}_{2}\right)$, aluminium, iron $\left(\mathrm{Fe}_{2} \mathrm{O}_{3}\right)$ and titanium $\left(\mathrm{TiO}_{2}\right)$ in the soil and amorphous materials, if present. Therefore, the silica, aluminium and iron contents correspond to the secondary minerals and not to the primary minerals, such as, for example, the quartz present in the soil sample. 
The ACP soil is highly laterite $(K I>1,4)$ and the MCP soil is low laterite (KI $<1,4)$.

Table 3.5 - Sulfur attack test results.

\begin{tabular}{|c|c|c|c|c|c|}
\hline Sample & $\mathrm{SiO}_{2}$ & $\mathrm{Al}_{2} \mathrm{O}_{3}$ & $\mathrm{Fe}_{2} \mathrm{O}_{3}$ & $\mathrm{TiO}_{2}$ & $\mathrm{Ki}$ \\
\hline ACP & 186 & 205 & 89 & 10,3 & 1,54 \\
\hline MCP & 121 & 250 & 97 & 14,8 & 0,82 \\
\hline
\end{tabular}

\subsection{3}

Mineralogical characterization

The mineralogical composition is important for better understanding of many mechanical behavior of soils. For example, the existence of smectite, which has the property of increasing the double layer in the presence of water, can give the soil an expansive behavior (Espinoza, 2010). A preliminary idea about the mineralogical characterization of the samples was obtained by conducting differential thermal analysis test.

\subsubsection{1 \\ Differential Thermal Analysis (DTA)}

Thermal Analysis (DTA) is a thermal technique in which the temperature difference between the sample and an inert substance is measured when both are exposed to a controlled temperature environment (Mothé \& Azevedo, 2002).

Changes in the temperature of the sample are caused by the transitions or enthalpic reactions (endothermic or exothermic) due to phase changes, melting, vaporization, dehydration reactions, oxidation, reduction reactions among others. The temperature changes during these physical and / or chemical variations are detected by the differential method (Mothé, 2009).

According to Santos (1928), the capillary water in clay particles presents an endothermic peak, with a maximum temperature of $110^{\circ} \mathrm{C}$, acute and more intense as more water is present. The gibbsite loses water of about $350{ }^{\circ} \mathrm{C}$, with an endothermic peak in the thermogram. At $450^{\circ} \mathrm{C}$ the dihydroxylation reaction of the kaolinite begins, which is completed at $600{ }^{\circ} \mathrm{C}$, temperature in which is revealed by the presence of an endothermic peak in the thermogram. 
The tests were carried out at the Department of Materials Science and Metallurgy of PUC-Rio, within a Perkin Elmer equipment and Pyris data acquisition system. Test were performed in a temperature range from 0 to $880^{\circ} \mathrm{C}$, in a $20^{\circ} \mathrm{C}$ per minute rate.

As observed in the obtained results, shown in Figure 3.9, both soils present clay fraction basically constituted by kaolinite and gibbsite. The fine fraction of MCP sample is formed exclusively of kaolinite, whereas ACP sample is composed by kaolinite and gibbsite. This finding is in agreement with the sulfur attack results, which shows a higher laterization degree for the ACP soil.

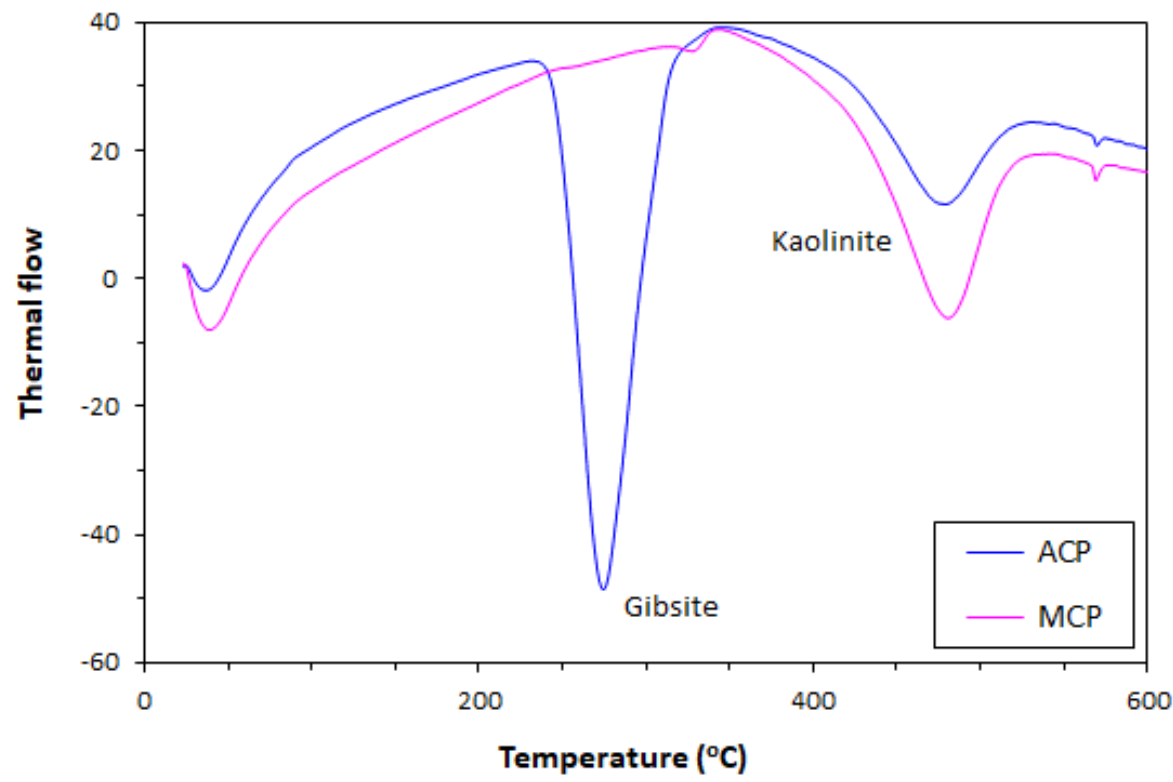

Figure 3.9 - DTA results for the ACP and MCP soils. 


\section{4}

\section{Equipment and methodologies}

Two sets of laboratory tests were performed on the investigation about rheological properties of the studied soils. The first is the modified cylindrical tube slump test, in which shear rate, viscosity and yield stress are obtained through kinematic, physical and geometrical measures. The second is the flow test executed in the rotational rheometer, where flow curves provide relations between viscosity, shear stress and shear rate.

This chapter presents detailed explanation about tests purposes, its particularities, the methodologies involving results interpretation and the laboratorial routines developed to perform the experiments.

\section{1 Cylindrical tube slump test}

The execution of slump tests in this study involves two main purposes. The first one is to measure the viscosity developed by the material during its fall and spreading due to self-weight. For that, a methodology based on Newton's Law of viscosity has been developed in order to measure the material's shear rate during the test. Newton's law defines shear rate as the fluid's variation rate between horizontal velocity and vertical position, when the top plate moves horizontally and the bottom one stays still. It is important to state that the same mechanism is involved in the rheometer flow test. The second aim is to calculate both plastic viscosity and yield stress by employing semi empirical and analytical solutions.

In this sense, the methodology herein used consists in plotting the horizontal velocity against the vertical displacement, and then calculating the shear rate developed by the material in the slump test. After that, viscosities corresponding to the measured shear rates are obtained in a combined analysis with the rheometer's relation between viscosity and shear rate. The second purpose of the slump test is to calculate viscosity and yield stress through analytical models. For that, specific 
mass and height and diameter variation are measured to provide the input parameters required by the models.

\subsection{1 \\ Modified slump test set-up}

The slump test set-up used in this study is well described in Galindo (2013), though some adjustments were taken to improve the experiment. The most important modification is the test geometry, which changed from an Abraham's cone (internal volume around $\left.5500 \mathrm{~cm}^{3}\right)$ to a smaller cylindrical tube $\left(1600 \mathrm{~cm}^{3}\right)$. Less material amount was necessary for tests, improving manual laboratory procedures, such as organization and cleaning. Besides, analytical solutions found in the literature provide viscosity and yield stress calculations for the cylindrical slump test problem, so that, allowing the present study to draw comparisons between experimental and analytical results.

A sketch of the developed slump testing set-up is shown in Figure 4.1 and Figure 4.2. The scheme comprises an aluminium main frame on which a pulley system is adapted, in a manner that the cylindrical tube develops a smooth lifting under a fast velocity; a long-stroke-range linear variable differential transformer (LVDT) with a low restriction to free-fall of its inner rod, linked to a fast recording data acquisition system coupled to a laptop, for vertical displacement measuring; a filming set-up to perform frontal recording of the experiment, for horizontal displacement measuring (see Figure 4.7).

To minimize undesirable friction, tubes were fabricated from Teflon billets. Additionally, a silicone mat was introduced at the base of the tube, which also helped to prevent leakage of slurry/water at the base of the cone. To guarantee that the LVDT would follow the fast collapse rate of the soil, an acrylic plate was adapted to the end of the inner rod of this instrument. The suction developed under this plate, positioned in intimate contact with the moistened soil, was expected to provide an adequate response of the displacement transducer at the beginning of the test. The weight of such inner rod and the coupled acrylic plate imposed an overpressure on top of the soils of circa $0.20 \mathrm{kPa}$, which was considered in calculations analysis. 

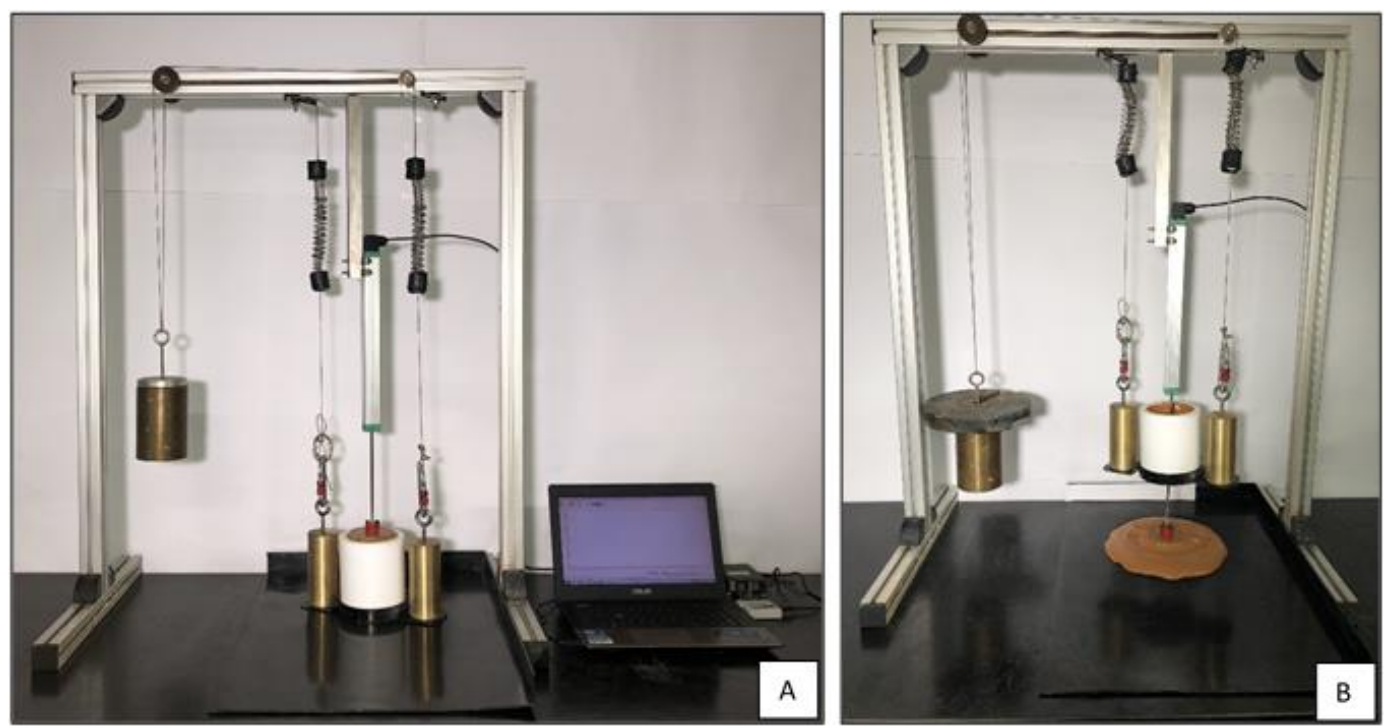

Figure 4.1 - Modified slump test set-up. (A) Before testing. (B) After testing.

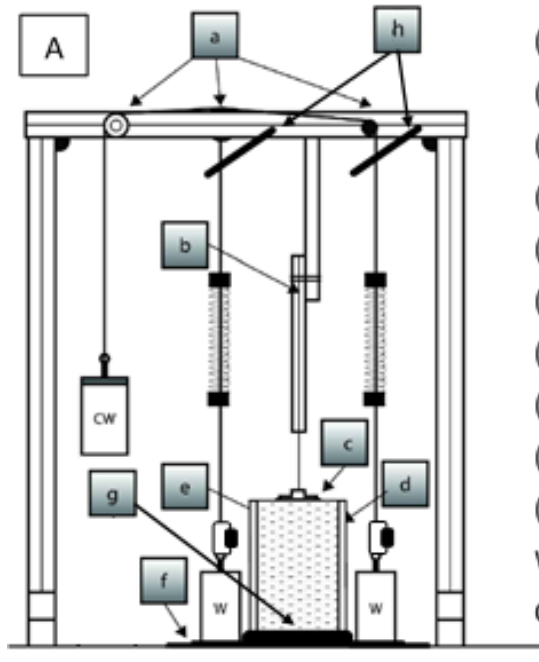
(a) Wheels
(b) LVDT
(c) Acrylic plate
(d) Cylindrical tube
(e) Soil
(f) Silicone mat
(g) Clasp
(h) Damping supports
(i) Springs
(j) Autolocking carabiners
$\mathrm{W}=$ Dead weight
$\mathrm{CW}=$ Counter weight

B

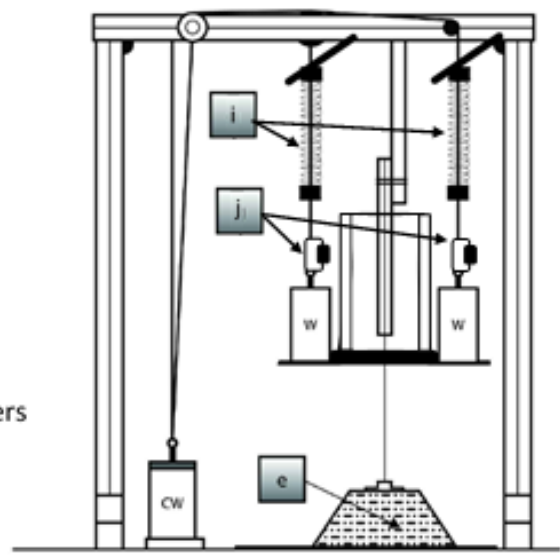

Figure 4.2 - Sketch of the modified slump test set-up. (A) Before testing. (B) After testing.

A damping system was developed in order to minimize vibrations effects during the soil-mass slump and runout, which could lead to displacements not related to the flow due to own-weight. The system consists in two rigids supports attached to the top beam of the main frame (Item $\mathrm{H}$ in Figure 4.2), and two spring series attached to the raising cables (Item I). When the counter weight is loaded, the springs shock against the supports and a flat stopping occurs, so that no extra displacements are observed.

Autolocking carabiners were fastened to the cable's extremities connected to the cylindrical tubes (Item J in Figure 4.2). These items allow quick connection and removal of the tubes during the execution of the tests. The carabiners support a 
maximum load of $25 \mathrm{kN}$, providing a secure lift of the tubes system whose weight is around $0,1 \mathrm{kN}$. Clasps were fabricated to perform a firm connection between the tubes and the dead weights (Item G). The steel made pieces were galvanized and coated with non-oxidant black ink.

\subsection{2}

\section{Tubes design}

Three different cylindrical tubes were tested in this study (Figure 4.3). Each of them presents a different aspect ratio geometry: a same internal diameter $(100 \mathrm{~mm})$ was fixed, and three different heights $(100,150$ and $200 \mathrm{~mm})$ were chosen to verify if a determined geometry would lead to a best set of results. The external diameter was set to $130 \mathrm{~mm}$, resulting in a thick wall of the tubes $(15 \mathrm{~mm})$. So that, the constriction necessary to firm the system dead weight-tube-clasp, led to negligible deformation of tubes' internal wall (Figure 4.4). Tubes were fabricated from Teflon billets, allowing low friction between soil and the inner wall of the tubes.
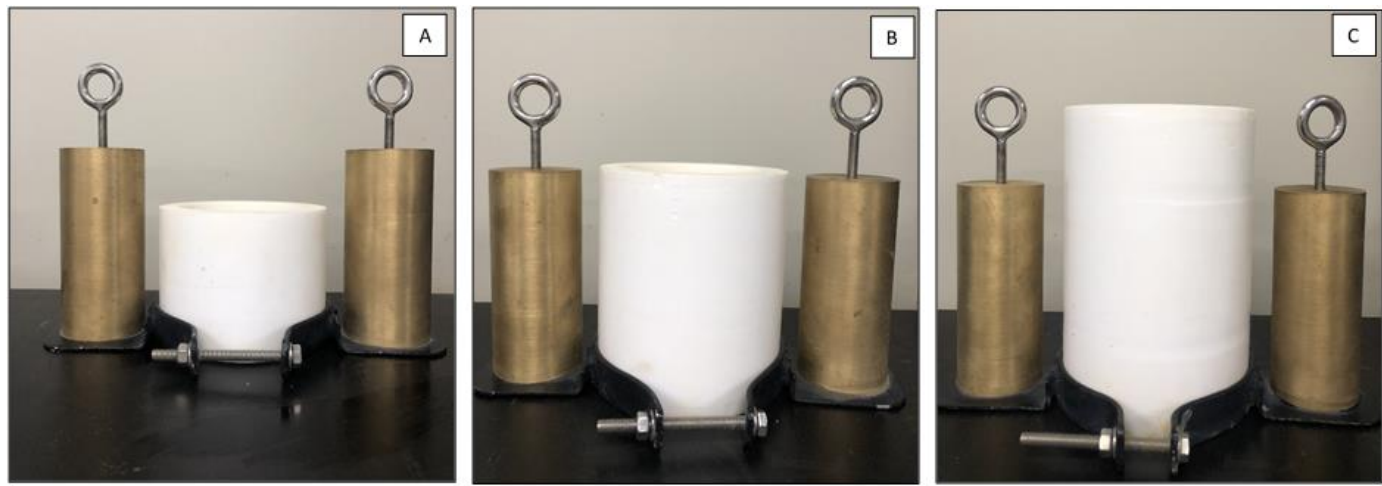

Figure 4.3 - Series of tested tubes with different heights $\mathrm{H}_{0}$, and same internal and external diameters: 10 and $13 \mathrm{~cm}$, respectively. (A) $\mathrm{H}_{0}=10 \mathrm{~cm}$. (B) $\mathrm{H}_{0}=15 \mathrm{~cm}$. (C) $\mathrm{H}_{0}=20 \mathrm{~cm}$.
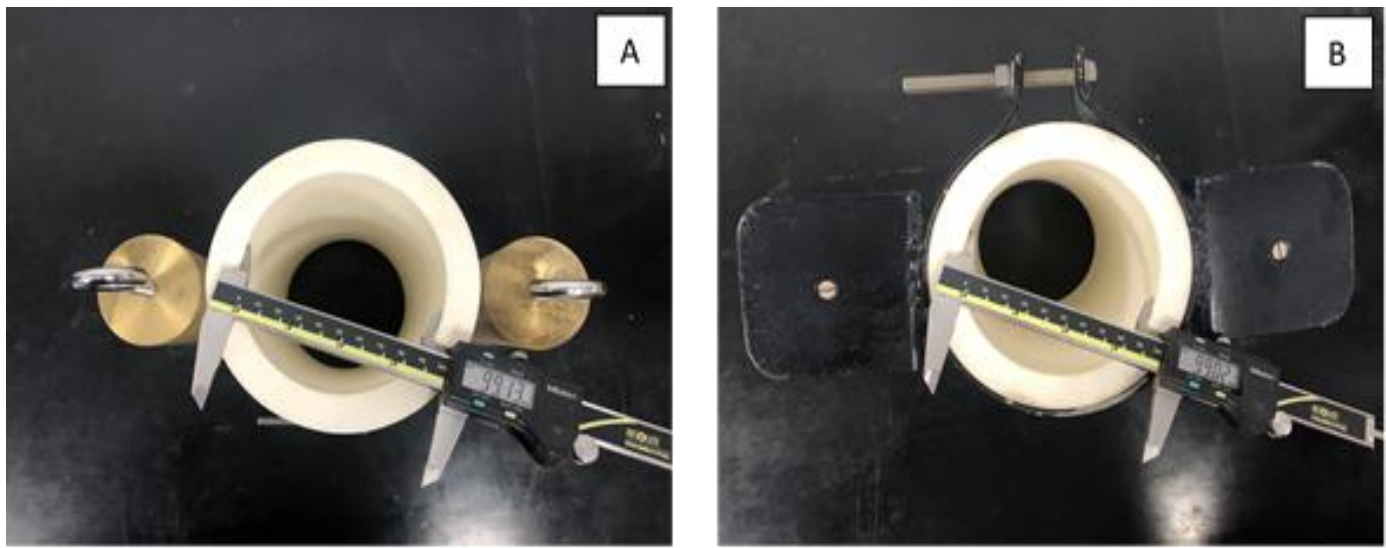

Figure 4.4 - Verification of no radial deformation due to constriction. 
To guarantee the same weight of the systems dead weight-tube-clasp, and also the same point of connection between dead weights and carabiners (same height at which the rising cables attach to the dead weights), those weights were designed to a fix height and a certain diameter which would lead to equal total mass of the group. Design calculations are presented in Table 4.1Table 4.1 and a total mass of around $10.2 \mathrm{~kg}$ was reached to all tubes' apparatus.

Table 4.1 - Design of the tubes' apparatus. Dead weights' diameters were set to result in equal total masses of the apparatus. All tubes have the same internal and external diameters: 10 and $13 \mathrm{~cm}$, respectively. All dead weights have the same height: $14.3 \mathrm{~cm}$.

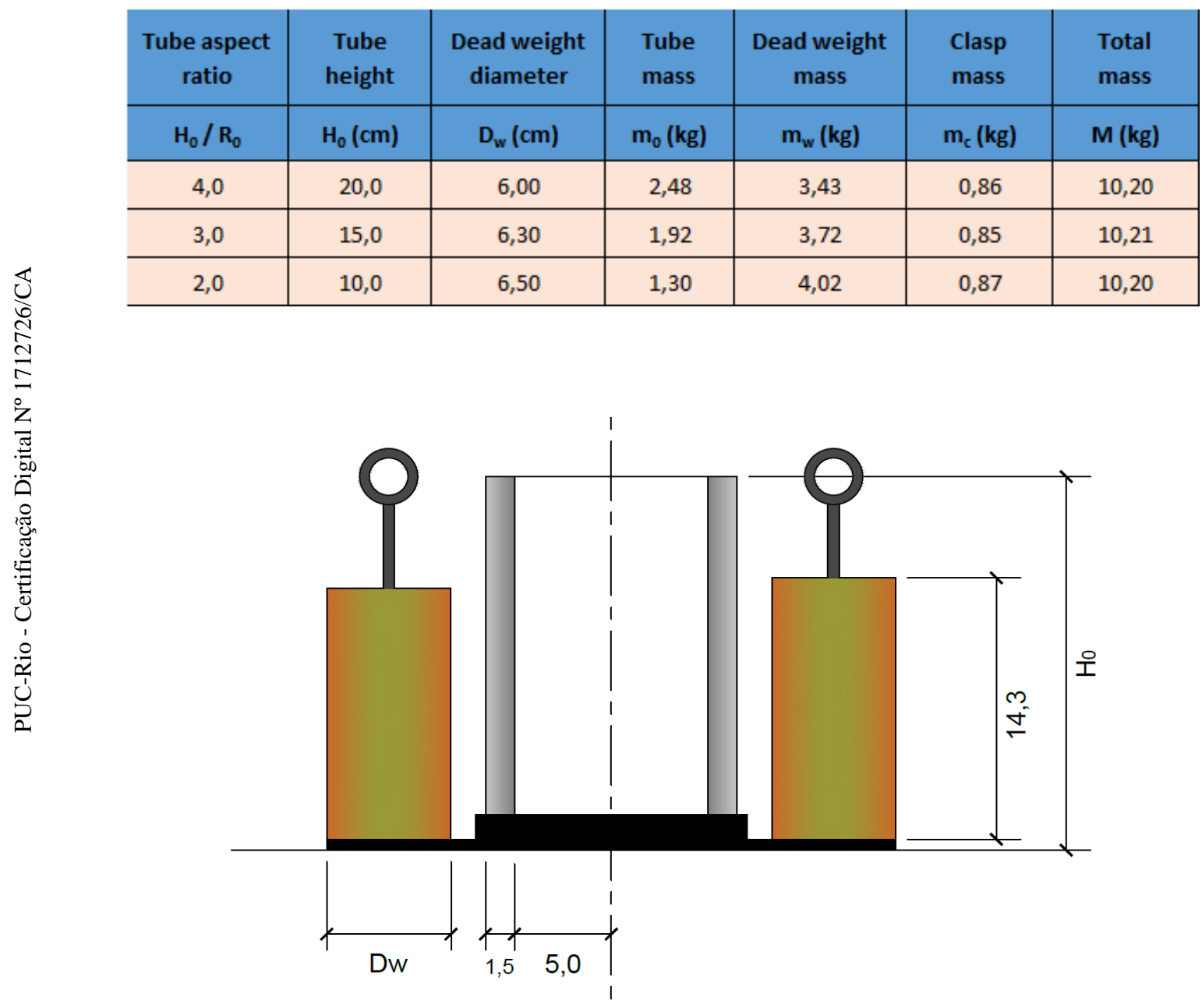

Figure 4.5 - Design sketch of the tubes' apparatus. 


\subsection{3 \\ Displacements measurement}

The herein developed methodology for shearing rate determination involves kinematic analysis of slump and runout movement (vertical and horizontal, respectively). Both slump and runout displacements are measured in the test, and after that velocity and acceleration are obtained through derivation of the polynomial fitting that adjusts the displacement-time curves.

\subsubsection{1 \\ Vertical displacements}

The methodology for vertical displacements determinations was developed by Galindo (2013). The system presented in Figure 4.6Figure 4.6 and consists in a long-stroke-range linear variable differential transformer (LVDT) with a low restriction to free-fall of its inner rod, linked to a fast recording data acquisition system coupled to a laptop. A Tecnolog® FS120 potentiometer, with a $0.2 \%$ precision, received data from the linear transducer, forwarding them to the Novus MyPCLab® data acquisition system, which in turn transferred the information to the computer, storing one read per 0.01s (Figure 4.6Figure 4.6 B).
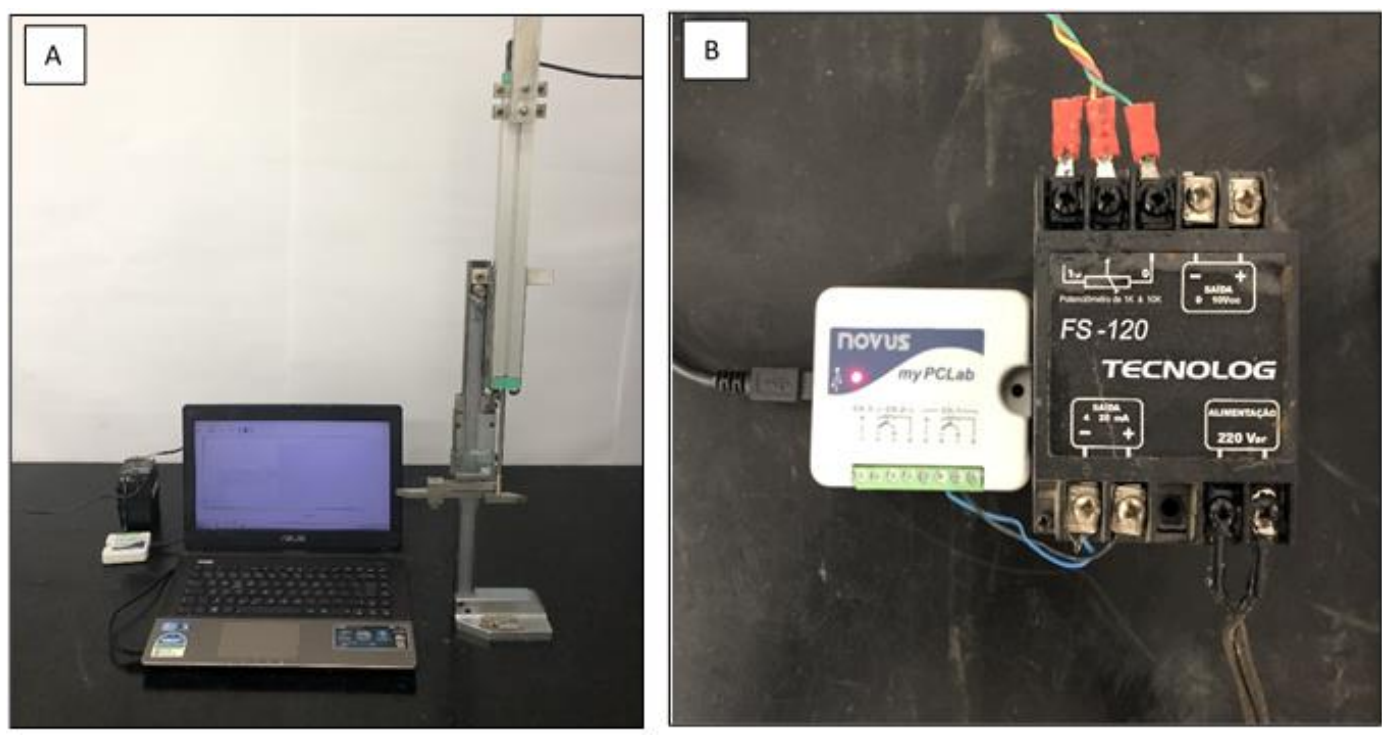

Figure 4.6 - Vertical displacements measurement devices. (A) Left: potentiometer and data acquisition system. Centre: laptop. Right: LVDT attached to the calliper. (B) Left: MyPCLab data acquisition system. Right: Tecnolog potentiometer. 
The LVDT was calibrated with a manual caliper, in which millimetric measures are taken with a magnifying glass, while the inner rod is moved down in a coupled movement with the glass (Figure 4.6Figure 4.6 A). The calibration result is presented in Appendix A.

\subsubsection{2}

\section{Horizontal displacements}

A methodology was developed for measuring runout displacements. As shown in Figure 4.7, tests were filmed frontally, providing a set of frames (see Figure 4.9) on which the left border positions of the flowing spread could be measured, in equal time intervals, through a Digital Image Processing (DIP) procedure (see Figure 4.10). Movements were recorded with an iPhone $8 \mathrm{~S}$, in a $4 \mathrm{~K}$ movie resolution and a $30 \mathrm{fps}$ (frames per second) recording velocity. To guarantee positioning repeatability, the iPhone was placed over a tripod and marks were drawn in the floor to ensure that the most adequate camera position would be always kept (Items $\mathrm{C}$ and $\mathrm{D}$ in Figure 4.7).
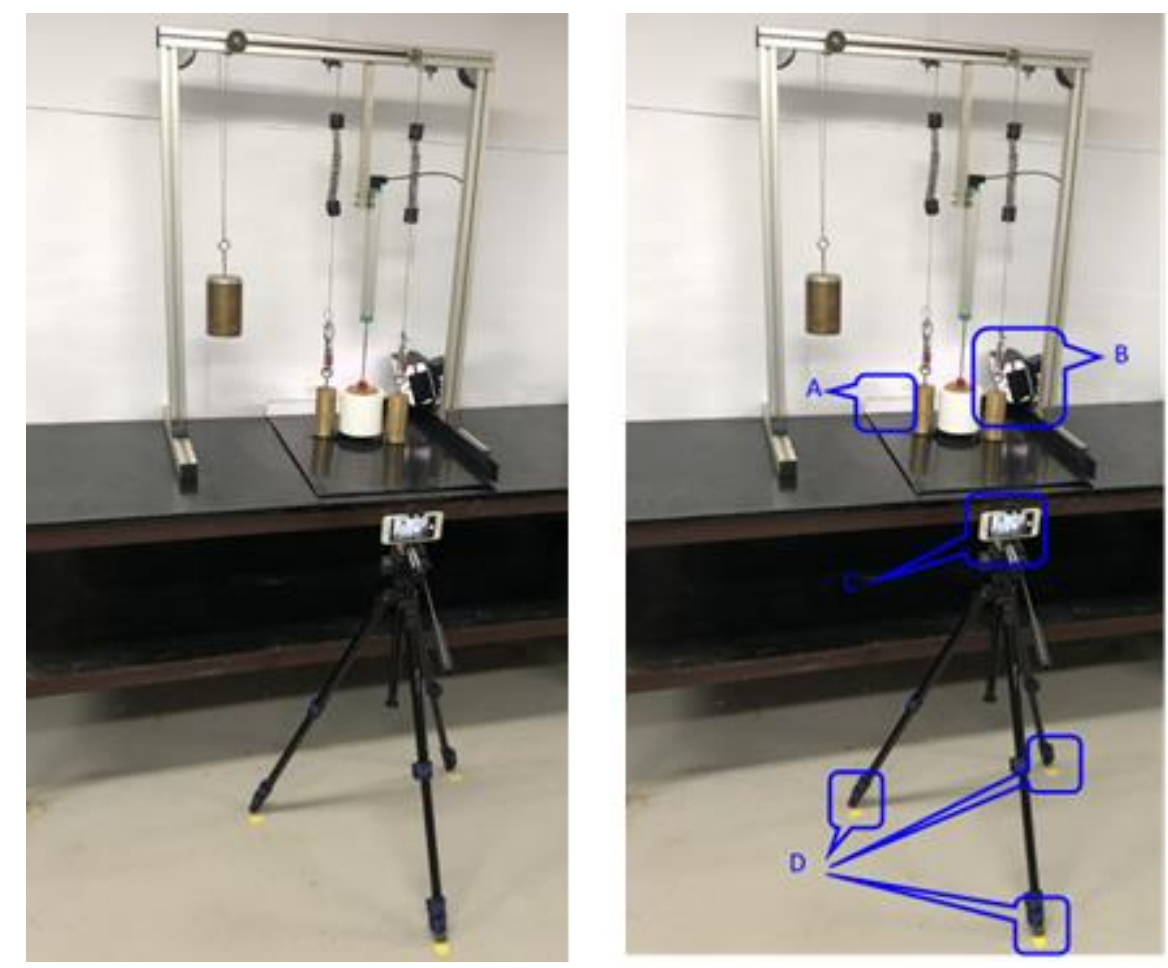

Figure 4.7 - Test filming set-up. (A) White background. (B) Led lamp. (C) Camera attached to a tripod. (D) Position marks for the tripod. 
DIP analysis demands certain brightness and contrast requirements and so care was taken in order to achieve the best quality of tests recording. For that, a white background was placed behind the runout left path (Item A in Figure 4.7) and a TL-320 Led Lamp with $5500 \mathrm{~K}$ color temperature (Item B in Figure 4.7Figure 4.7) was fixed in a manner to lighten the background but not the runout, as shown in Figure 4.8. Additionally, the room on which tests were performed was devoid of light incidence by blocking the windows with black paperboard.

For tests execution, the room lamps were turned off and the led lamp turned on, so that the runout movement resembles a shadow (as low light strikes the soil spread), and a good acceptance of DIP is observed.

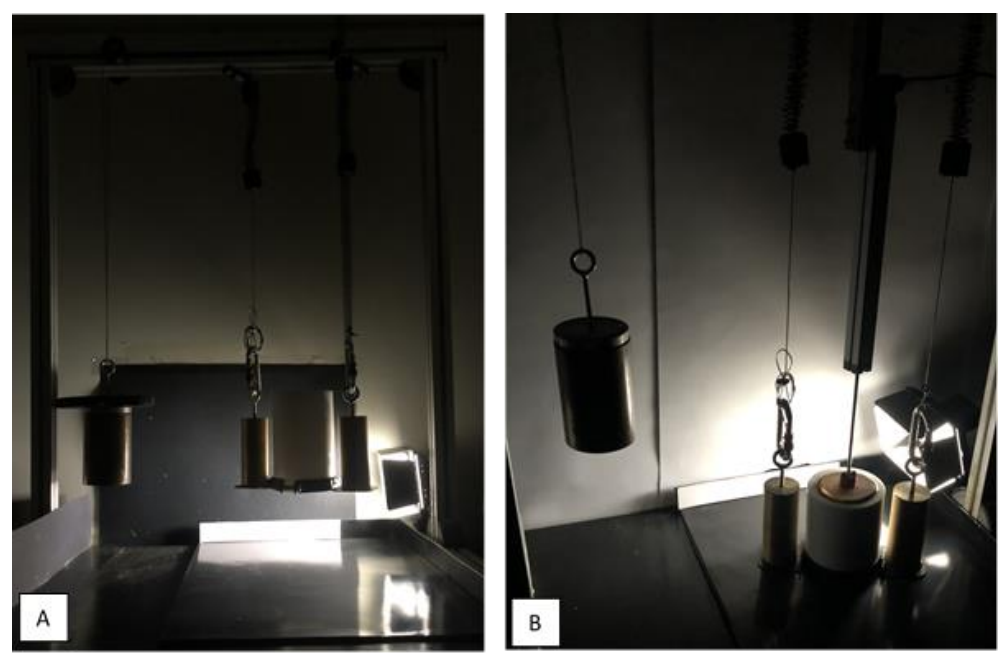

Figure 4.8 - Procedures for brightness and contrast requirements by the DIP software.

\subsubsection{3 \\ Digital Image Processing (DIP)}

The DIP analysis was performed with the ImageJ Fiji software. Firstly, movies were fragmented to frames (in a 1/30 second interval between each frame) with a FFMPEG plugin for Windows 10 Command Prompt. After that, frames were dragged as stacks into the Fiji program, and a pixel-centimeter scale was set in relation to the dead weight diameter. Stacks were cropped into smaller windows where runout was observed. Finally, an own tool analysis of the software calculated the soil's position of the left border, in each frame. Below are presented an original frame stack recorded with the iPhone (Figure 4.9), and an output stack given by the ImageJ software (Figure 4.10). 

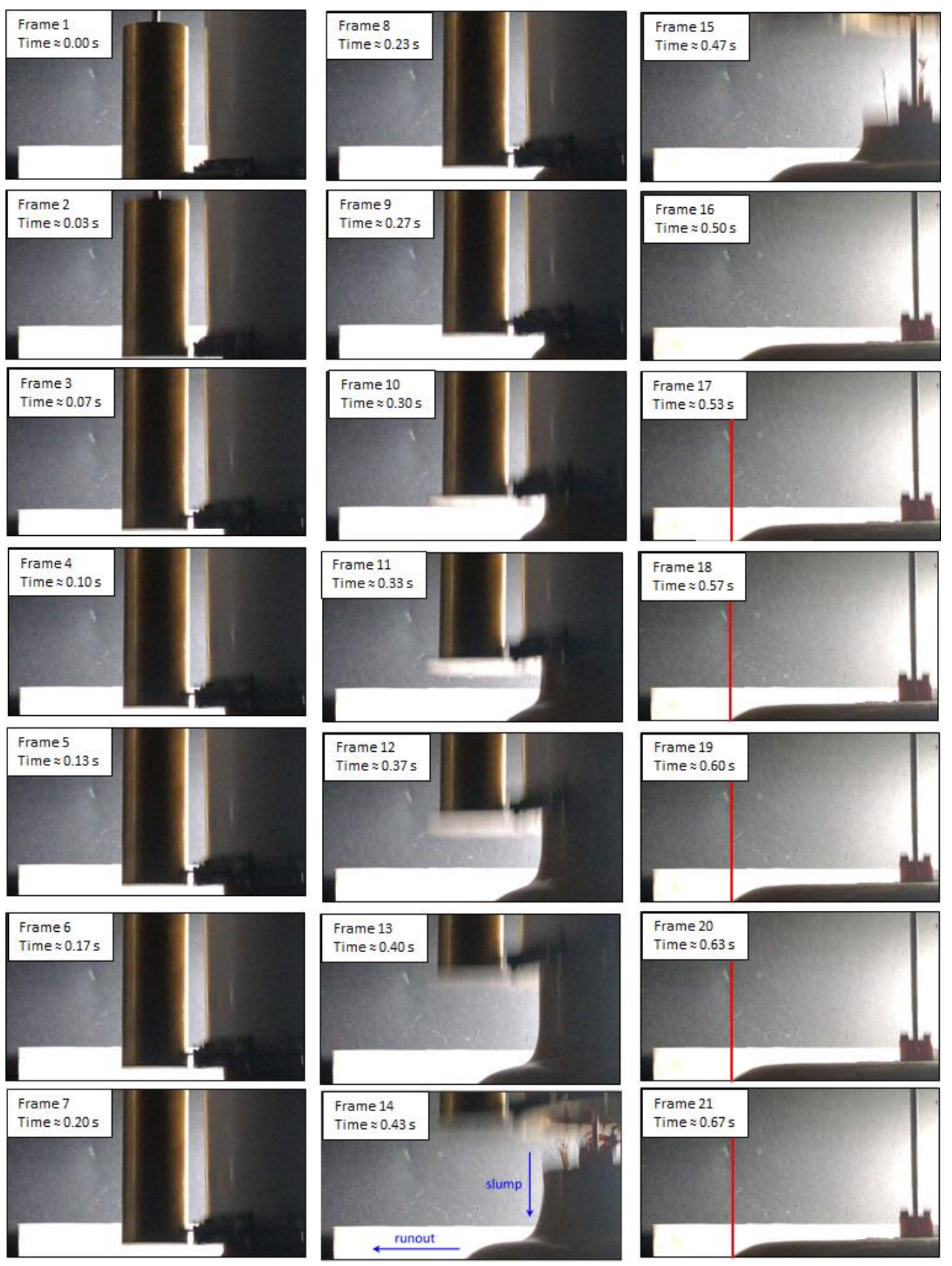

Figure 4.9- Original frame stack obtained through test filming. Red lines assign the frames in which the soil motion is over.

It is interesting to note here that both slump and runout motions seem to cease simultaneously, between frames 18 and 19 (assigned with red lines in Fig. 4.9), that is, approximately at $0.6 \mathrm{~s}$ after the test is started as the counterweight is loaded. Such finding is ratified in the velocity-time curves herein obtained (see Figure 4.12 B). This discussion will be further explored in Item 5.1.4. 


\section{Frame 7}

Frame
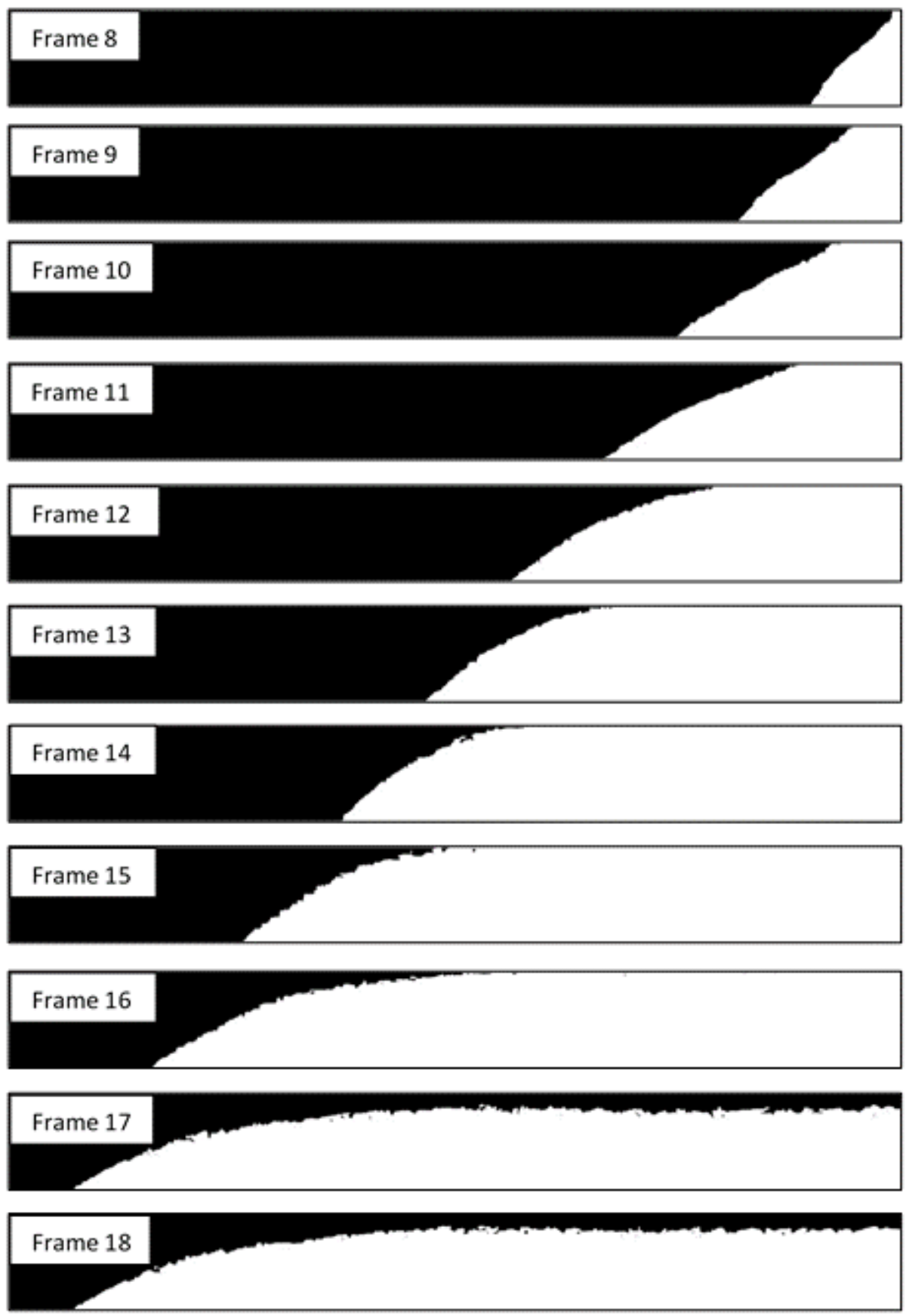

Figure 4.10 - Output frame stack given by the ImageJ software.

A calibration was performed to verify if the pixel-centimetre scale is linear along all the runout path. An object was moved in three-centimetre spaced marks and the frames was DIP analysed in the same methodology as the tests' videos were. The calibration set-up and result are presented in Appendix B. 


\subsection{4}

\section{Shear rate interpretation}

No attempt has been made so far to define shear strain rates in slump tests (de Campos \& Galindo, 2015). A methodology to do so is proposed in what follows, considering results of triplicated slump tests performed at four differing moisture contents in both studied soils and assuming that accelerating shear rates resulting from slump tests would be equivalent to applied shearing strain rates in rheometer devices. Based on Newton's model, the shear rate is herein defined as the rate between horizontal velocity and vertical displacement during a flow event.

Considering that in a debris flow event, the rate at which a flowing mass moves is associated to acceleration - once the descendent movement predominantly concerns to acceleration due to gravitational-kinetic energy transfer mechanisms it was investigated shear rates associated with runout acceleration, by evaluating this movement's acceleration time interval (refer to Figure 4.11Figure 4.11 C).

The methodology consists in analysing the runout acceleration interval ( $t_{0}-$ $t_{f}$ ), and then determining the function derivative (Eq. 2) of the runout velocity and slump displacement relationship, in the $v_{0}-v_{f}$ and $y_{0}-y_{f}$ intervals, respectively.

Typical results obtained from the slump tests are shown in Figure 4.12. Polynomial fitting was applied in the displacement experimental points, and then velocity and acceleration were obtained by function derivative.

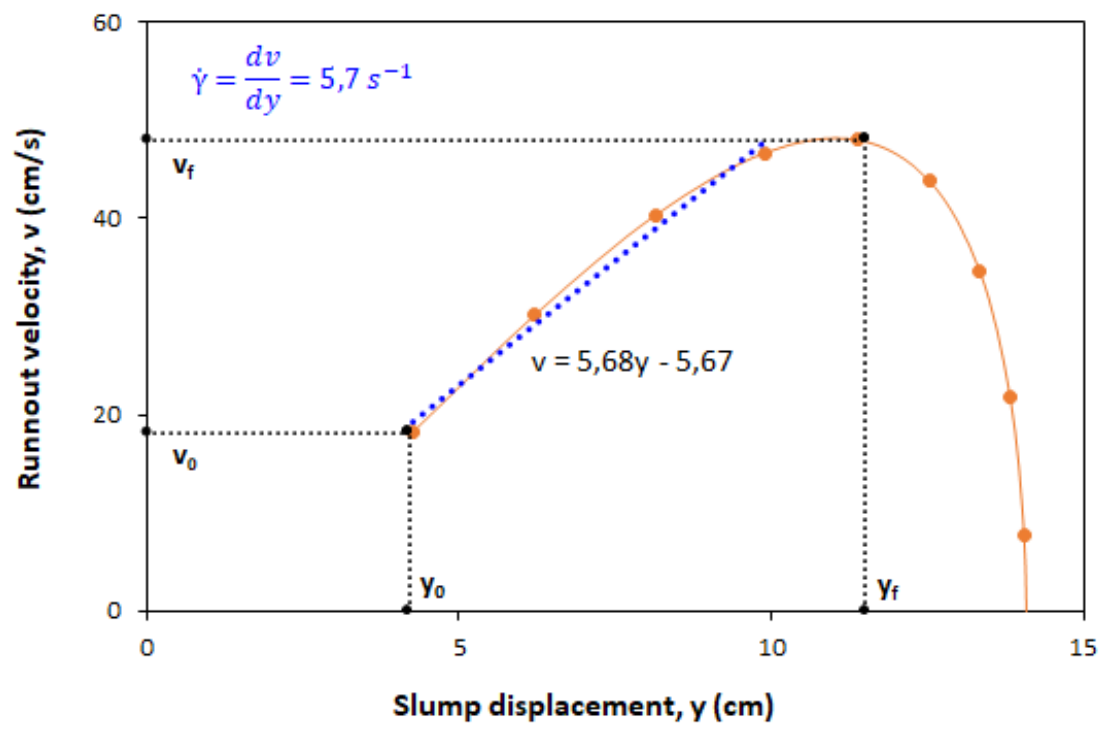

Figure 4.11 - Shear rate interpretation by graphical analysis of a typical velocitydisplacement curve. 

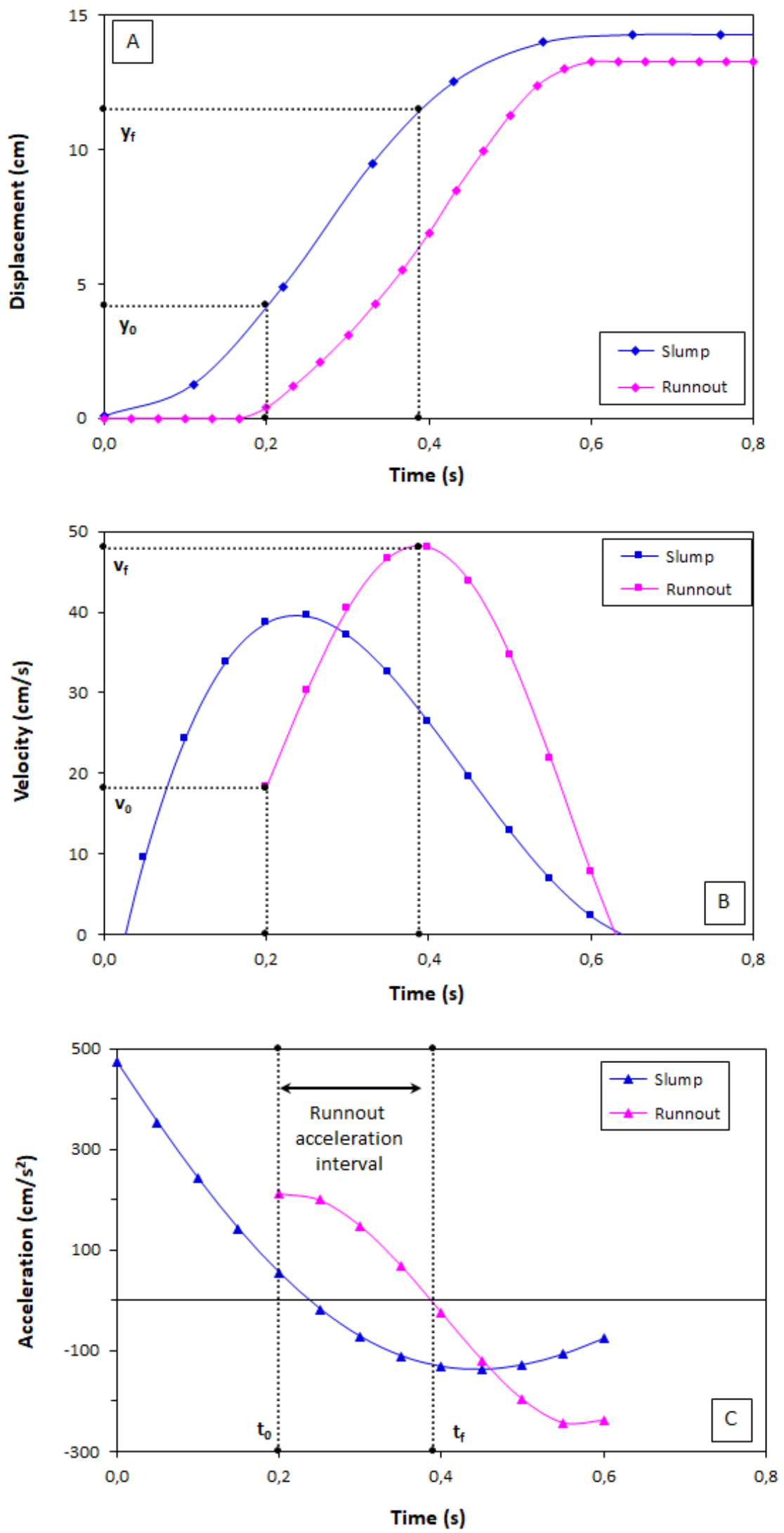

Figure 4.12 - Typical kinematical curves, for both runout and slump movements, obtained in the cylindrical slump test. (A) Displacement-time curves. (B) Velocity-time curves. (C) Acceleration-time curves. 


\subsection{5 \\ Experimental procedure}

Prior to testing, soil samples were oven dried at $60 \mathrm{o}$ C. This temperature was set to provide a speed up of clayey soils drying without mineralogical characteristics modification of the fine fraction of the soils. After grinding, the material passing through the ASTM sieve \#40 $(0,42 \mathrm{~mm})$ was collected. Approximately $3 \mathrm{~kg}$ of sieved material was necessary for each set of tests.

Then, the water contents at which the sub-samples would be tested was defined, and a calculation of the approximate mass of water to be added to each stage was taken. It is important to state that the range of testing moisture content, defined through preliminary slump tests, was taken within 1.3 and 2 times the liquidity limit of each material. The lower limit was set in order to guarantee that no air-filled voids would remain in the material inserted in the tubes. The higher limit was taken to minimize effects of sample segregation (particles sedimentation) and eventual fluid leakage at the base of the truncated cone before starting the tests.

The experimental routine applied to the tests is listed below:

1) Homogenize and moisten, for 10 minutes, the soil to the designed water content in a planetary mixer device (Figure 4.13);
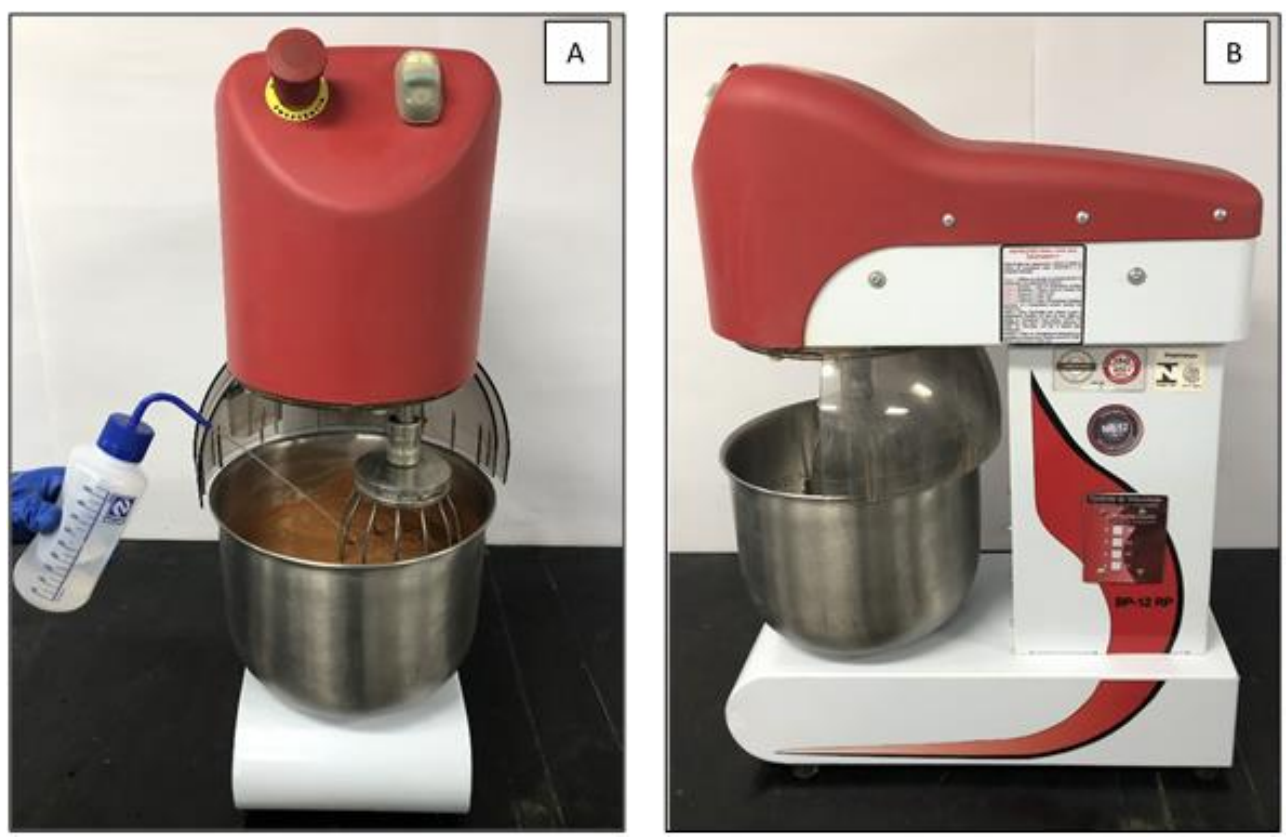

Figure 4.13 - Soil homogenization with the mixer. (A) Frontal view. (B) Lateral view. 
2) Collect a sub-sample for moisture verification;

3) Weigh the initial mass in a balance, fill the tube with the soil and weigh the remaining mass in the mixer. The mass variation in the mixer is the amount inserted in the tube, providing the total specific mass of the tested sample (Figure 4.14).
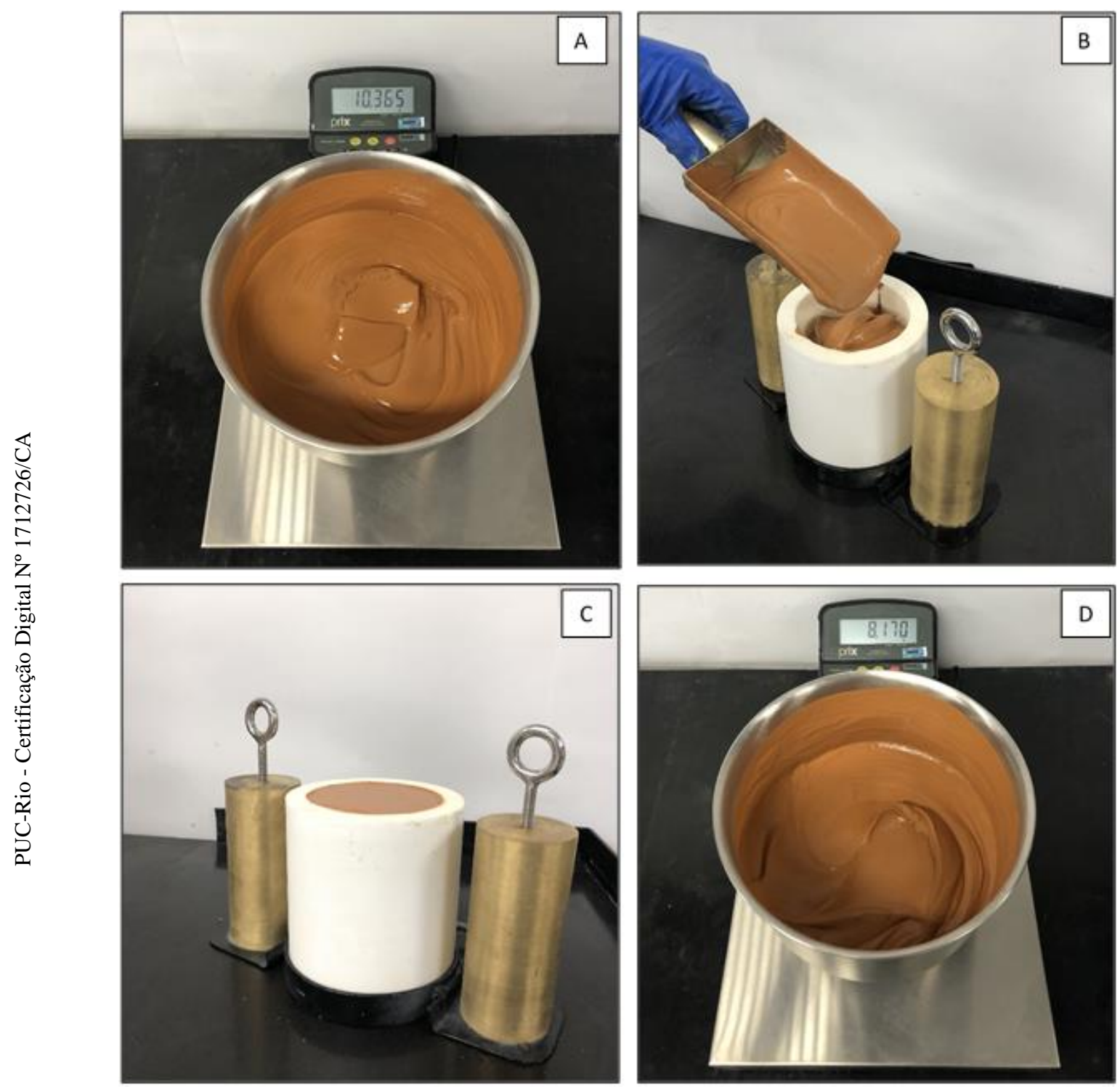

Figure 4.14 - Cylindrical tube filling with soil. (A) Soil mass in the mixer prior to filling the tube. (B and C) Tube filling. (D) Soil mass in the mixer after filling the tube.

4) Initialize the LVDT acquisition data system, turn off the room lights, turn of the LED lamp and initialize the camera recording;

5) Lift the tube by pulling an extra counter weight of $8 \mathrm{~kg}$; 
6) Turn on the lights, turn off the LED lamp and finalize the LVDT and camera systems;

Measure the water content, final diameter and final height (Figure 4.15).
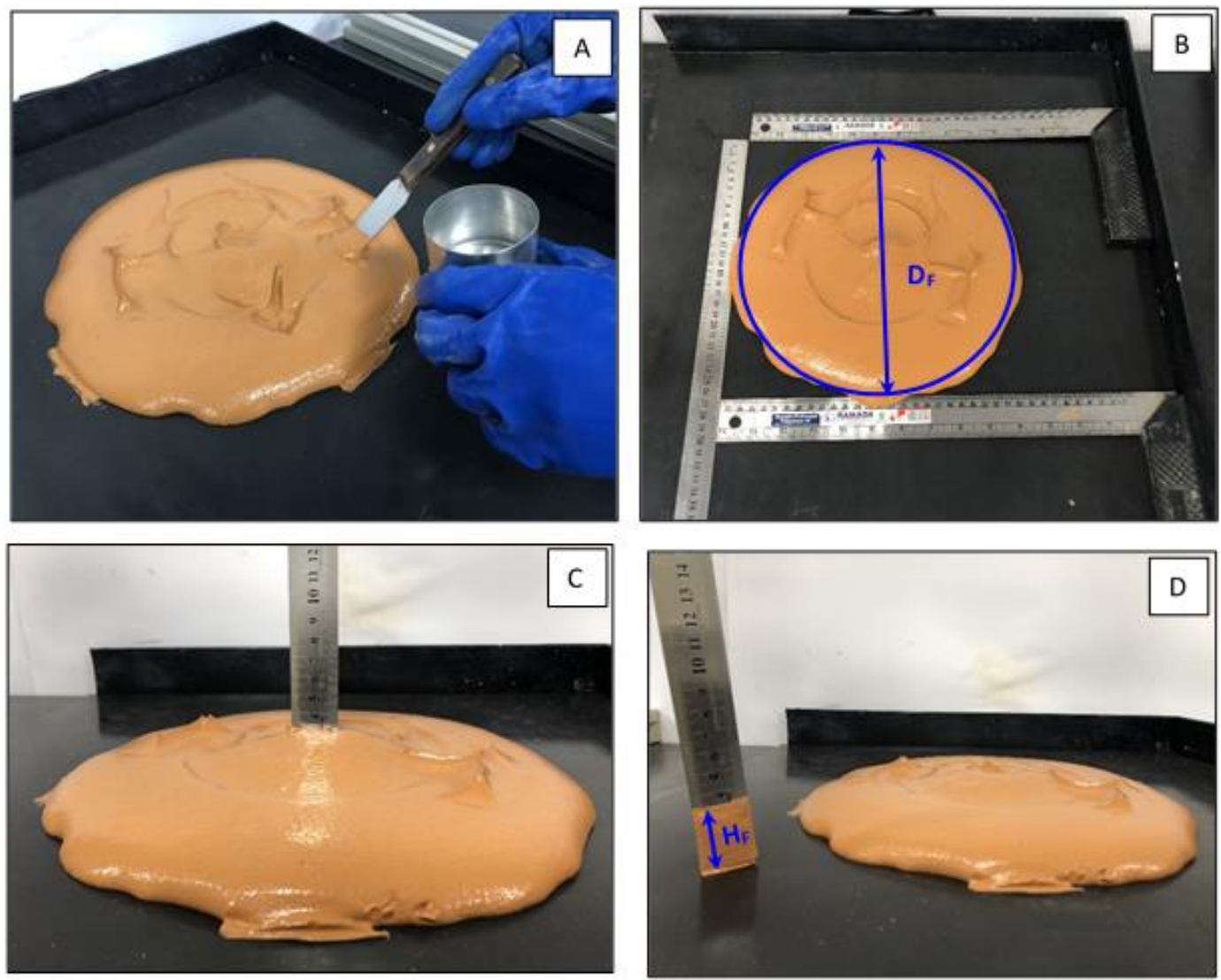

Figure 4.15 - procedures taken after the end of the test. (A) Sub-sample collecting for moisture verification. (B) Final diameter $\left(\mathrm{D}_{\mathrm{f}}\right)$ measuring. (C and D) Final height $\left(\mathrm{H}_{\mathrm{f}}\right)$ measuring.

It is relevant to comment that no significant moisture variation was observed, after homogenization, along the mixer's tub vertical axis. For that verification, samples were collected along three different heights: 4,8 and $12 \mathrm{~cm}$ from the bottom of the tub. The water content varied in a maximum difference of $1 \%$ between the three samples. Neither relevant variations related to water content prior and after testing were noticed.

Also relevant is the fact that the final diameters and heights, measured with a scaler (refer to Figure 4.15Figure 4.15), were compared to those obtained through displacement readings (LVDT and camera) and maximum $0.2 \mathrm{~cm}$ differences were observed. 


\section{2}

\section{Rheometer}

Flow tests were performed in a rotational rheometer Discovery. Figure 4.16 shows the device and its coupled software data acquisition system. The test provides relations among viscosity, shear stress and shear rate. Those curves comprise important aspects of fluids' rheological behaviour and so they are used not only to measure yield stress and viscosity, but also to provide better understating about flow mechanisms concerning soil-mass materials.

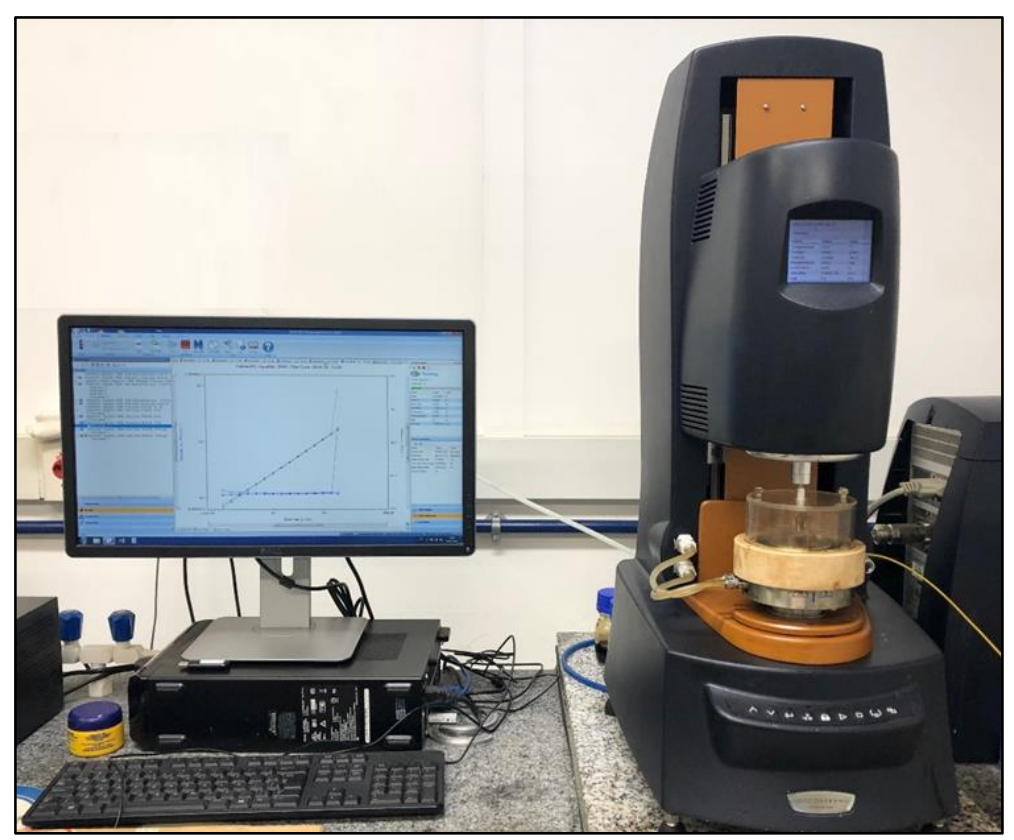

Figure 4.16 - Discovery rotational rheometer and its coupled computer for data acquisition.

\subsection{1 \\ Geometry}

The rheometer was equipped with a crosshatch plate-to-plate geometry (Figure 4.17). Such geometry was chosen as its grooves avoids material sliding during the test. Furthermore, it provides a simpler sample preparation for very viscous materials and soft solids. The device has a diameter of $49.96 \mathrm{~mm}$.

For the chosen geometry, the maximum gap between the parallel plates was of $4.0 \mathrm{~mm}$. O'Brien \& Julien (1988) suggest that such gap, h, should be ten times larger than the diameter of the largest soil particle, to avoid misleading testing interpretations. Barnes (2000) mentions that such ratio should be within 5 and 10 . 
Based on that, as mentioned earlier, all soils were passed through the sieve \#40 (0.42 mm opening) prior to testing.

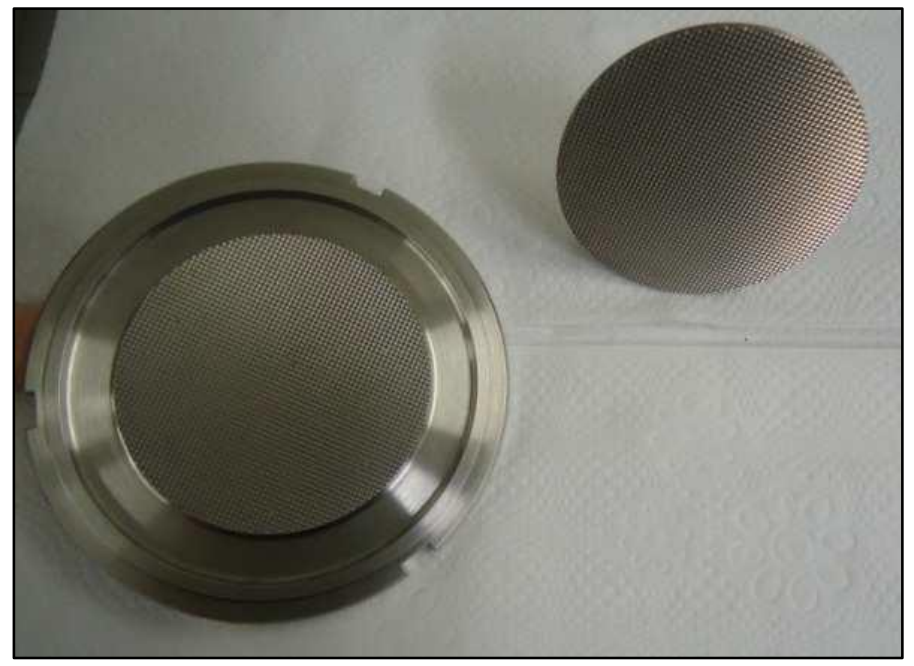

Figure 4.17 - Cross hatch plates used in the rheometer. Left: bottom plate. Right: upper plate (Galindo, 2013).

Extreme care was required to both minimize drying up of the small mass of soil used in the rheometer tests (variable within 15 and $20 \mathrm{~g}$ ) and to avoid soil segregation within the parallel disks. A maximum 5\% difference was observed between sub-samples collected prior and after the tests. Furthermore, it was observed that the more viscous soils (lower water content) were stressing too much the engine of the rheometer, and that the less viscous soils (higher water content) were spreading beyond the limits of the parallel disks. To minimize these, samples thickness was set to $2.0 \mathrm{~mm}$ as a standard to run all rheometer tests (Figure 4.18).

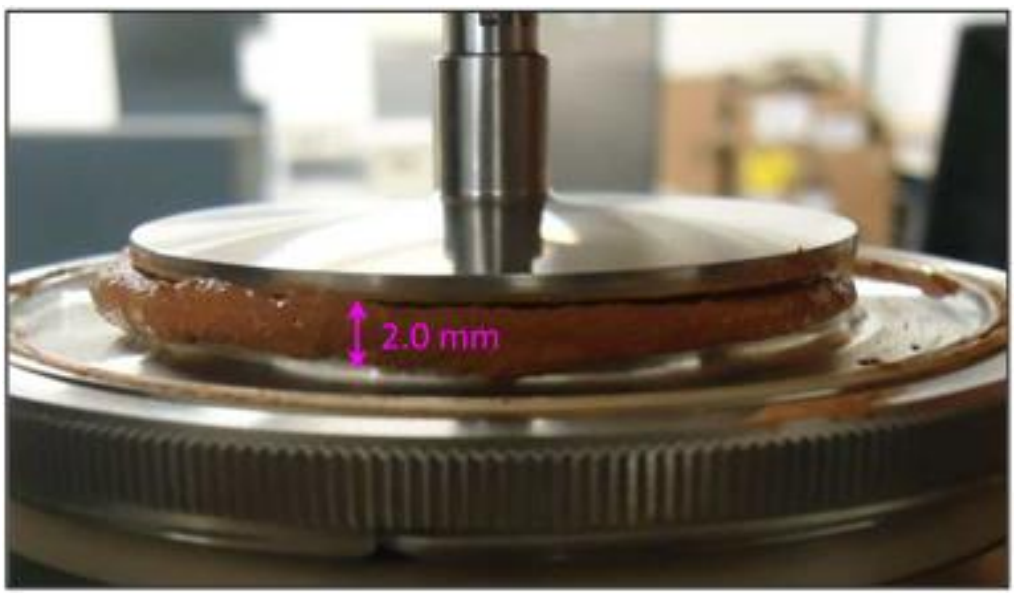

Figure 4.18 - Rheometer sample with a $2.0 \mathrm{~mm}$ gap (Galindo, 2013). 


\subsection{2}

\section{Flow tests}

Flow ramp tests (or sweep tests) are deformation-controlled type, where shear rates are incrementally increased/decreased, and the shear stress is determined with the devices' motor applied torque, according to Equation 23.

$$
\tau=\frac{2 M}{\pi R^{3}}
$$

Where $\tau$ is the shear stress, $\mathrm{M}$ is the measured torque and $\mathrm{R}$ is the plate radius. Viscosity is then calculated as the ratio $\tau / \gamma$. As it is suggested in O'Brien \& Julien (1988), tests were executed in a shear rate range commonly observed in debris flows materials ( 1 to $\left.100 \mathrm{~s}^{-1}\right)$.

To investigate the occurrence of hysteresis phenomena in the flow curves, sweep tests were realized, uninterruptedly, in acceleration (shear rate increasing) and deceleration ramps (shear rate decreasing). As it is suggested in di Santolo et al. (2012), to avoid material sedimentation and drying, tests had a total duration of 120s. In order to follow the same conditions as the slump tests, a controlled temperature of $22{ }^{\circ} \mathrm{C}$ was imposed to all the tests.

\subsection{3 \\ Interpretation methodology}

The main purpose of the rheometric tests execution is to determine the yield stress and the viscosity of the samples with same water content as those tested in the cylindrical slump tests. For this, relationships among shear stress, viscosity and shear rate are obtained in the sweep tests performed in the rheometer. Figures 4.19 and 4.20 show typical flow curves obtained within the rheometer.

As it is shown in Figure 4.19, yield stresses are obtained in the shear stress - shear rate curves, as the stress which denotes the beginning of the plastic-linear regime, for both acceleration and deceleration ramps. As it was said earlier, the viscosity - shear rate curve is used in the combined analysis involving slump tests' 
shear rates. The viscosity corresponding to the measured slump test shearing rate is obtained directly in the graph (Fig. 4.20).

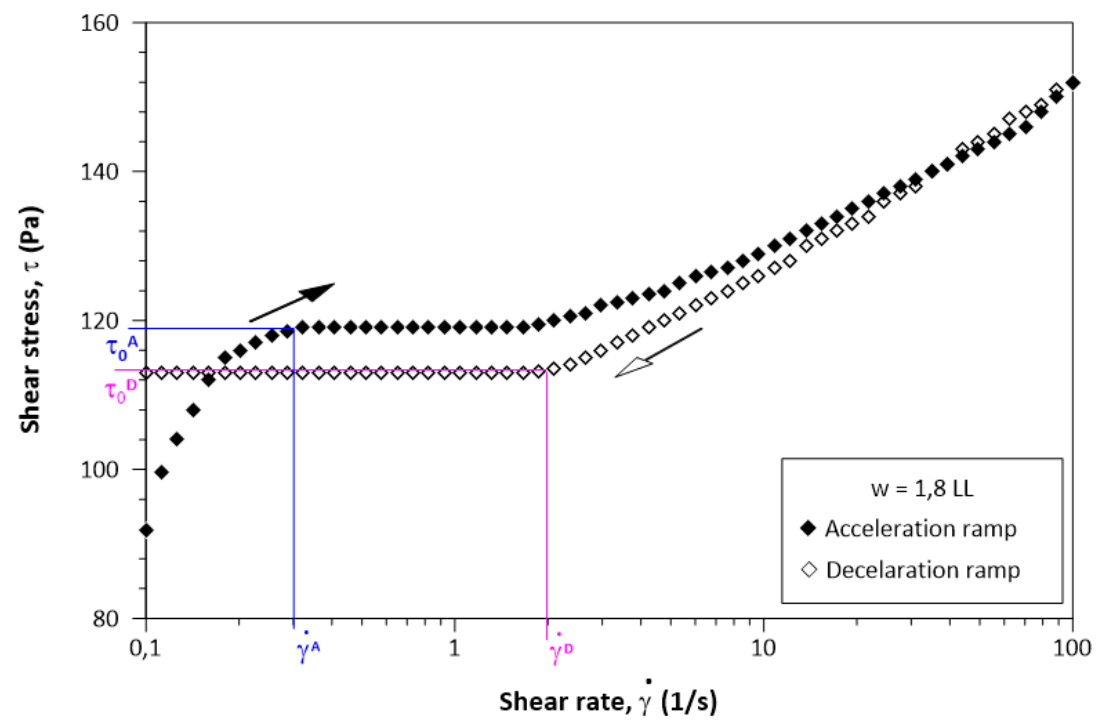

Figure 4.19 - Typical shear stress flow curve obtained in the sweep tests performed in the rheometer.

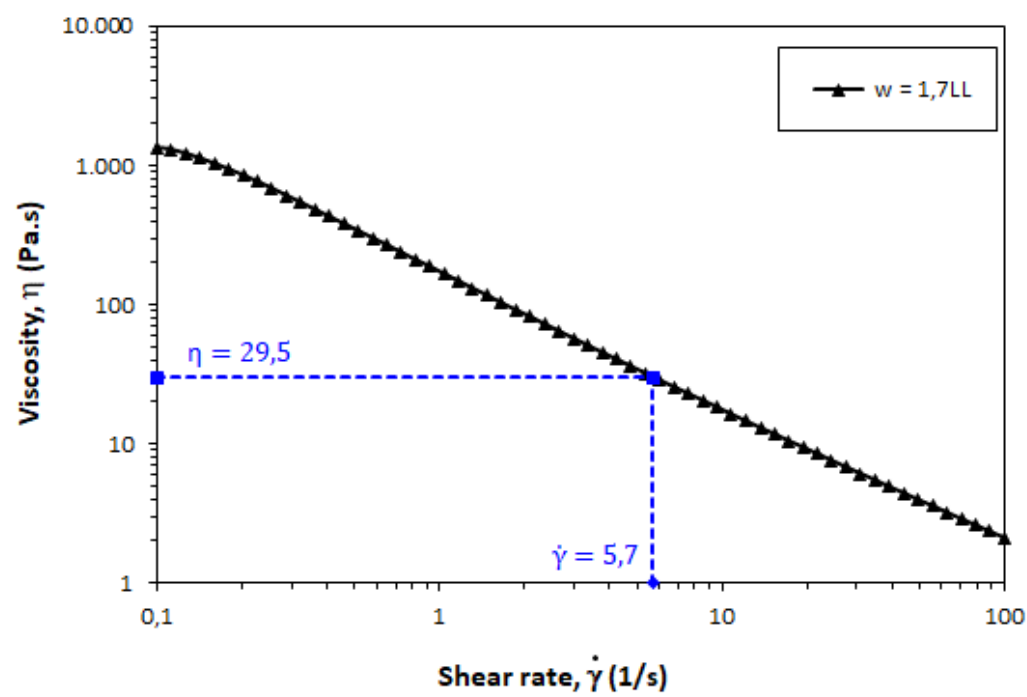

Figure 4.20 - Typical viscosity flow curve obtained in the sweep tests performed in the rheometer.

It is important to state that the viscosity flow curves were also obtained in acceleration and deceleration ramps. Though, as it will be seen in Item 5.2.2, the curves overlap each other, as the viscosity shows not to be affected by the hysteresis phenomena in the materials and tests evaluated in this work. 


\subsection{4 \\ Experimental procedure}

Sample preparation for the rheometer tests followed similar procedures employed for the slump tests. The above observations and preliminary tests defined the experimental procedure adopted:

1) Adjust the temperature $\left(22^{\circ} \mathrm{C}\right)$ and start the test programming, providing as input data: the gap $(2.0 \mathrm{~mm})$ and the shear rate range to be used in each ramp, as follows: 0.1 to $100.0 \mathrm{~s}^{-1}$ for the acceleration ramp, and 100.0 to $0.1 \mathrm{~s}^{-1}$ for the deceleration ramp (Fig. $4.21 \mathrm{~A}$ );

2) With the aid of a mixer, homogenize (approximately 10 minutes), $1 \mathrm{~kg}$ of dry soil (passing through sieve \# 40) with the amount of water calculated for the first test point (Fig. 4.21 B);

3) Collect a quantity of material to check its moisture;

4) Use a syringe to take the material to the rheometer (Fig. 4.21 C);

5) Decrease the size of the gap $(2.1 \mathrm{~mm})$ to promote the spreading of the material (Fig. 4.21Figure 4.21 D);

6) Remove the excess material, promoting the cleaning of the side of the geometry (Fig. 4.21 E);

7) Adjust the gap $(2.0 \mathrm{~mm})$, fit the protective cover of acrylic and start the test (Fig. 4.21 F);

8) Collect a new sub-sample for moisture verification;

9) Repeat the previous procedures (3 to 7) two more times to ensure repeatability of the assay;

10) For the analysis of a new moisture, it is necessary to replace the material in the mixer, to add the corresponding amount of water, to blend for 10 minutes and to repeat the previous steps.

It is important to state that a maximum 5\% water content difference was observed when comparing the sub-samples collected prior to and after the testing. 

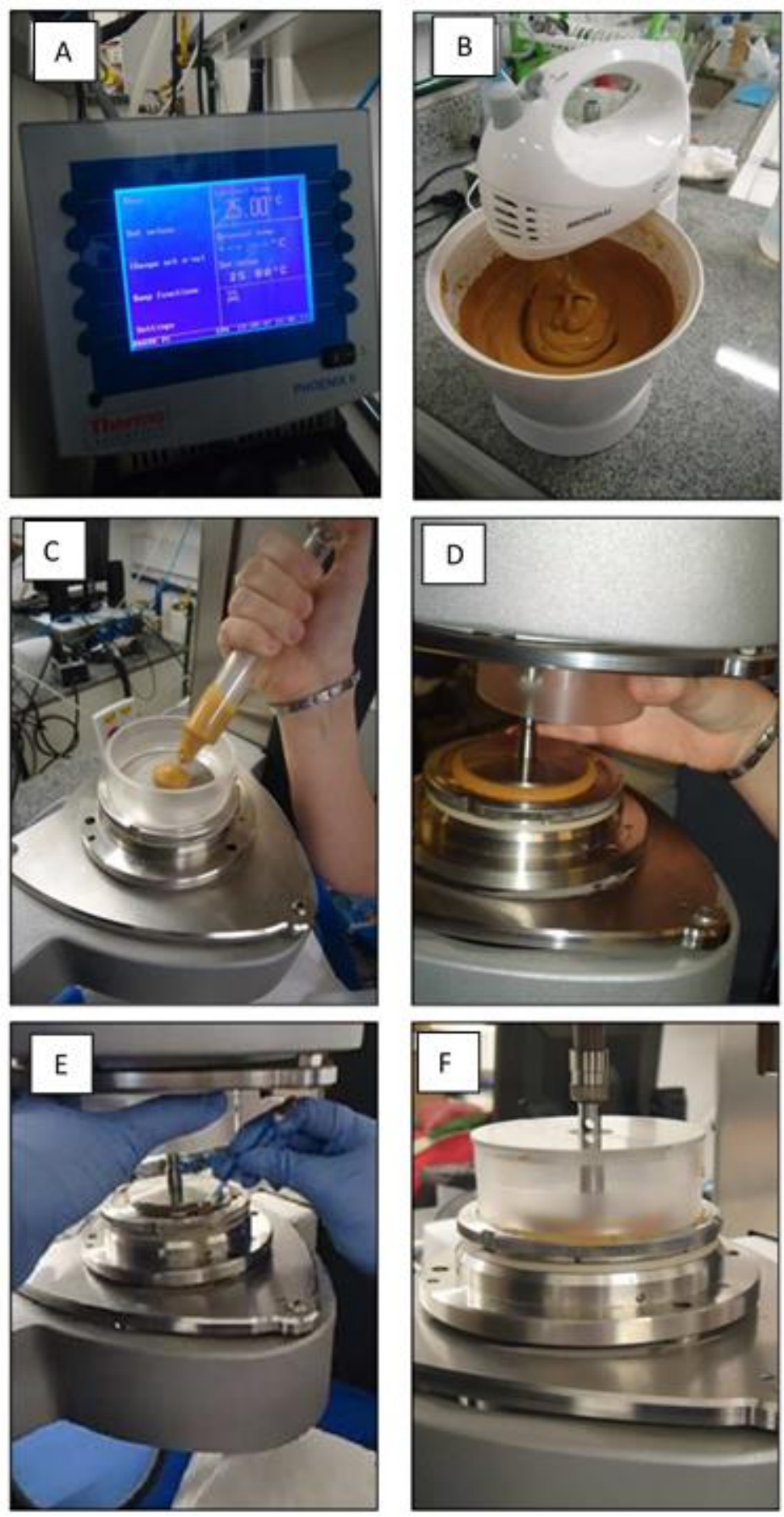

Figure 4.21 - Rheometric tests' experimental procedures (adapted from Galindo, 2013). (A) Temperature adjustment. (B) Soil homogenization in a mixer. (C) Material filling with a syringe. (D) Gap adjustment down to $2.0 \mathrm{~mm}$. (E) Excess of material removal. (F) Test execution. 


\section{5 \\ Results and discussions}

This chapter presents all results, as well as its analyses and discussions, related to both ACP and MCP soils, obtained through both cylindrical slump tests and rheometric tests. Slump test results concerns exclusively those obtained with the tube R4 (with initial height $H_{0}=20 \mathrm{~cm}$ ). Explanations are given about the criteria on choosing the best tube among the others. Results are shown on how plastic viscosity and yield stress were obtained by experimental tests and analytical solutions, through physical, geometrical, kinematical and rheological analyses.

\section{1 \\ Cylindrical tube slump test}

For the slump tests analyses, it is firstly presented an explanation about the choice of the best tube aspect ratio; then results concerning to tube R4 are shown, as follows: physical indexes, geometrical and kinematic analyses, shear rate interpretation, and the routines developed to calculate analytical results.

\subsection{1}

\section{Tubes analysis}

Table 5.1 presents the yield stresses obtained in the rheometer and through Baudez \& Coussot (1994) analytical solution for the cylindrical slump test. Such analytical approach was applied to the three types of tubes evaluated on this study. Tubes are named according to the aspect ratio $H_{0} / R_{0}$. In Figure 5.1 it is plotted comparisons between yield stress - water content relationships, obtained in the 4 approaches. Those graphs show that, for both soils, a significant discrepancy between the results related to the tubes $\mathrm{R} 2$ and $\mathrm{R} 3$, when comparing them to the tube $\mathrm{R} 4$ and the rheometer. 
Based on the hypothesis that the reference results are those obtained in rheometer tests, the tube $\mathrm{R} 4\left(H_{0}=20 \mathrm{~cm}\right)$ was the only one able to provide acceptable data. Hence, all results from now on will be related to this tube.
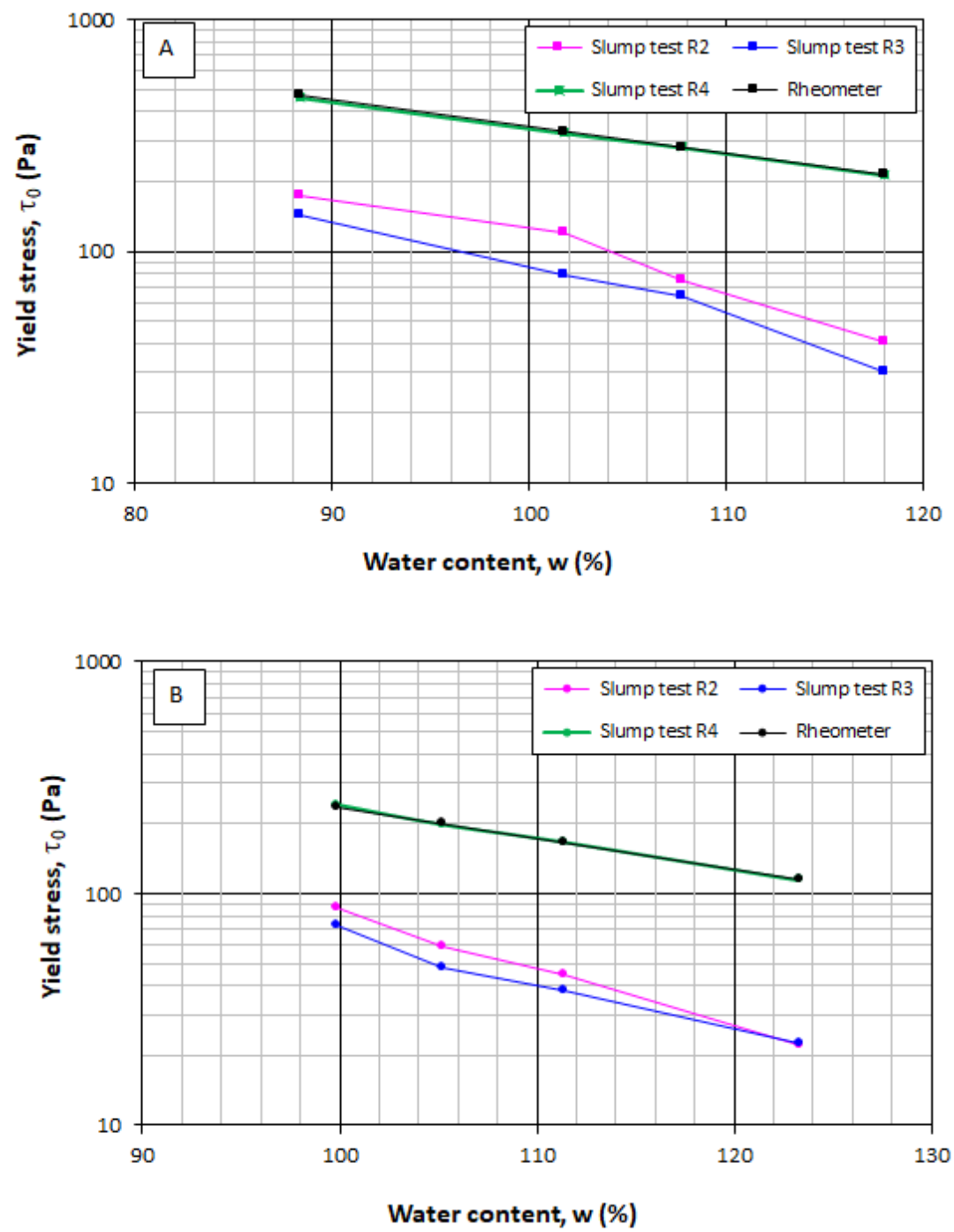

Figure 5.1 - Comparisons between yield stresses obtained in the rheometer and in the analytical solution for cylindrical slump test. The latter performed with tubes R2 $\left(\mathrm{H}_{0}=10 \mathrm{~cm}\right), \mathrm{R} 3\left(\mathrm{H}_{0}=15 \mathrm{~cm}\right)$ and $\mathrm{R} 4\left(\mathrm{H}_{0}=20 \mathrm{~cm}\right)$. (A) ACP samples' results. (B) MCP samples' results. 
Table 5.1 - Yield stresses obtained in the rheometer and in the analytical solution for the cylindrical slump test. The latter performed with tubes $\mathrm{R} 2\left(\mathrm{H}_{0}=10 \mathrm{~cm}\right), \mathrm{R} 3\left(\mathrm{H}_{0}=15 \mathrm{~cm}\right)$ and $\mathrm{R} 4\left(\mathrm{H}_{0}=20 \mathrm{~cm}\right)$. All the tubes have the same initial radius $\mathrm{R}_{0}=5 \mathrm{~cm}$.

\begin{tabular}{|c|c|c|c|c|c|c|}
\hline \multirow{4}{*}{ Material } & \multirow{2}{*}{\multicolumn{2}{|c|}{ Water content }} & \multicolumn{4}{|c|}{ Yield stress } \\
\hline & & & \multicolumn{4}{|c|}{$\tau_{0}(\mathrm{~Pa})$} \\
\hline & \multirow{2}{*}{$w / L L$} & \multirow{2}{*}{ w (\%) } & \multicolumn{3}{|c|}{ Slump test } & \multirow{2}{*}{ Rheometer } \\
\hline & & & Tube R2 & Tube R3 & Tube R4 & \\
\hline \multirow{4}{*}{$\mathrm{ACP}$} & 1,4 & 88,3 & 172,5 & 144,1 & 461,0 & 467,4 \\
\hline & 1,6 & 101,7 & 120,0 & 78,5 & 324,9 & 328,1 \\
\hline & 1,7 & 107,7 & 75,4 & 64,1 & 281,5 & 280,0 \\
\hline & 1,8 & 118,0 & 40,9 & 30,0 & 214,1 & 213,8 \\
\hline \multirow{4}{*}{$\mathrm{MCP}$} & 1,5 & 99,9 & 87,4 & 73,0 & 241,7 & 236,8 \\
\hline & 1,6 & 105,2 & 59,0 & 48,0 & 198,7 & 200,8 \\
\hline & 1,7 & 111,4 & 44,7 & 38,0 & 166,9 & 166,1 \\
\hline & 1,8 & 123,3 & 22,0 & 22,6 & 114,5 & 114,9 \\
\hline
\end{tabular}

\subsection{2}

\section{Physical indexes}

Physical indexes of the samples tested in the cylindrical slump tests are presented in Table 5.2. Water content $(w)$, total specific mass $(\rho)$ and specific gravity of the grains $\left(G_{s}\right)$ were determined in laboratory, (see items 2.2 and 3.1.4). All other indexes were calculated by standard indexes correlations. Computed saturation degrees $(S)$ were all circa of $100 \%$, validating the initial assumption that samples would be saturated.

Table 5.2 - ACP and MCP soils' physical indexes, obtained in the cylindrical slump test samples.

\begin{tabular}{c|c|c|c|c|c|c|c|c|}
\multirow{2}{*}{ Material } & \multicolumn{2}{|c|}{ Water content } & $\begin{array}{c}\text { Specific } \\
\text { mass }\end{array}$ & $\begin{array}{c}\text { Dry specific } \\
\text { mass }\end{array}$ & $\begin{array}{c}\text { Void } \\
\text { ratio }\end{array}$ & $\begin{array}{c}\text { Solid } \\
\text { concentration }\end{array}$ & Porosity & $\begin{array}{c}\text { Saturation } \\
\text { degree }\end{array}$ \\
\cline { 2 - 9 } & $\mathrm{w} / \mathrm{LL}$ & $\mathrm{w}(\%)$ & $\mathbf{\rho}\left(\mathrm{g} / \mathrm{cm}^{3}\right)$ & $\rho_{\mathrm{d}}\left(\mathrm{g} / \mathrm{cm}^{3}\right)$ & $\mathrm{e}$ & $\mathrm{Cv}(\%)$ & $\mathrm{n}(\%)$ & $\mathrm{S}(\%)$ \\
\hline \multirow{4}{*}{$\mathrm{ACP}$} & 1,4 & 88,3 & 1,49 & 0,79 & 2,36 & 29,7 & 70,3 & 99,5 \\
\cline { 2 - 9 } & 1,6 & 101,7 & 1,44 & 0,71 & 2,73 & 26,8 & 73,2 & 99,2 \\
\cline { 2 - 9 } & 1,7 & 107,7 & 1,42 & 0,68 & 2,89 & 25,7 & 74,3 & 99,1 \\
\cline { 2 - 9 } & 1,8 & 118,0 & 1,40 & 0,64 & 3,14 & 24,1 & 75,9 & 99,9 \\
\hline \multirow{4}{*}{$\mathrm{MCP}$} & 1,5 & 99,9 & 1,46 & 0,73 & 2,73 & 26,8 & 73,2 & 99,7 \\
\cline { 2 - 9 } & 1,6 & 105,2 & 1,44 & 0,70 & 2,88 & 25,8 & 74,2 & 99,5 \\
\cline { 2 - 9 } & 1,7 & 111,4 & 1,42 & 0,67 & 3,05 & 24,7 & 75,3 & 99,3 \\
\cline { 2 - 9 } & 1,8 & 123,3 & 1,39 & 0,62 & 3,38 & 22,9 & 77,1 & 99,5 \\
\hline
\end{tabular}


Solid concentration $\left(C_{v}\right)$ was calculated by Equation 1 . The first parcel is the index definition, is the ratio between solids volume $\left(V_{s}\right)$ and total volume of the sample $(V)$. The second parcel is obtained through correlation between indexes. It is interesting to note that solid concentration decreases as water content increases.

$$
C_{v}=\frac{V_{s}}{V}=\frac{1}{1+e}
$$

\subsection{3}

\section{Geometrical analyses}

Table 5.3 shows geometrical measurements taken manually with a scale (refer to Figure 4.15), before and after slump tests execution. Those measures provide not only input parameters for the analytical models herein applied, but also to verify whether displacements obtained by the LVDT and the camera would be equal to

Table 5.3 - ACP and MCP soils' geometrical parameters, related to both initial and final conditions of the cylindrical slump tests. All the tubes have the same initial height $\mathrm{H}_{0}=20 \mathrm{~cm}$, and the same initial radius $\mathrm{R}_{0}=5 \mathrm{~cm}$.

\begin{tabular}{|c|c|c|c|c|c|c|c|c|c|}
\hline \multirow{2}{*}{ Material } & \multicolumn{2}{|c|}{ Water content } & \multirow{2}{*}{$\begin{array}{c}\begin{array}{c}\text { Final } \\
\text { height }\end{array} \\
\mathrm{H}_{\mathrm{f}}(\mathrm{cm})\end{array}$} & \multirow{2}{*}{$\begin{array}{c}\begin{array}{c}\text { Final } \\
\text { diameter }\end{array} \\
D_{f}(\mathrm{~cm})\end{array}$} & \multirow{2}{*}{$\begin{array}{c}\begin{array}{c}\text { Heigh } \\
\text { variation }\end{array} \\
\Delta H(\mathrm{~cm})\end{array}$} & \multirow{2}{*}{$\begin{array}{c}\begin{array}{c}\text { Radius } \\
\text { variation }\end{array} \\
\Delta R(\mathrm{~cm})\end{array}$} & \multirow{2}{*}{$\begin{array}{c}\begin{array}{c}\text { Aspect } \\
\text { variation ratio }\end{array} \\
\Delta R / \Delta H\end{array}$} & \multirow{2}{*}{$\begin{array}{c}\begin{array}{c}\text { Height } \\
\text { variation ratio }\end{array} \\
\Delta \mathrm{H} / \mathrm{H}_{0}\end{array}$} & \multirow{2}{*}{$\begin{array}{c}\begin{array}{c}\text { Radius } \\
\text { variation ratio }\end{array} \\
\Delta \mathrm{R} / \mathrm{R}_{0}\end{array}$} \\
\hline & w/LL & $w(\%)$ & & & & & & & \\
\hline \multirow{4}{*}{ ACP } & 1,4 & 88,3 & 12,2 & 21,8 & 7,8 & 5,9 & 1,32 & 0,39 & 1,18 \\
\hline & 1,6 & 101,7 & 9,8 & 25,6 & 10,2 & 7,8 & 1,31 & 0,51 & 1,56 \\
\hline & 1,7 & 107,7 & 8,9 & 28,0 & 11,1 & 9,0 & 1,23 & 0,56 & 1,80 \\
\hline & 1,8 & 118,0 & 7,2 & 33,4 & 12,8 & 11,7 & 1,09 & 0,64 & 2,34 \\
\hline \multirow{4}{*}{ MCP } & 1,5 & 99,9 & 7,7 & 29,6 & 12,3 & 9,8 & 1,26 & 0,62 & 1,96 \\
\hline & 1,6 & 105,2 & 6,6 & 33,4 & 13,4 & 11,7 & 1,15 & 0,67 & 2,34 \\
\hline & 1,7 & 111,4 & 5,7 & 36,8 & 14,3 & 13,4 & 1,07 & 0,72 & 2,68 \\
\hline & 1,8 & 123,3 & 4,0 & 44,4 & 16,0 & 17,2 & 0,93 & 0,80 & 3,44 \\
\hline
\end{tabular}

As it would be expected, both variations of height and radius increase with samples' moisture. Analysing the height variation ratios $\left(\Delta H / H_{0}\right)$ it is observed a percentual difference ranging from 40 to $80 \%$ of the initial height, while radius ratios $\left(\Delta R / R_{0}\right)$ vary from nearly unity to circa of 4 times the initial radius. As it can be seen in Figure 5.2, although relative radius increasement is significantly larger 
than relative heights', when it comes to the aspect variation ratio $(\Delta R / \Delta H)$ a declining relationship occurs. This indicates that, when the water content is increased, height variations are more expressive than radius variations.

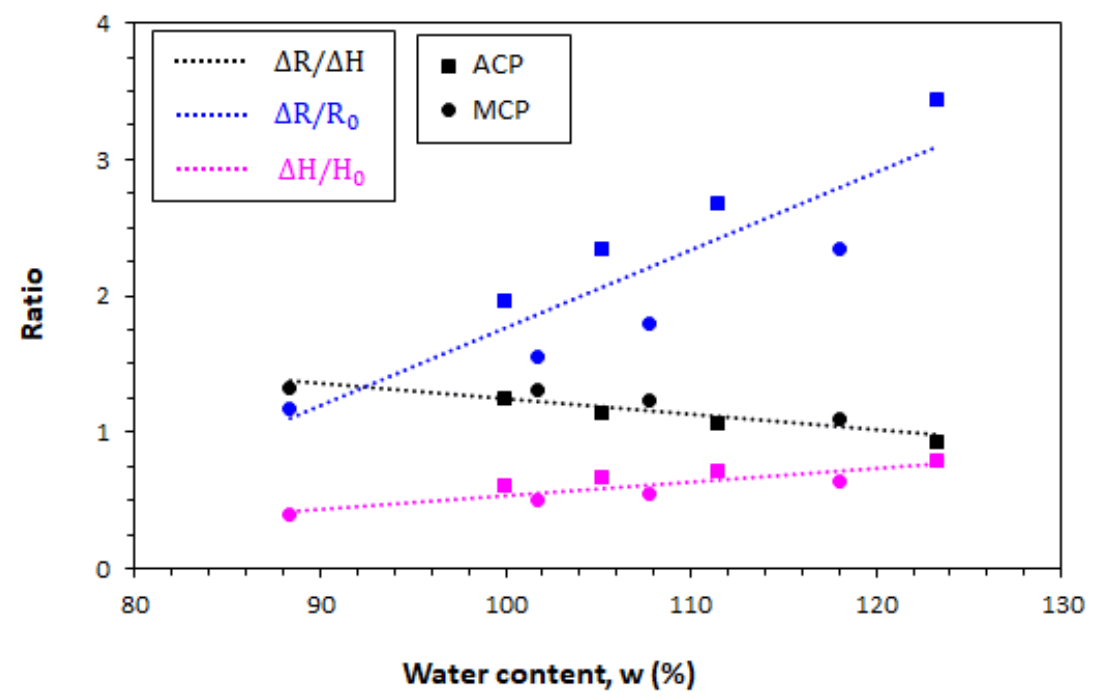

Figure 5.2 - Comparisons between geometrical ratios obtained in the cylindrical slump tests. Relationships concerning to aspect, height and radius variation ratios $\left(\Delta R / \Delta H, \Delta R / R_{0}\right.$ and $\Delta \mathrm{H} / \mathrm{H}_{0}$, respectively) and water content are drawn for both ACP (squares) and MCP (circles) samples.

\section{1 .4 \\ Kinematical analyses}

Kinematical results concerning to cylindrical slump tests are shown in Figures 5.3 to 5.6. Vertical and horizontal displacements were obtained, respectively, by LVDT and camera readings. Polynomial fitting was applied to the displacements' experimental points (Figures 5.3 to $5.6, \mathrm{~A}$ ). With that, velocity and acceleration curves were respectively obtained through first and second derivative of the displacement-time curve (Figures 5.3 to 5.6, B and C). The polynomials' equations are presented in Table 5.4. Slump and runout velocity and acceleration intervals' between 0.6 and $0.8 \mathrm{~s}$ are not plotted as the polynomial fitting isn't appropriate to this time interval (Figures 5.3 to 5.6, B and C, respectively). 
Table 5.4 - Polynomial fitting of the displacement-time curves, obtained with Excel trendline tool.

\begin{tabular}{|c|c|c|c|}
\hline \multirow[t]{2}{*}{ Material } & \multirow{2}{*}{$\begin{array}{c}\begin{array}{c}\text { Water } \\
\text { content }\end{array} \\
\mathrm{w} / \mathrm{LL} \\
\end{array}$} & \multicolumn{2}{|c|}{$\begin{array}{c}\text { Polynomial fitting } \\
y=a x^{6}+b x^{5}+c x^{4}+d x^{3}+e x^{2}+f x+g\end{array}$} \\
\hline & & Slump discplacements & Runout discplacements \\
\hline \multirow{4}{*}{$\mathrm{ACP}$} & 1,4 & $y=-107,0 x^{6}+152,9 x^{5}+199,9 x^{4}-460,0 x^{3}+240,8 x^{2}-12,5 x+0,1$ & $y=-411,8 x^{6}+1454,5 x^{5}-1841,8 x^{4}+959,5 x^{3}-156,2 x^{2}+7,8 x-0,1$ \\
\hline & 1,6 & $y=-86,9 x^{6}+112,1 x^{5}+200,1 x^{4}-414,9 x^{3}+213,0 x^{2}-11,2 x+0,1$ & $y=-772,1 x^{6}+2444,6 x^{5}-2832,8 x^{4}+1405,7 x^{3}-251,4 x^{2}+15,0 x-0,1$ \\
\hline & 1,7 & $y=40,3 x^{6}-256,5 x^{5}+583,3 x^{4}-592,8 x^{3}+254,8 x^{2}-18,9 x+0,1$ & $y=-786,7 x^{6}+2514,8 x^{5}-2963,7 x^{4}+1522,0 x^{3}-298,2 x^{2}+19,5 x-0,2$ \\
\hline & 1,8 & $y=18,9 x^{6}-132,1 x^{5}+322,0 x^{4}-342,7 x^{3}+148,2 x^{2}-6,6 x+0,03$ & $y=-475,4 x^{6}+1562,1 x^{5}-1889,6 x^{4}+993,3 x^{3}-197,9 x^{2}+13,4 x-0,1$ \\
\hline \multirow{4}{*}{ MCP } & 1,5 & $y=925,9 x^{6}-2990,2 x^{5}+3733,6 x^{4}-2204,0 x^{3}+557,0 x^{2}-5,5 x+0,0$ & $y=-849,6 x^{6}+2949,9 x^{5}-3737,1 x^{4}+2019,7 x^{3}-389,5 x^{2}+24,4 x-0,2$ \\
\hline & 1,6 & $y=-16,8 x^{6}-186,6 x^{5}+689,5 x^{4}-793,4 x^{3}+342,7 x^{2}-20,1 x+0,1$ & $y=-1141,0 x^{6}+3612,6 x^{5}-4186,2 x^{4}+2077,3 x^{3}-371,6 x^{2}+22,1 x-0,2$ \\
\hline & 1,7 & $y=59,9 x^{6}-356,1 x^{5}+777,9 x^{4}-772,1 x^{3}+327,4 x^{2}-23,6 x+0,1$ & $y=-1042,3 x^{6}+3388,6 x^{5}-4059,9 x^{4}+2117,4 x^{3}-419,7 x^{2}+27,8 x-0,3$ \\
\hline & 1,8 & $y=162,0 x^{6}-768,9 x^{5}+1401,9 x^{4}-1194,1 x^{3}+438,2 x^{2}-22,2 x+0,1$ & $y=-803,2 x^{6}+2639,4 x^{5}-3192,8 x^{4}+1678,3 x^{3}-334,3 x^{2}+22,7 x-0,2$ \\
\hline
\end{tabular}

As expected, the curves show that the higher the samples' moisture, the higher are the maximum displacements and velocities developed by the soil flow in the cylindrical slump test (Figures 5.3 to 5.6, A and B, respectively). Note that, however, maximum accelerations don't present the same increasing tendency with water content. This finding was taken as irrelevant to the analyses as accelerationtime curves (Figures 5.3 to 5.6, C) serve mainly to illustrate the intervals at which movements are accelerating or decelerating (positive and negative values, respectively).

The S-shaped displacement-time curves (Figures 5.3 to 5.6, A) indicate that the soils' fall and spread velocities varies strongly during the test. Looking at the vertical velocities (Figures 5.3 and 5.5, B) it is seen that as the test begins, the falling soil's speed increases rapidly up to reaching a peak at circa of $0.2 \mathrm{~s}$, which is followed by a smoother decline down to $0 \mathrm{~cm} / \mathrm{s}$. This can be else seen in slump acceleration-time curves (Figures 5.3 and 5.5, C), as acceleration curves sharply decrease until becoming negative at $0.2 \mathrm{~s}$, and then showing a smooth tendency towards $0 \mathrm{~cm} / \mathrm{s}^{2}$.

Similar behavior is observed when looking at the horizontal velocities (Figures 5.4 and 5.6, B). However, the velocity-time curves show to be more symmetrical considering the vertical line at $0.4 \mathrm{~s}$, which denotes the transition from acceleration to deceleration stages. As a consequence, the respective acceleration curves (Figures 5.4 and 5.6, C) are less pronounced, showing an almost linear relationship during runout motion. 
When looking at all the results of the two soils, it is remarkable a $0.2 \mathrm{~s}$ time delay between the horizontal and the vertical movements, the latter beginning first. In DIP analysis it was observed no horizontal displacements on the first five frames (refer to Item 3.1.2). As it was said earlier, the time interval between frames is around $0.033 \mathrm{~s}(1 / 30)$. Hence, it was possible to detect such delay of $5 * 0.033 \approx$ $0.17 \mathrm{~s}$.

Moreover, it was noticed in DIP analysis that in all tests, runout and slump displacements cease at nearly the same frame, i.e., practically simultaneously at 0.6 $\mathrm{s}$ after the begging of the test (see Item 3.1.2). Looking at Figure 5.3 to Figure 5.6 $\mathrm{B}$, it is seen that both vertical and horizontal velocities go to $0 \mathrm{~cm} / \mathrm{s}$ at circa of 0.6 $\mathrm{s}$, ratifying that both motions cease almost simultaneously (this can be better viewed in Figure $4.12 \mathrm{~B}$, page 70). This finding agrees with the $0.2 \mathrm{~s}$ delay explained in the last paragraph.

Looking at the runout velocities (Figures 5.4 and 5.6, B), a declining stage is observed as a peak at $0.4 \mathrm{~s}$ is passed. This can be better viewed in the accelerationtime curves (Figures 5.4 and 5.6 C), as the lines' trend become negative around 0.4 s. Such deceleration suggests that friction effects, between the soils and the silicone mat, affect the flow more significantly at $0.4 \mathrm{~s}$ after the begging of the test, resulting in a deceleration which finally results in the ceasing of the flow.

Finally, it is interesting to note that vertical movements begin to decelerate (acceleration-time curves become negatives, Figures 5.3 and $5.5 \mathrm{C}$ ) at nearly the same instant as the horizontal movements start to develop (around the time of $0.2 \mathrm{~s}$, Figures 5.4 and 5.6 A). So, it appears that in the cylindrical slump test, the soils' runout is triggered by and keeps related to a slump slowdown mechanism, until the flow ceases. 

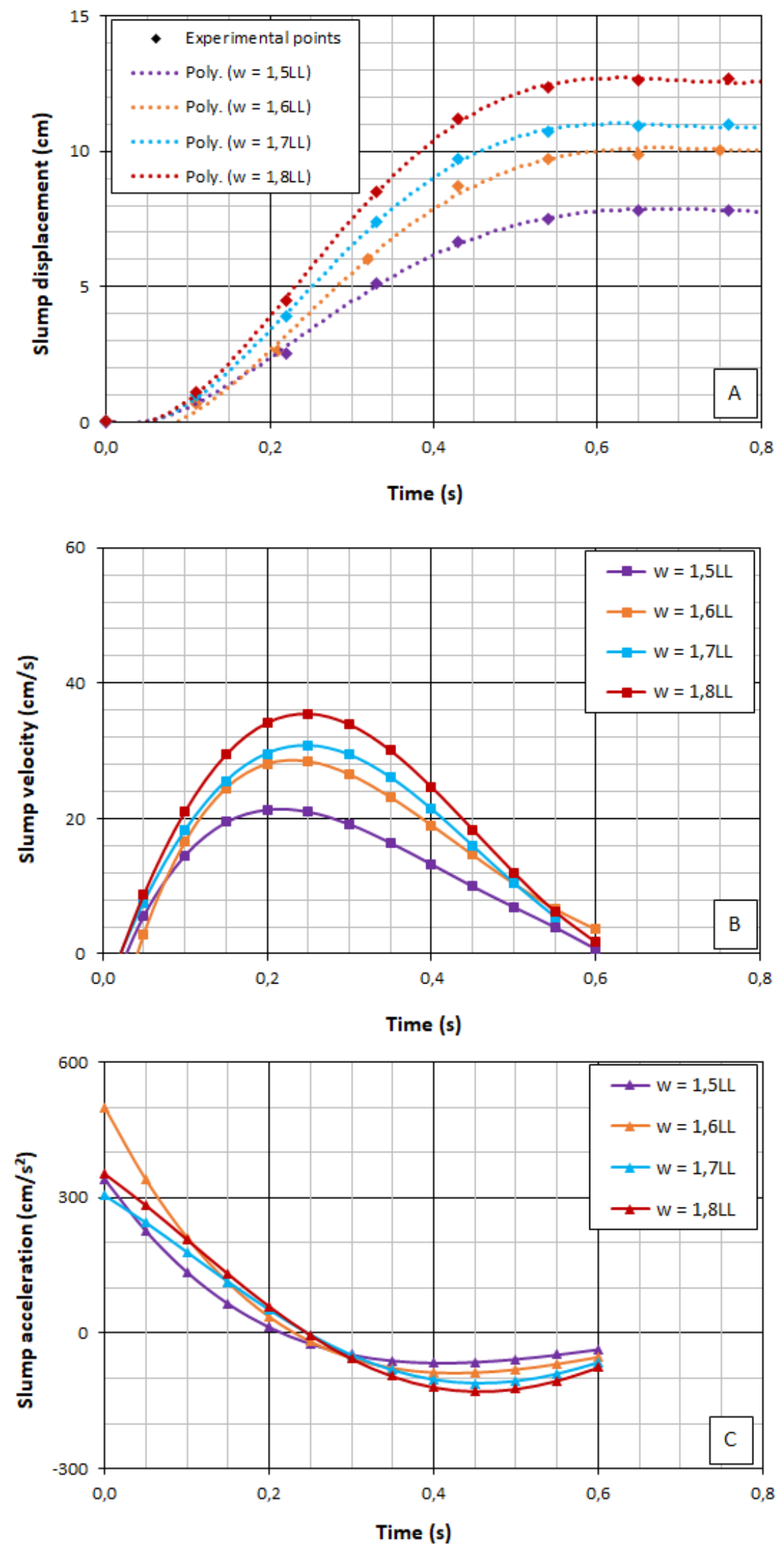

Figure 5.3 - ACP's samples kinematics curves of the slump (vertical) movement, obtained in the cylindrical slump test. (A) Displacement-time curves. (B) Velocity-time curves. (C) Acceleration-time curves. 

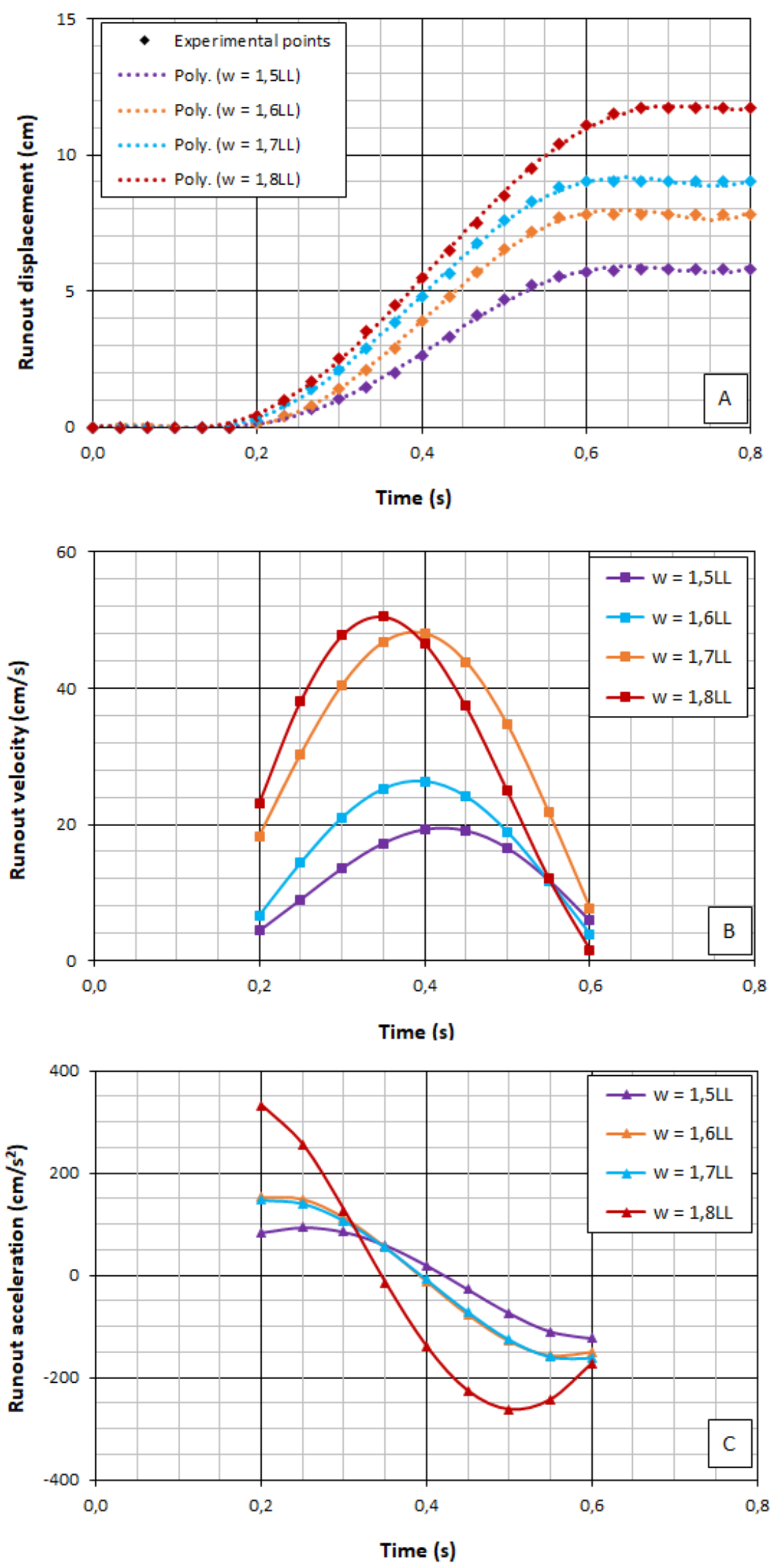

Figure 5.4 - ACP's samples kinematics curves of the runout (horizontal) movement, obtained in the cylindrical slump test. (A) Displacement-time curves. (B) Velocity-time curves. (C) Acceleration-time curves. 

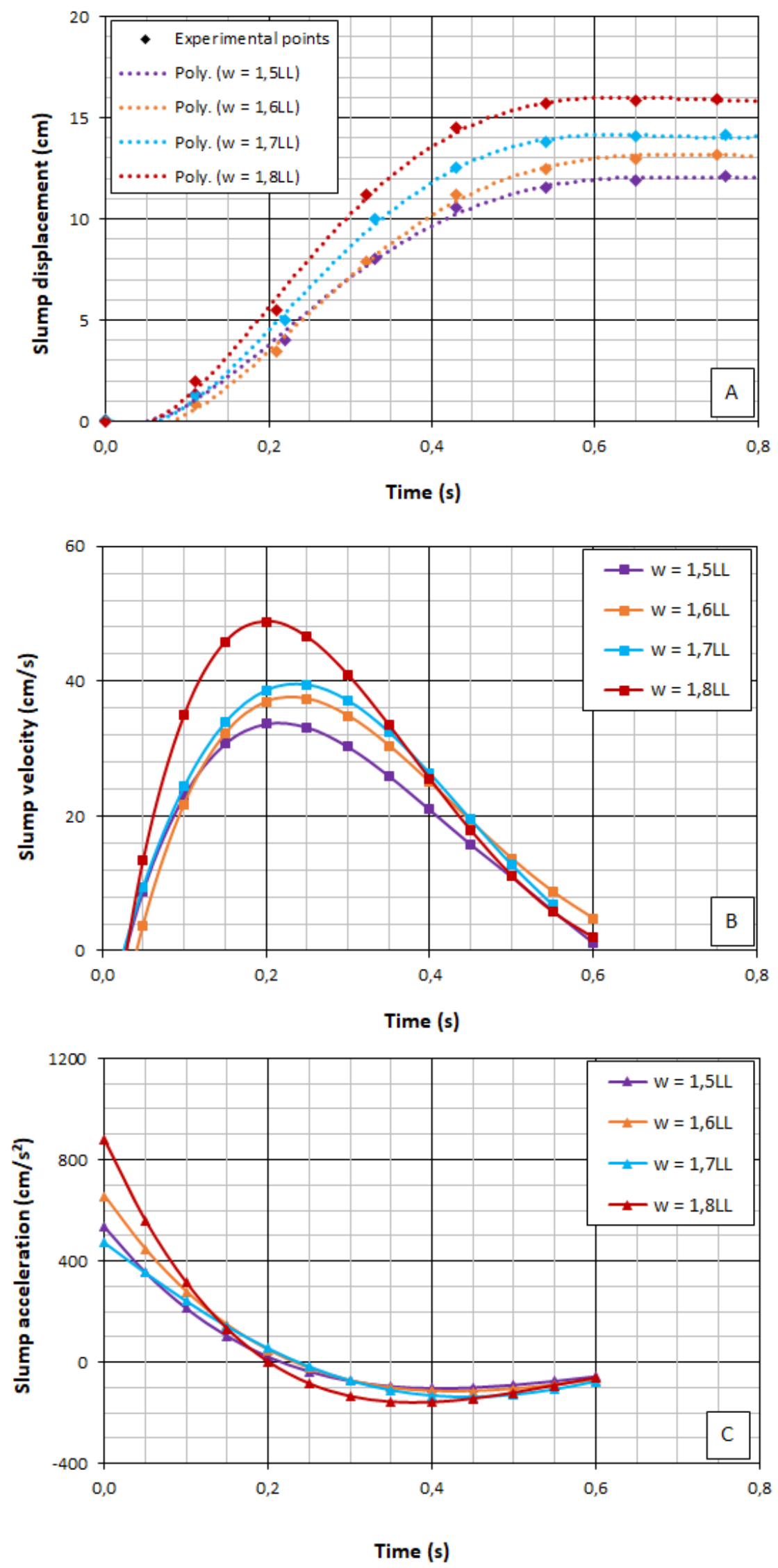

Figure 5.5 - MCP's samples kinematics curves of the slump (vertical) movement, obtained in the cylindrical slump test. (A) Displacement-time curves. (B) Velocity-time curves. (C) Acceleration-time curves. 

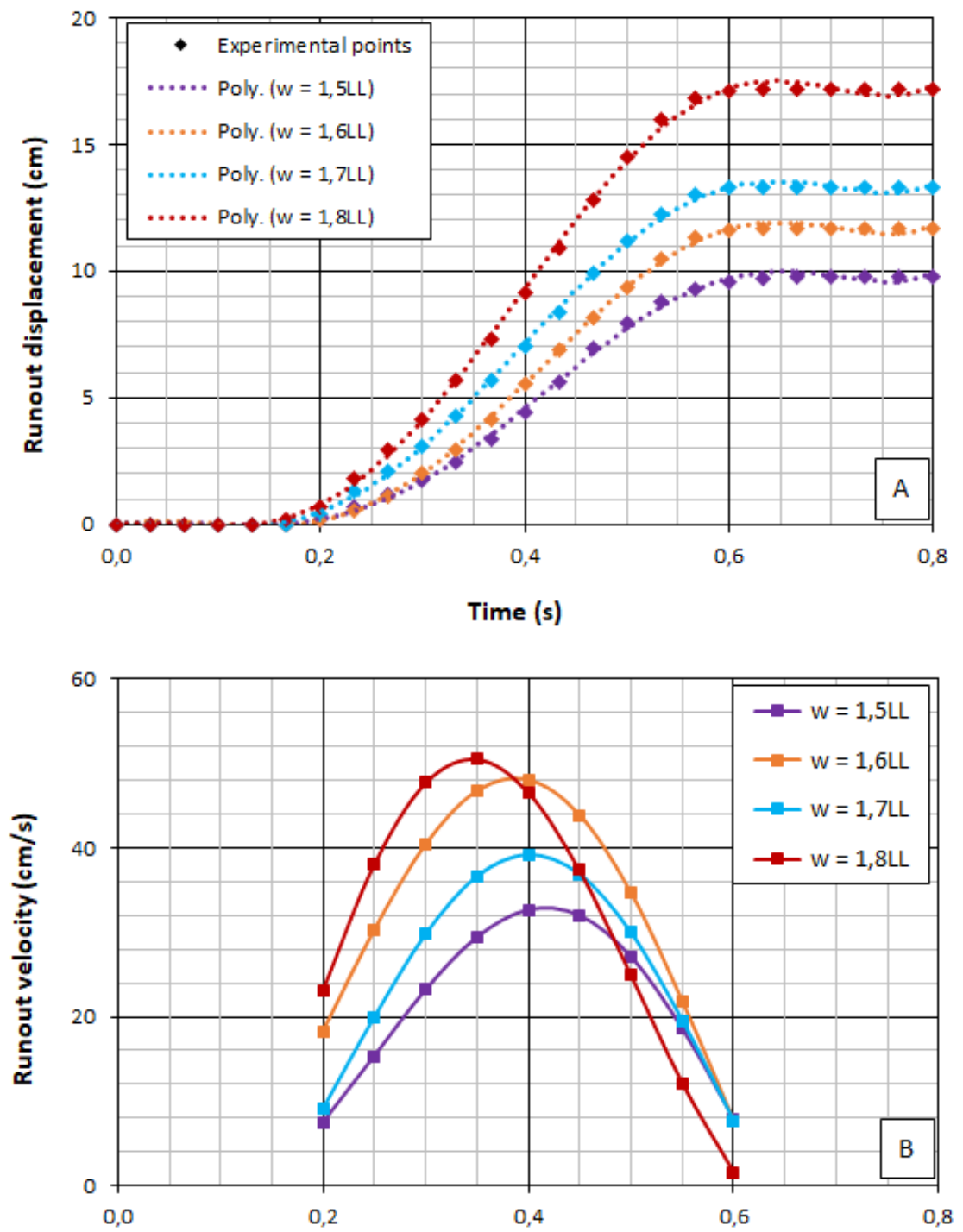

Time (s)

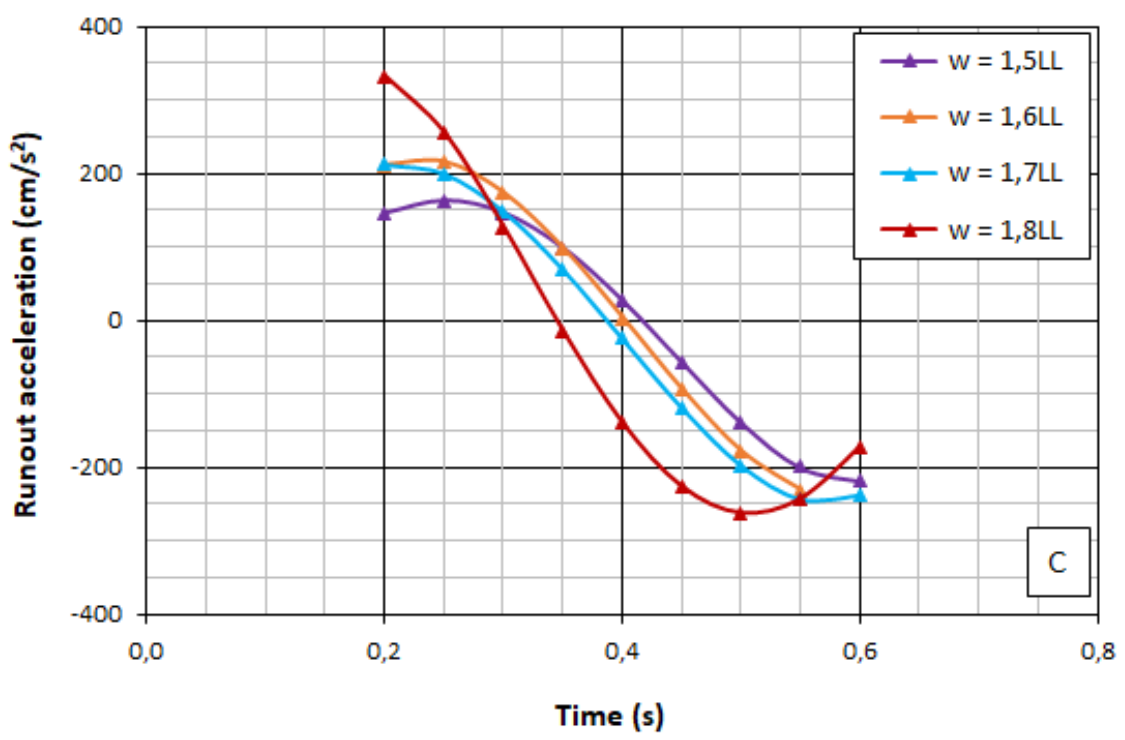

Figure 5.6 - MCP's samples kinematics curves of the runout (horizontal) movement, obtained in the cylindrical slump test. (A) Displacement-time curves. (B) Velocity-time curves. (C) Acceleration-time curves. 


\section{1 .5 \\ Shear rates determination}

Table 5.5 followed by Figures 5.7 to 5.9 show the shear rates found for the two soils. The involved methodology for shear rates interpretation is explained in Item 3.1.3. The technique consists in analyzing the runout acceleration leg (Figures 5.4 and 5.6, C), plotting the horizontal velocities against vertical displacements and, finally, verification of the derivative of this relationship (Figures 5.7 and 5.8).

As it was explained in the same item, some initial and final data (time, slump displacement and runout velocity) were defined for the shear rate evaluation. These values are presented in Table 5.5.

Table 5.5 - Parameters related to the adopted methodology for graphical interpretation of the shear rates, for both ACP and MCP samples used in the cylindrical slump tests.

\begin{tabular}{|c|c|c|c|c|c|c|c|c|}
\hline \multirow{2}{*}{ Material } & $\begin{array}{l}\text { Water } \\
\text { content }\end{array}$ & $\begin{array}{c}\text { Initial } \\
\text { time }\end{array}$ & $\begin{array}{l}\text { Final } \\
\text { time }\end{array}$ & $\begin{array}{c}\text { Initial } \\
\text { displacement }\end{array}$ & $\begin{array}{c}\text { Final } \\
\text { displacement }\end{array}$ & $\begin{array}{l}\text { Initial } \\
\text { velocity }\end{array}$ & $\begin{array}{c}\text { Final } \\
\text { velocity }\end{array}$ & $\begin{array}{l}\text { Shear } \\
\text { rate }\end{array}$ \\
\hline & $w / L L$ & $t_{0}(s)$ & $t_{f}(s)$ & $y_{0}(\mathrm{~cm})$ & $y_{f}(s)$ & $v_{0}(\mathrm{~cm} / \mathrm{s})$ & $v_{f}(\mathrm{~cm} / \mathrm{s})$ & $\dot{\gamma}(1 / s)$ \\
\hline \multirow{4}{*}{ ACP } & 1,4 & 0,20 & 0,42 & 2,4 & 6,4 & 4,5 & 19,4 & 4,1 \\
\hline & 1,6 & 0,20 & 0,42 & 2,6 & 8,1 & 6,6 & 25,8 & 4,6 \\
\hline & 1,7 & 0,20 & 0,38 & 3,3 & 10,2 & 10,3 & 48,0 & 5,2 \\
\hline & 1,8 & 0,20 & 0,34 & 3,8 & 8,6 & 23,2 & 50,6 & 7,1 \\
\hline \multirow{4}{*}{ MCP } & 1,5 & 0,20 & 0,35 & 3,8 & 8,5 & 7,5 & 29,4 & 4,4 \\
\hline & 1,6 & 0,20 & 0,35 & 3,5 & 8,8 & 9,1 & 36,7 & 5,2 \\
\hline & 1,7 & 0,20 & 0,35 & 4,2 & 10,2 & 15,9 & 48,0 & 5,7 \\
\hline & 1,8 & 0,20 & 0,30 & 8,6 & 12,6 & 23,2 & 47,8 & 6,2 \\
\hline
\end{tabular}

Analyzing the horizontal velocity - vertical displacement curves (Figures 5.7 and 5.8), it is interesting to note that different tendencies occur along the test. The runout acceleration and deceleration stages are well noted as they are marked by a peak which characterizes the transition between velocity increasing and decreasing. As shear rates are defined as a relation among velocity and position, this behaviour indicates that shearing rates vary in the cylindrical slump test. By this, it is concluded that viscosity should also vary along the flow.

As explained in Item 3.1.3, this study aims to evaluate the rheological behavior concerning to acceleration aspects. Hence, shear rates were defined as the derivative of the function which fits the $v=v(y)$ function, on the most accentuated sub-leg of the acceleration interval (Figures 5.7 and 5.8). 
Figure 5.7 shows the shear rate - water content relationship for the two soils. It is observed a unique increasing tendency between shear rates and moisture. This behaviour was expected as by handling the materials, it could be observed that the higher the water content, the higher the material's liquidity, and so the higher should be the rheological speed of the soils.

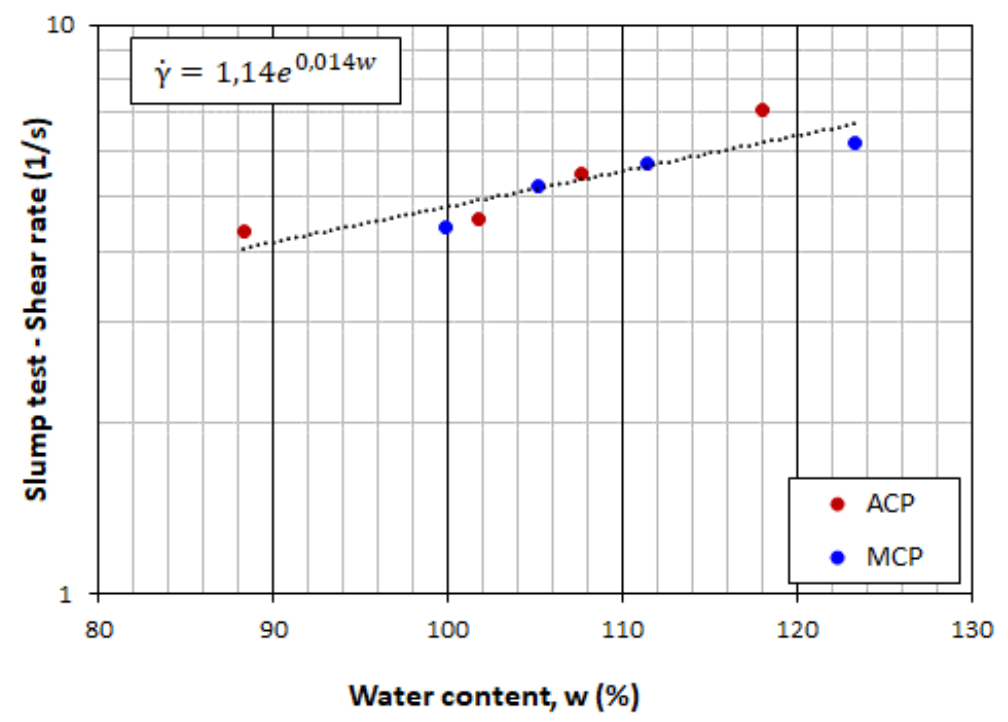

Figure 5.7 - Shear rates variation with water content, obtained in the cylindrical slump tests performed with both ACP and MCP samples. 

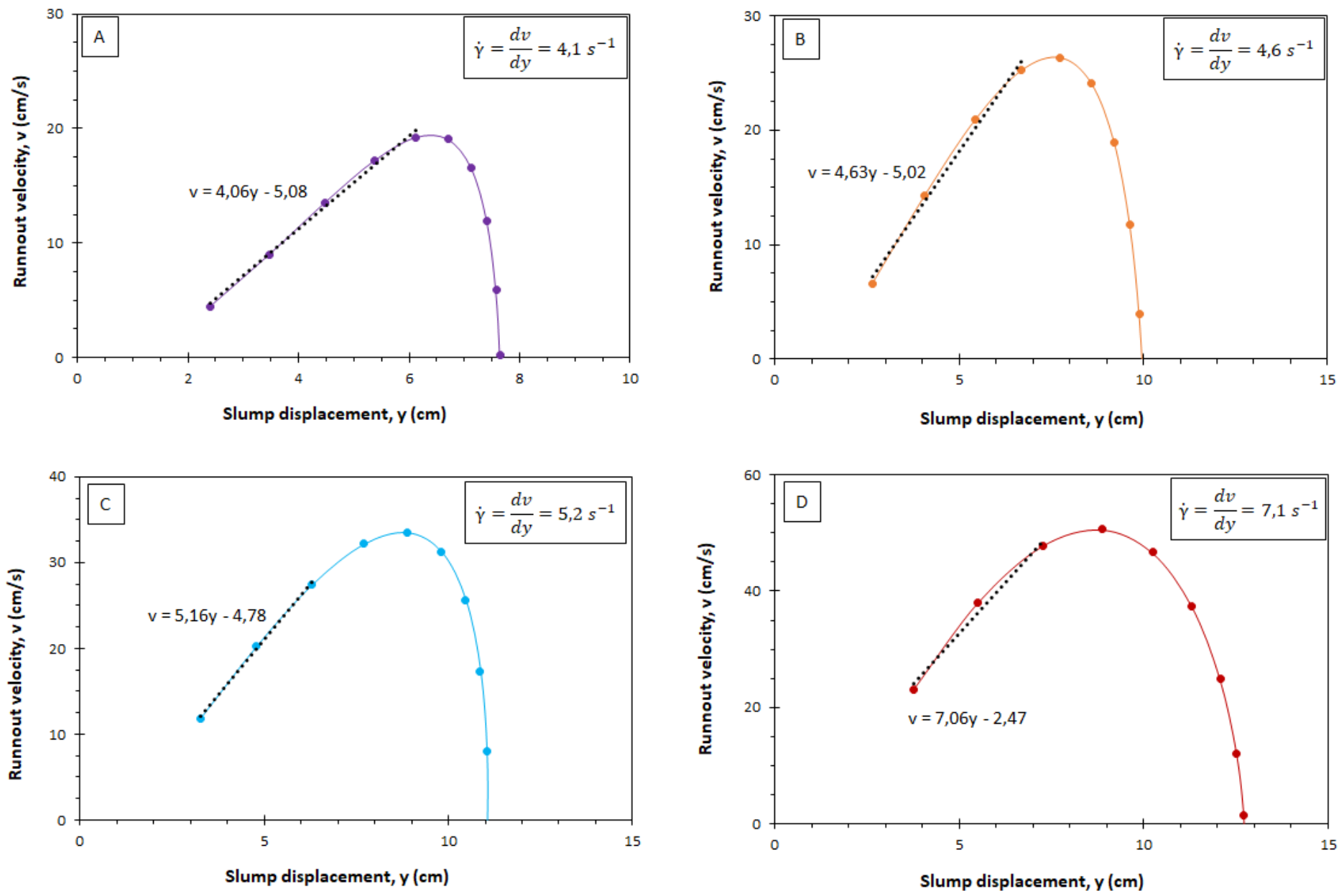

Figure 5.8 - Shear rate interpretation of the ACP samples tested in the cylindrical slump tests. (A) $\mathrm{w}=1,4 \mathrm{LL}$. (B) $\mathrm{w}=1,6 \mathrm{LL}$. (C) $\mathrm{w}=1,7 \mathrm{LL}$. (D) $\mathrm{w}=1,8 \mathrm{LL}$. 

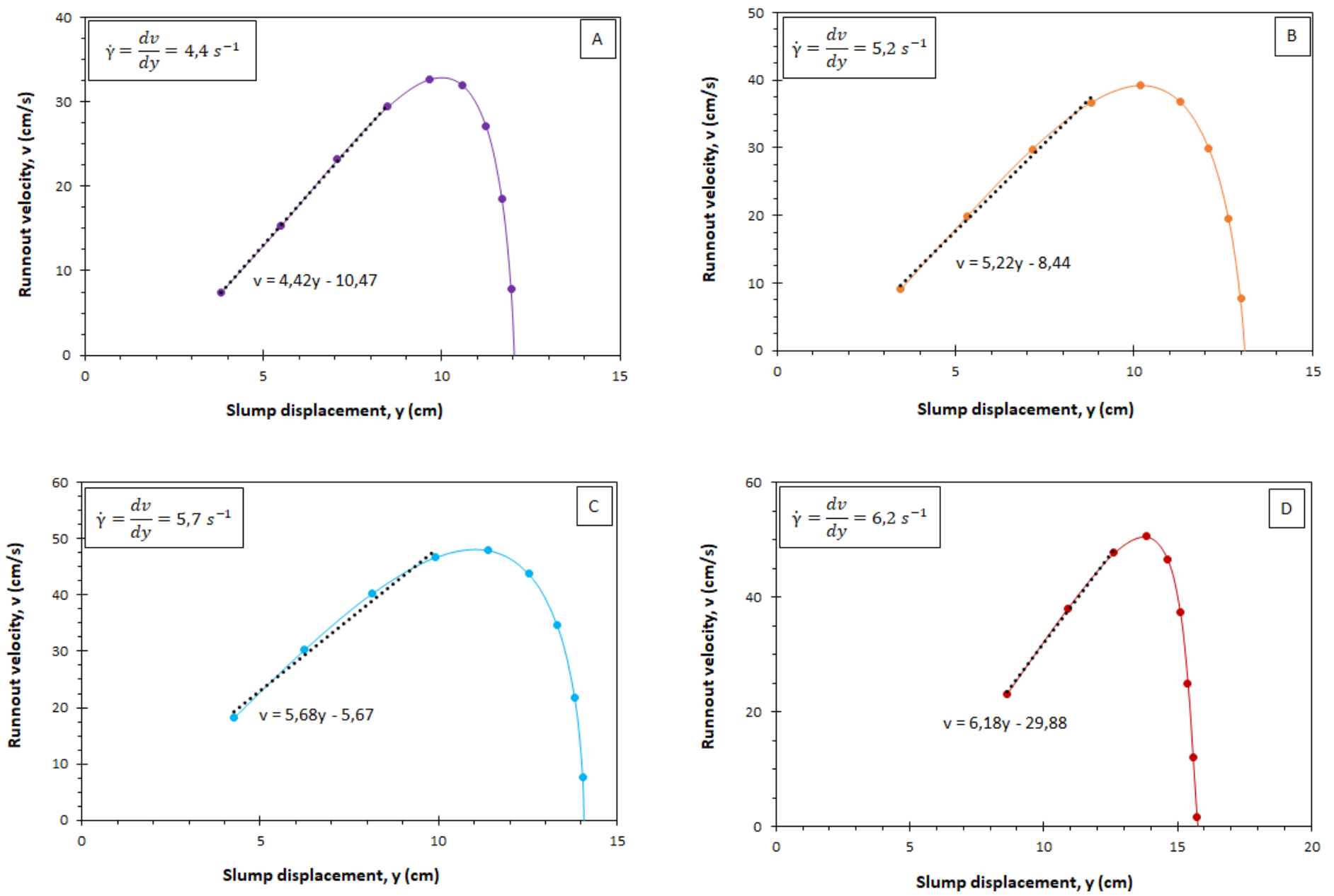

Figure 5.9 - Shear rate interpretation of the MCP samples tested in the cylindrical slump tests. $(\mathbf{A}) \mathrm{w}=1,5 \mathrm{LL} .(\mathbf{B}) \mathrm{w}=1,6 \mathrm{LL} .(\mathbf{C}) \mathrm{w}=1,7 \mathrm{LL} .(\mathbf{D}) \mathrm{w}=1,8 \mathrm{LL}$. 


\subsection{6}

\section{Literature solutions}

As presented in the literature review of this work (see Item 2.3), analytical solutions of the cylindrical slump test problem are proposed by few authors. This study used the solutions for yield stress and viscosity presented in the Item 2.3. For yield stress investigation, it was employed the Baudez \& Coussot (2004) solution, whereas for viscosity, the Staron et al. (2004) solution was applied.

Tables 5.6 and 5.7 show the calculation routines developed for each solution. Basically, the equations (ref. to Item 2.2) were programmed in Excel cells, and input parameters such as specific mass and height/radius variation were used to results output. As it can be seen in the referred tables, the verification convergence conditions were well accomplished as three decimal places values were obtained.

\subsubsection{1 Virtual height}

As it was said in the Item 2.3 (ref. to pages 42 and 43), a virtual height is considered in the yield stress analytical solution, by adding to the initial height of the sample, a second term related to an object pressure over the soil column, as it is putted forward by Baudez \& Coussot (2004). In this study, an acrylic disc is inserted at the top surface of the slump test soil samples as it is coupled to the LDVT rod (see Fig. 4.1 A), in order to improve the device's vertical position readings, following suggestions pointed by Galindo (2013).

Below are shown the input physical and geometrical measurements, taken in the laboratory, as well as the Equation 42 solving.

$$
\begin{gathered}
m_{0}^{\text {disc }}=164,82 \mathrm{~g} \\
\rho_{\text {acrylic }}=1,18 \frac{\mathrm{g}}{\mathrm{cm}^{3}} \\
R_{\text {disc }}=4,86 \mathrm{~cm} \\
z_{0}^{\text {disc }}=\frac{m_{0}^{\text {disc }}}{\rho_{\text {acrylic }} \cdot \pi \cdot R_{\text {disc }}^{2}} \cong 1,88 \mathrm{~cm}
\end{gathered}
$$


The rod's overweight was considered to increase such virtual height to a value of $z_{0}=2,0 \mathrm{~cm}$, which was considered to all samples (Tables 5.6 and 5.7).

It is important to state that by employing the Staron et al. (2004) semi empiric solution for viscosity, it was observed that the verification convergence condition was only reached as this same virtual height was inputted. As convergence was verified, for both yield stress and viscosity solutions, the resulting values showed to be extremely closed to those obtained in the rheometric tests (as it will be discussed in the Item 5.4, page 105). Such finding indicates that the coupled roddisc overweight affects significantly the rheological behaviour of the herein studied materials in the cylindrical tube slump test.

Table 5.6 - Calculation routine employed to the analytical determination of yield stresses, through Baudez \& Coussot (2004) solution. All samples have $H_{0}=20.0 \mathrm{~cm}$ and $z_{0}=2.0$ $\mathrm{cm}$.

\begin{tabular}{|c|c|c|c|c|c|c|c|c|}
\hline \multirow{2}{*}{ Material } & \multirow{2}{*}{$\begin{array}{c}\begin{array}{c}\text { Water } \\
\text { content }\end{array} \\
\text { w/LL }\end{array}$} & \multirow{2}{*}{$\begin{array}{c}\begin{array}{c}\text { Height } \\
\text { variation }\end{array} \\
\Delta H(\mathrm{~cm})\end{array}$} & \multirow{2}{*}{$\begin{array}{c}\begin{array}{c}\text { Specific } \\
\text { mass }\end{array} \\
\rho\left(\mathrm{g} / \mathrm{cm}^{3}\right)\end{array}$} & \multirow{2}{*}{$\begin{array}{l}\begin{array}{l}\text { Initial } \\
\text { stress }\end{array} \\
\sigma_{0}(\mathrm{~Pa})\end{array}$} & \multirow{2}{*}{$\begin{array}{l}\begin{array}{c}\text { Yield } \\
\text { stress }\end{array} \\
\tau_{0}(\mathrm{~Pa})\end{array}$} & \multirow{2}{*}{$\begin{array}{c}\begin{array}{c}\text { Dimensionless } \\
\text { yield stess }\end{array} \\
\overline{\tau_{0}}\end{array}$} & \multicolumn{2}{|c|}{ Verification } \\
\hline & & & & & & & $p$ & $q$ \\
\hline \multirow{4}{*}{ ACP } & 1,4 & 7,8 & 1,49 & 3215,7 & 461,0 & 0,14 & 0,355 & 0,355 \\
\hline & 1,6 & 10,2 & 1,44 & 3107,8 & 324,9 & 0,10 & 0,464 & 0,464 \\
\hline & 1,7 & 11,1 & 1,42 & 3064,6 & 281,5 & 0,09 & 0,505 & 0,505 \\
\hline & 1,8 & 12,8 & 1,40 & 3021,5 & 213,8 & 0,07 & 0,582 & 0,582 \\
\hline \multirow{4}{*}{ MCP } & 1,5 & 12,3 & 1,46 & 3146,4 & 241,0 & 0,08 & 0,559 & 0,559 \\
\hline & 1,6 & 13,4 & 1,44 & 3107,8 & 198,7 & 0,06 & 0,609 & $\mathbf{0 , 6 0 9}$ \\
\hline & 1,7 & 14,3 & 1,42 & 3064,6 & 166,9 & 0,05 & 0,650 & 0,650 \\
\hline & 1,8 & 16,0 & 1,39 & 2999,9 & 114,5 & 0,04 & 0,727 & 0,727 \\
\hline
\end{tabular}

Table 5.7 - Calculation routine employed to the analytical determination of plastic viscosities, through Staron et. al (2004) solution. All samples have $a=4.4, H_{0}=20.0 \mathrm{~cm}$, $z_{0}=2.0 \mathrm{~cm}$ and $R_{0}=5.0 \mathrm{~cm}$.

\begin{tabular}{|c|c|c|c|c|c|c|c|c|c|c|c|}
\hline \multirow{2}{*}{ Material } & \multirow{2}{*}{$\begin{array}{c}\begin{array}{c}\text { Water } \\
\text { content }\end{array} \\
\text { w/LL }\end{array}$} & \multirow{2}{*}{$\begin{array}{c}\begin{array}{c}\text { Radius } \\
\text { variation }\end{array} \\
\Delta \mathrm{R}(\mathrm{cm})\end{array}$} & \multirow{2}{*}{$\begin{array}{c}\begin{array}{c}\text { Specific } \\
\text { mass }\end{array} \\
\rho\left(\mathrm{g} / \mathrm{cm}^{3}\right)\end{array}$} & \multirow{2}{*}{$\begin{array}{c}\begin{array}{c}\text { Initial } \\
\text { stress }\end{array} \\
\sigma_{0}(\mathrm{~Pa})\end{array}$} & \multirow{2}{*}{$\begin{array}{c}\begin{array}{c}\text { Yield } \\
\text { stress }\end{array} \\
\tau_{0}(\mathrm{~Pa})\end{array}$} & \multirow{2}{*}{$\begin{array}{c}\begin{array}{c}\text { Dimensionless } \\
\text { yield stess }\end{array} \\
\overline{\tau_{0}}\end{array}$} & \multirow{2}{*}{$\begin{array}{c}\text { Viscosity } \\
\eta \eta(\text { Pa.s) }\end{array}$} & \multirow{2}{*}{$\begin{array}{c}\begin{array}{c}\text { Dimensionless } \\
\text { viscosity }\end{array} \\
\bar{\eta}\end{array}$} & \multicolumn{3}{|c|}{ Verification } \\
\hline & & & & & & & & & $a_{0}$ & $\lambda 1$ & $\lambda .2$ \\
\hline \multirow{4}{*}{$\mathrm{ACP}$} & 1,4 & 5,9 & 1,49 & 730,8 & 461,0 & 0,63 & 106,7 & 2,04 & 1,23 & 0,372 & 0,372 \\
\hline & 1,6 & 7,8 & 1,44 & 706,3 & 324,9 & 0,46 & 71,1 & 1,41 & 0,97 & 0,454 & 0,454 \\
\hline & 1,7 & 9,0 & 1,42 & 696,5 & 281,5 & 0,40 & 51,5 & 1,04 & 0,90 & 0,515 & 0,515 \\
\hline & 1,8 & 11,7 & 1,40 & 686,7 & 213,8 & 0,31 & 30,3 & 0,62 & 0,77 & 0,645 & 0,645 \\
\hline \multirow{4}{*}{$\mathrm{MCP}$} & 1,5 & 9,8 & 1,46 & 716,1 & 241,7 & 0,34 & 54,7 & 1,07 & 0,75 & 0,537 & 0,537 \\
\hline & 1,6 & 11,7 & 1,44 & 706,3 & 198,7 & 0,28 & 38,0 & 0,75 & 0,67 & 0,627 & 0,627 \\
\hline & 1,7 & 13,4 & 1,42 & 696,5 & 166,9 & 0,24 & 29,4 & 0,59 & 0,60 & 0,705 & 0,705 \\
\hline & 1,8 & 17,2 & 1,39 & 681,8 & 114,5 & 0,17 & 19,8 & 0,41 & 0,45 & 0,871 & 0,871 \\
\hline
\end{tabular}




\section{2 \\ Rheometer}

The flow curves obtained in the plate-plate rheometer tests are presented in Figures 5.10 to 5.13 what follows. These curves represent relations among viscosity, shear stress and shear rate throughout a 2 minutes rotational flow developed by torque transmission to the upper plate of the rheometer, on a $49.96 \mathrm{~mm}$ diameter and 2.0 mm thickness sample.

Ideally, tests should have been performed in the rheometer immediately after the cylindrical slump tests execution, thus using the same sample and preserving moisture and void ratio values. However, as both types of tests were performed in different laboratories, this was not possible. In order to assure compatibility between the tests, a rigorous routine for moisture control of the samples tested in the rheometer was developed, based on sample's moistures obtained in the slump tests. At the end, differences smaller than $1.0 \%$ were observed between the moisture values of the samples within both tests.

\subsection{1 \\ Shear stress analyses}

Shear stress - shear rate relationships for both tested soils are presented in Figure 5.10. As the test is initialized, along the acceleration ramp a creep regime is established, where the material behaves as a solid: low increases in shear rate are associated with rapid increase of shear stress. This stage is followed by a flow regime after yield stress is reached (a stress plateau is established). As a certain shear rate is passed, a new interval, where shear stress turns to increase, is observed. From a rate of $100 \mathrm{~s}^{-1}$, when the deceleration ramp begins, shear stress decreases down to a given shear rate, when it becomes nearly constant up to the end of the test: a second yield stress is developed, as will be seen later.

It is interesting to note that in preliminary tests performed under different ranges of shear rates (from 0.001 to $1000.0 \mathrm{~s}^{-1}$ ) with the same 2 minutes duration, the creeping regime was found to be dependent both on initial shear rate and speed increment rate. Nonetheless, in all tests it was observed that the shear stress-rate relation remained identical for shear rates higher than $1.0 \mathrm{~s}^{-1}$. An example of that 
observation is that the stress plateau was established at approximately the same shear rate for both acceleration and deceleration ramps in all preliminary tests. These findings indicate that the stablished flow regime is not sensible neither to initial shear rates nor to the speed increment rate in what refers to the present work.
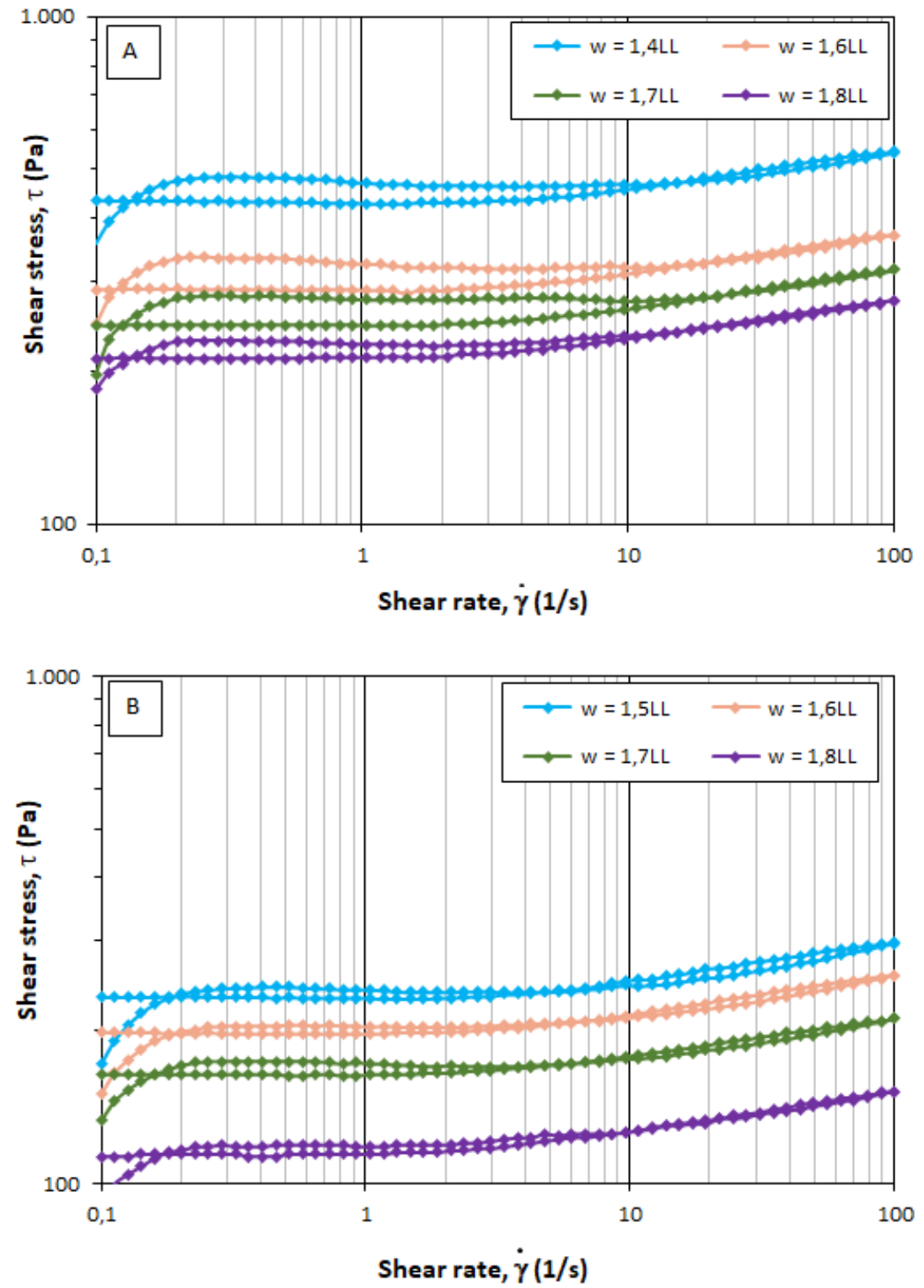

Figure 5.10 - Shear stress flow curves obtained in the rheometer. (A) ACP soil. (B) MCP soil.

Di Santolo et al. (2011) found similar results when testing pyroclastic sediments within a natural slope with debris flow history, located in Italy. For the authors, no solid conclusion can be drawn about the creeping regime, as it is dependent to both initial strain rate and incremental rate. 
It is also relevant to comment that for both soils the shear stress plateau is within the shear rate interval ranging from 1 to circa of $10 \mathrm{~s}^{-1}$. Similar interval is observed in the slump test shear rates $\left(4\right.$ to $\left.7 \mathrm{~s}^{-1}\right)$, confirming that yield stress is reached by the soils during its fall and spread in the slump test.

\subsubsection{1}

\section{Hysteretic behavior of the flow curves}

When comparing the acceleration and deceleration ramps of both soils in Figure 5.10, it can be observed a small but noticeable hysteresis in the ACP material (Figure 5.10 A), while little hysteresis effect occurs in the MCP soil (Figure 5.10 B). As up to $5 \%$ difference in water content was observed in sub-samples collected before and after the tests (see item 3.1.1), this phenomenon could be related to moisture loss along the tests. However, moisture loss would be related to a decrease of the degree of saturation of the samples. On the other hand, soils' desaturation would imply in increments of shear stress as a result of tensions related to matric suction. As this has not happened, the observed variations in water content before and after tests are herein considered as not relevant to the hysteretic phenomena.

According to di Santolo et al. (2011), hysteresis is a consequence of thixotropy effects: the fragile arrange of the grains-water structure collapses as large deformations develop. To the authors, the yield stresses concern to flow set (acceleration) and stoppage (deceleration) and when it comes to debris flow analysis, the motion's development and ceasing conditions can be related to the different stresses.

By considering hysteresis, two different yield stresses where defined: one related to the acceleration $\operatorname{ramp}\left(\tau_{0}^{\mathrm{A}}\right)$, and the other to deceleration $\left(\tau_{0}{ }^{\mathrm{D}}\right)$. Such stresses are presented in Table 5.8, as well as the hysteresis ratio $\left(\tau_{0}{ }^{\mathrm{A}} / \tau_{0} \mathrm{D}\right)$, which denotes a percentual difference between them. As it was said on Item 3.2.3, the method for estimating the yield stresses related to those stages was determined by standardizing the shear rates required to reach those stresses, as it follows: the acceleration shear rate was set as $0.2 \mathrm{~s}^{-1}$, and the deceleration as $3.0 \mathrm{~s}^{-1}$. 
Table 5.8 - Yield stress determined in both acceleration and deceleration ramps of the flow tests performed in the rheometer with the two soils.

\begin{tabular}{|c|c|c|c|c|c|}
\hline \multirow{3}{*}{ Material } & \multicolumn{2}{|c|}{ Water content } & \multirow{2}{*}{\multicolumn{2}{|c|}{$\begin{array}{c}\text { Yield stress } \\
\tau_{0}(\mathrm{~Pa})\end{array}$}} & \multirow{3}{*}{$\begin{array}{c}\begin{array}{c}\text { Hysteresis } \\
\text { ratio }\end{array} \\
\tau_{0}{ }^{A} / \tau_{0}{ }^{D}\end{array}$} \\
\hline & \multirow{2}{*}{$w / L L$} & \multirow{2}{*}{$w(\%)$} & & & \\
\hline & & & Acceleration & Deceleration & \\
\hline \multirow{4}{*}{$\mathrm{ACP}$} & 1,4 & 88,3 & 467,4 & 430,1 & 1,09 \\
\hline & 1,6 & 101,7 & 328,1 & 288,7 & 1,14 \\
\hline & 1,7 & 107,7 & 280,0 & 248,0 & 1,13 \\
\hline & 1,8 & 118,0 & 213,8 & 214,3 & 1,00 \\
\hline \multirow{4}{*}{$\mathrm{MCP}$} & 1,5 & 99,9 & 236,8 & 232,1 & 1,02 \\
\hline & 1,6 & 105,2 & 200,8 & 199,5 & 1,01 \\
\hline & 1,7 & 111,4 & 166,1 & 165,0 & 1,01 \\
\hline & 1,8 & 123,3 & 114,9 & 116,2 & 0,99 \\
\hline
\end{tabular}

The hysteresis ratio indicates that differences around $10 \%$ occur for the ACP soil, whereas no relevant differences occur for the MCP soil. This can be better seen by contrasting the plotted points with the linear 1:1 relation shown in Figure 5.11. According to di Santolo et al. (2011), this observation suggests that in the field, the MCP soil should present similar stress states on its outset and stoppage, while in the ACP soil this should differ. As this study approaches results concerning to acceleration stages, from now on yield stresses will be considered only in relation to those obtained in acceleration ramps.

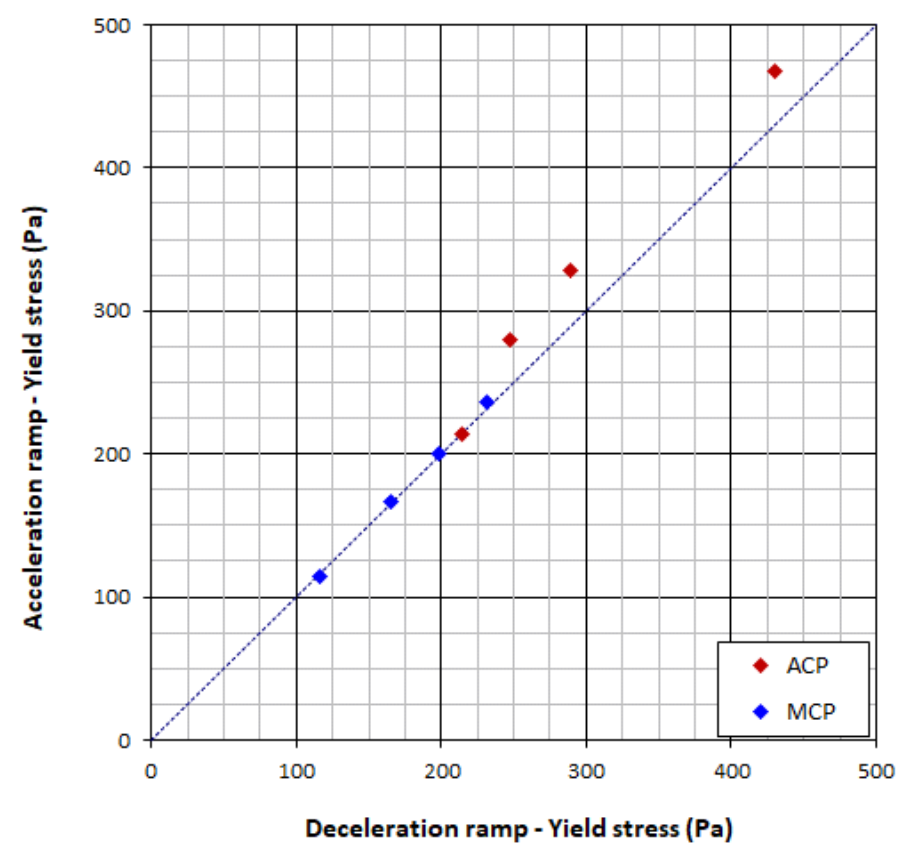

Figure 5.11 - Comparison between yield stresses determined in both acceleration and deceleration ramps of the flow tests performed, with the two soils, in the rheometer. Linear 1:1 relation highlights the concordant and the discordant points. 


\section{2 .2}

\section{Viscosity analyses}

Figure 5.12 shows the viscosity flow curve obtained within the MCP sample with $w=1.8 L L$, considering both the acceleration and deceleration ramps of the rheometric test. It can be observed in these figure that hysteresis doesn't affect the viscosity paths of the sample, as it was said in Item 4.2.3 Identical behaviour was observed for all samples concerning to the two soils. Hence, it is concluded that for the studied soils, hysteretic phenomena affect exclusively the shear stress flow curves.

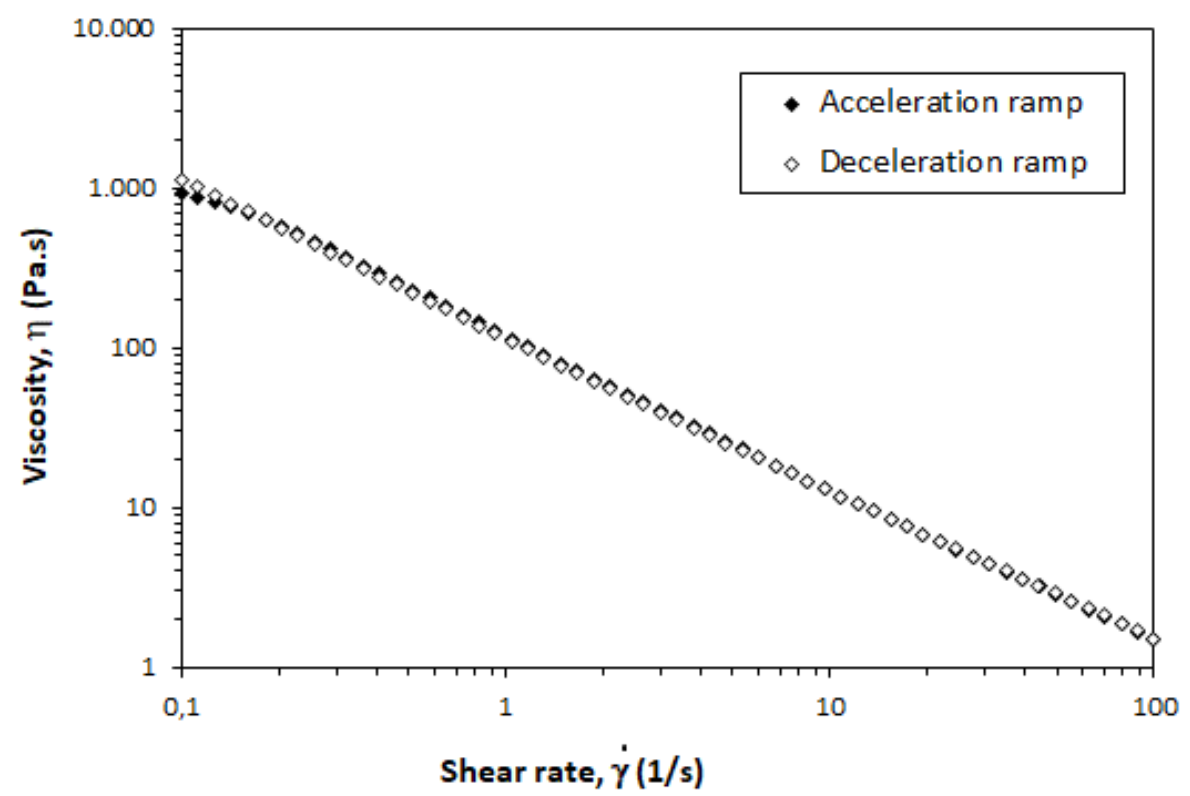

Figure 5.12 - Viscosity flow curve obtained in the rheometer within the MCP sample with $\mathrm{w}=1,8 \mathrm{LL}$.

Figure 5.13 shows the log-log relation between viscosity and shear rate obtained for both soils. To improve graphical viewing, data are plotted only concerning to acceleration ramps. The curves show that as the test begins, a creep regime is observed as high values of viscosity are associated with low shear rates, and so the materials present a semi-solid behavior. As the shear rates increase, a rapid viscosity decline outcomes a shear stress increase, until a flow regime is established. Such regime is associated with a yield stress plateau (refer to Figure 5.10). As a consequence, lower viscosity values are observed as the test develops. 
The wide and continuous log-linear decay of viscosity for both soils, ranging from 5000 to nearly $1 \mathrm{~Pa}$.s appoints that viscosity should present a strong variation during a flow event, inclusive in the slump test, where different shear rates are observed along the runout movement (ref. to Item 5.1.5). For that discussion, the following item will present combined analyses concerning to both slump test and rheometer results.
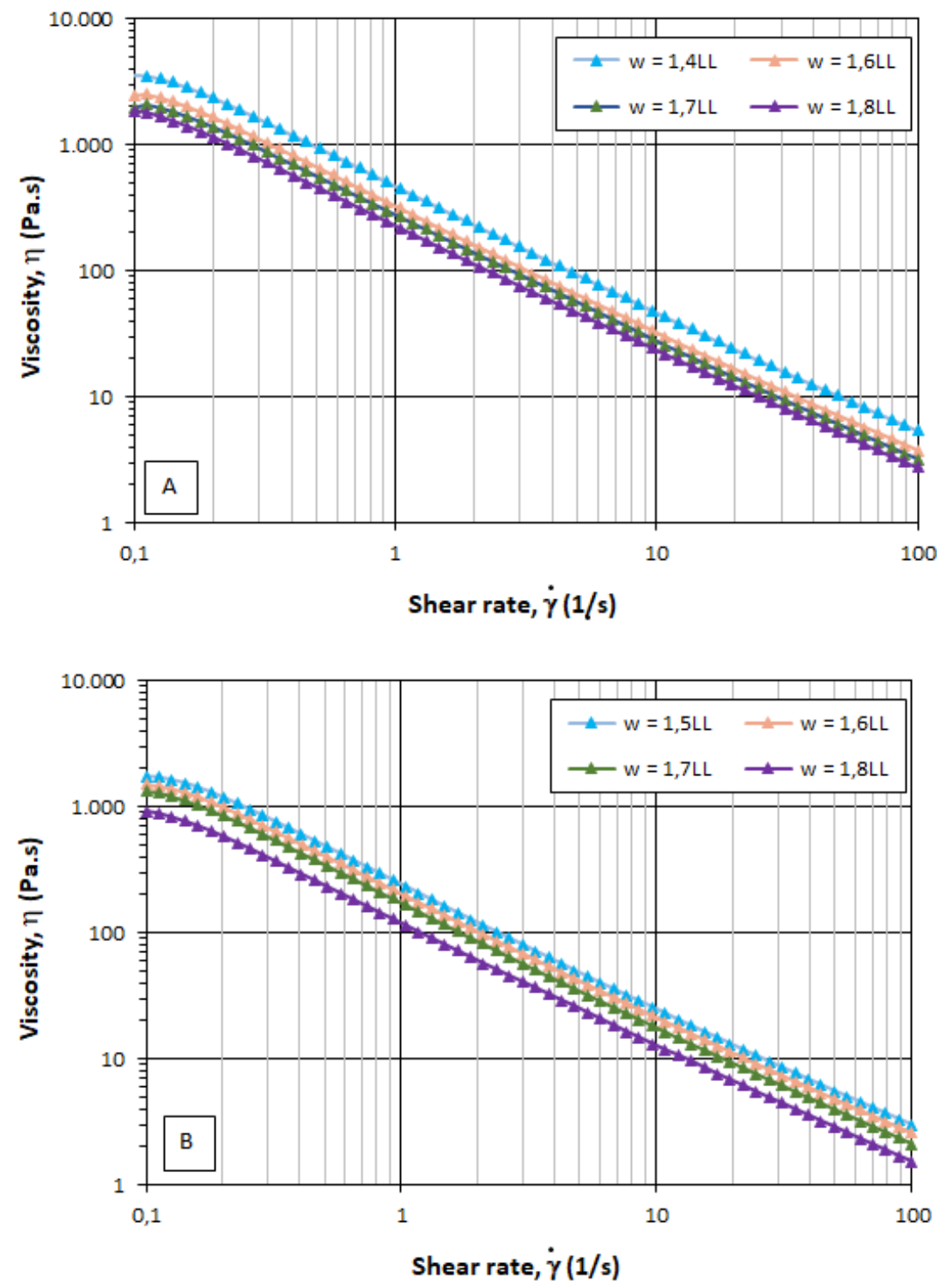

Figure 5.13 - Viscosity flow curves obtained in the rheometer. (A) ACP soil. (B) MCP soil. 


\section{3 Combined analyses}

Figure 5.14Figure 5.14 shows, in linear scales, the variation of viscosity and shear stress with shear rate, for the MCP sample with $w=1,8 \mathrm{LL}$. When looking to the viscosity flow curve, an abrupt transition from an almost asymptotic decay to a nearly constant relation is noted in the referred figure. When plotting the same graph for all the curves of both soils, identical behavior is observed. Furthermore, by plotting the shear rate interval found in this work (ranging approximately from 4 to $8 \mathrm{~s}^{-1}$ ) in the same figure, it is seen that this interval is associated with a region marked by low values of viscosity. Thus, it is herein considered that the shearing rates, developed by the soils in the cylindrical tube slump tests, concern to critical values of viscosity.

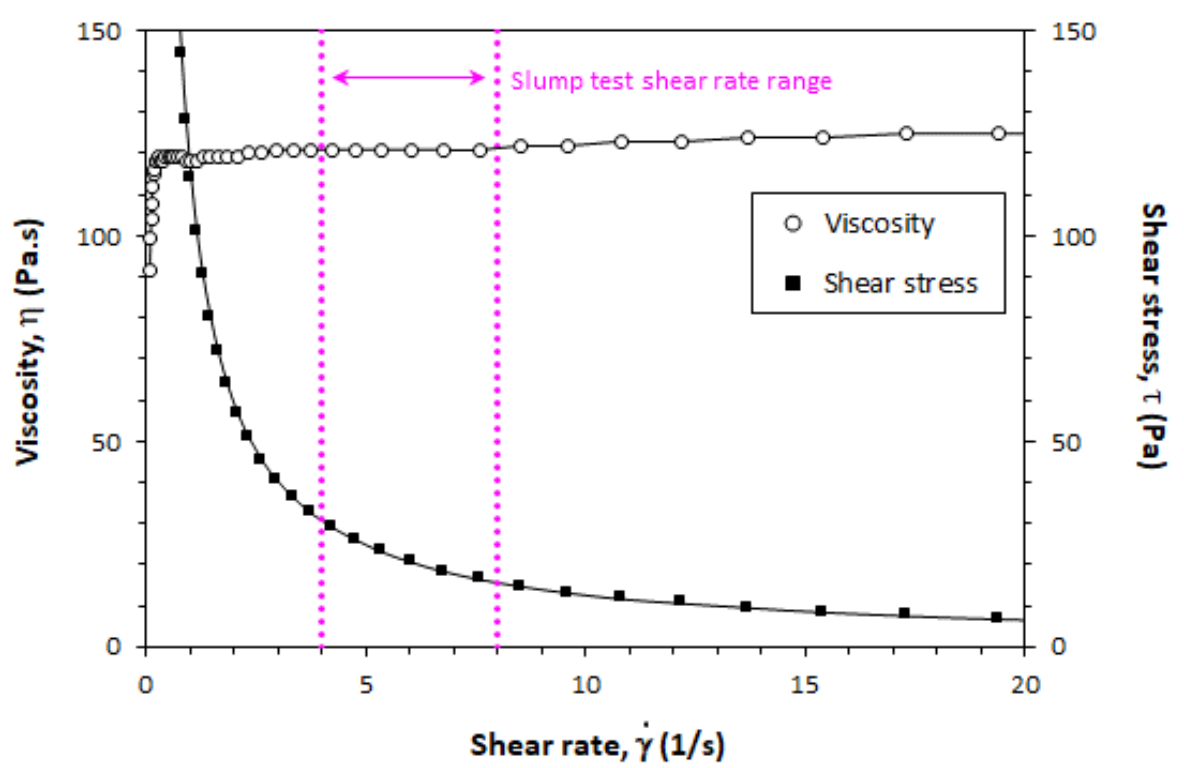

Figure 5.14 - Linear axis viscosity - shear stress - shear rate relationships obtained in the rheometer within the MCP sample with $\mathrm{w}=1,8 \mathrm{LL}$. Dotted lines assign the slump test shear rate interval.

As slump tests resulted in essentially low strain rates, it could be said that they are representative of pseudo-Newtonian viscosities (creep regime). However, it can be seen in Figure 5.14 that the slump tests' shear rates interval is associated with the plastic regime, which is denoted by the yield stress plateau. Thus, it is considered that the results of the present study refer to plastic viscosity. 
For the combined analyses, the shear rates obtained in the cylindrical slump tests and its corresponding viscosities, obtained in the rheometer, are presented in Figure 5.15Figure 5.15.

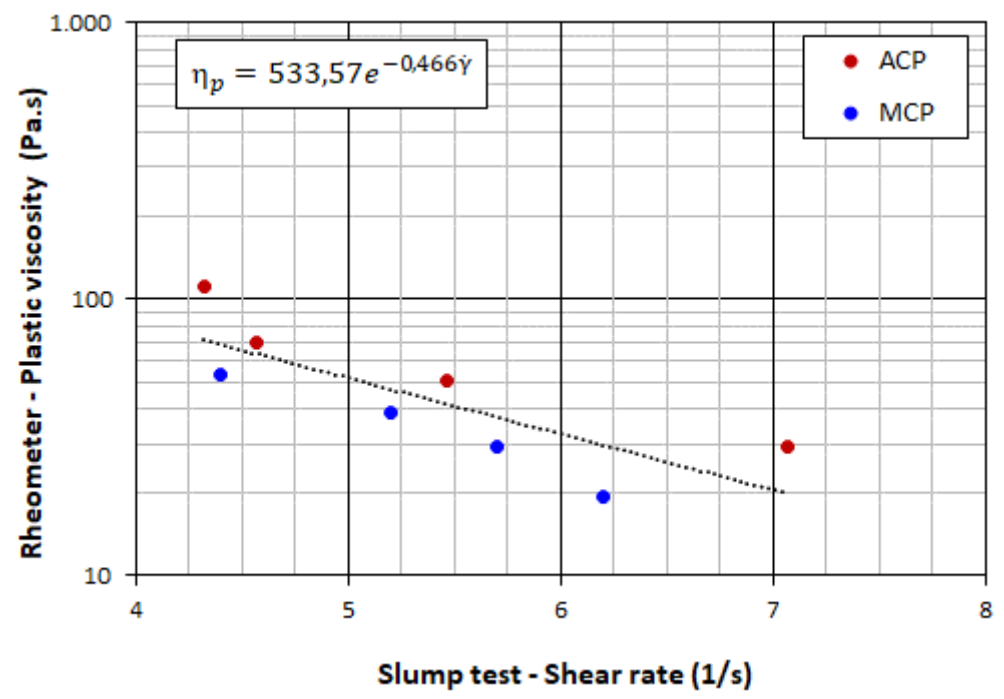

Figure 5.15 - Plastic viscosities, found in the rheometer, corresponding to the shearing rates obtained in the cylindrical slump tests performed with the two soils.

\section{4}

\section{Final discussions}

Table 5.9 shows average physical indexes (water content and solids concentration) of soil samples used in the rheometer and in the modified slump tests, as well as the rheological parameters (shear rate, plastic viscosity and yield stress) obtained from both analytical and experimental methodologies.

Table 5.9 - General results concerning to physical indexes and rheological parameters obtained by both analytical and experimental methodologies.

\begin{tabular}{|c|c|c|c|c|c|c|c|c|}
\hline \multirow{3}{*}{ Material } & \multicolumn{2}{|c|}{ Water content } & \multirow{3}{*}{$\begin{array}{c}\begin{array}{c}\text { Solid } \\
\text { concentration }\end{array} \\
\mathrm{C}_{\mathrm{v}}(\%)\end{array}$} & \multirow{3}{*}{$\begin{array}{c}\text { Shear rate } \\
\dot{\gamma}(1 / \mathrm{s}) \\
\text { Slump test }\end{array}$} & \multirow{2}{*}{\multicolumn{2}{|c|}{$\begin{array}{c}\text { Plastic viscosity } \\
\eta_{p} \text { (Pa.s) }\end{array}$}} & \multirow{2}{*}{\multicolumn{2}{|c|}{$\begin{array}{c}\text { Yield stress } \\
\tau_{0}(\mathrm{~Pa})\end{array}$}} \\
\hline & \multirow{2}{*}{ w/LL } & \multirow{2}{*}{$w(\%)$} & & & & & & \\
\hline & & & & & Analytical & Experimental & Analytical & Experimental \\
\hline \multirow{4}{*}{ ACP } & 1,4 & 88,3 & 29,7 & 4,3 & 106,7 & 111,2 & 461,0 & 467,4 \\
\hline & 1,6 & 101,7 & 26,8 & 4,6 & 71,1 & 69,7 & 324,9 & 328,1 \\
\hline & 1,7 & 107,7 & 25,7 & 5,5 & 51,5 & 50,4 & 281,5 & 280,0 \\
\hline & 1,8 & 118,0 & 24,1 & 7,1 & 30,3 & 29,5 & 214,1 & 213,8 \\
\hline \multirow{4}{*}{ MCP } & 1,5 & 99,9 & 28,2 & 4,4 & 54,7 & 53,1 & 241,7 & 236,8 \\
\hline & 1,6 & 105,2 & 27,4 & 5,2 & 38,0 & 38,6 & 198,7 & 200,8 \\
\hline & 1,7 & 111,4 & 26,7 & 5,7 & 29,4 & 29,5 & 166,9 & 166,1 \\
\hline & 1,8 & 123,3 & 24,2 & 6,2 & 19,8 & 19,4 & 114,5 & 114,9 \\
\hline
\end{tabular}


Figure 5.16 shows comparisons between analytical and experimental data for both plastic viscosities (Fig. 5.16 A) and yield stresses (Fig. 5.16 B). In this figure we notice an equivalent relationship along the linear 1:1 relation, for the two rheological parameters. Thus, it is considered that the developed combined methodology involving cylindrical slump test shear rates and rheometer viscosities is valid, as well as is the graphical yield stress interpretation herein employed.
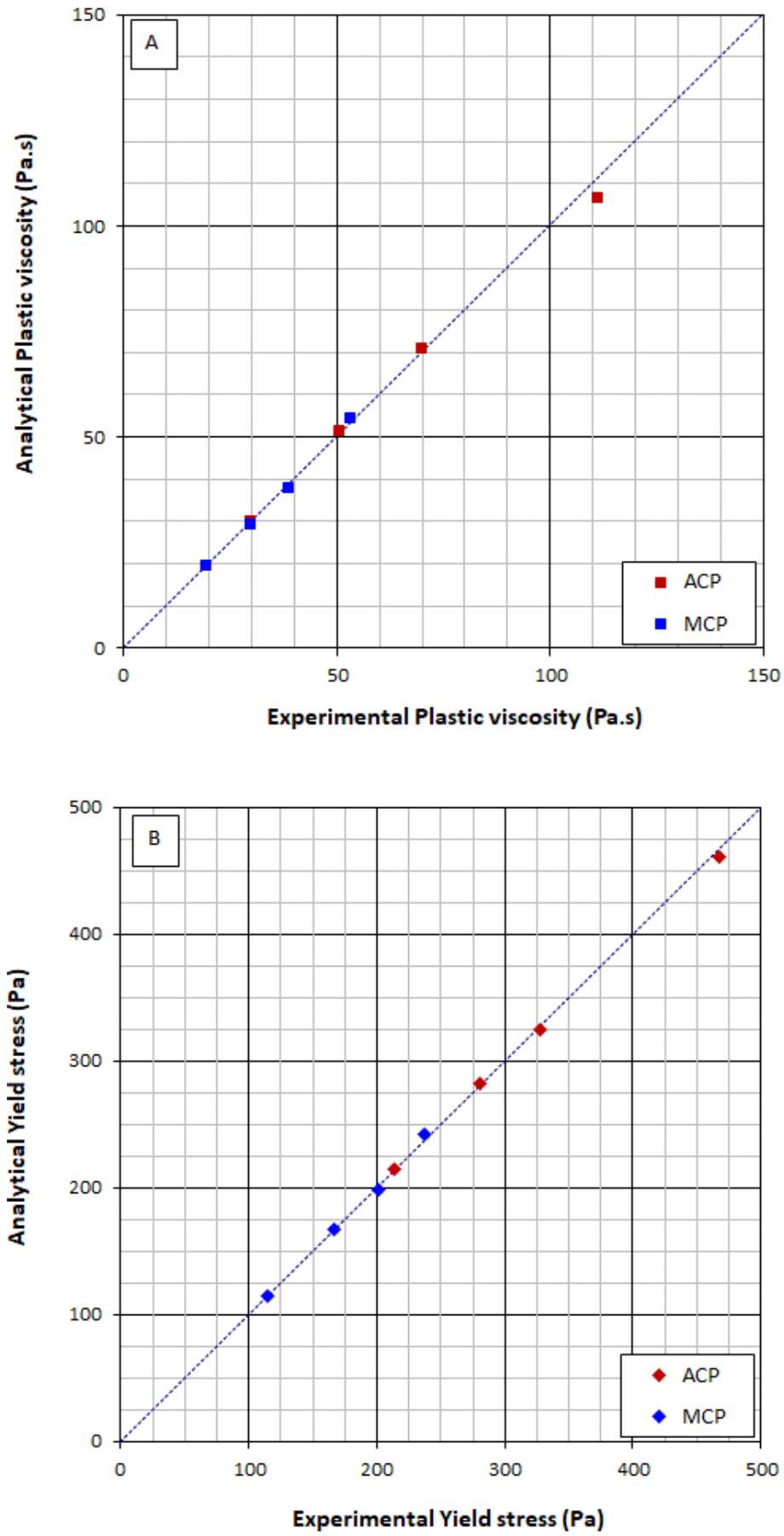

Figure 5.16 - Comparison between analytical and experimental results, where linear 1:1 relation outlines the concordant points. (A) Viscosity results. (B) Yield stress results. 
In Figure 5.17 it is presented, for the both soils, relationships between yield stress and physical indexes. It is seen that for a given solids concentration or a given water content, the yield stresses of the samples ACP are jointly represented by a single relation, whereas samples MCP are represented by another one, with the latter samples (MCP) showing lower yield stresses. Hence it was proposed a region with a unique equation which should be representable of tropical soils' yield stress variation with physical indexes.
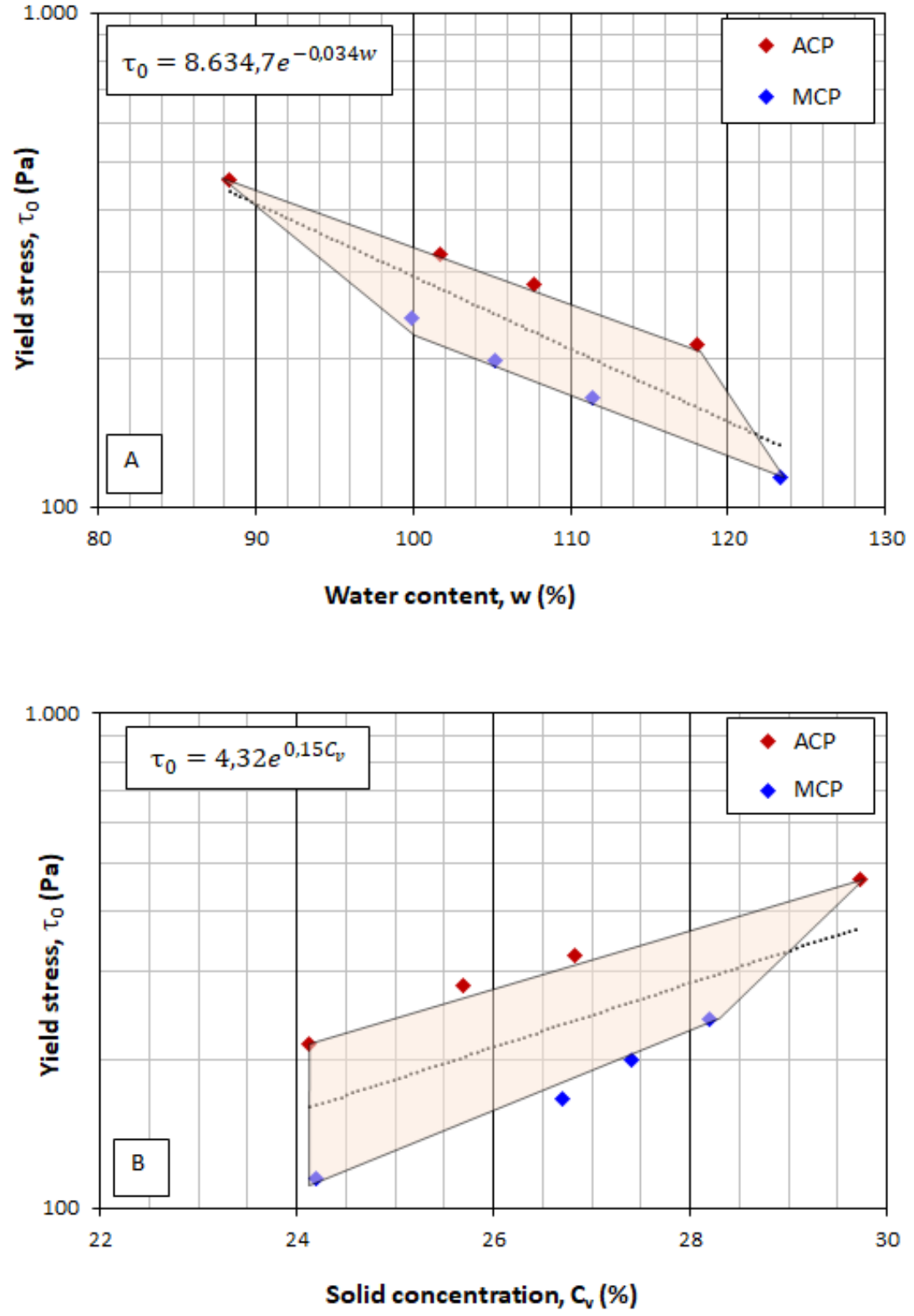

Figure 5.17 - Yield stress variation with physical indexes. (A) Water content. (B) Solid concentration. 
On the other hand, when plotting the plastic viscosities against the physical indexes (Fig. 5.18), these relationships can be well represented by a single equation for both ACP and MCP soils.
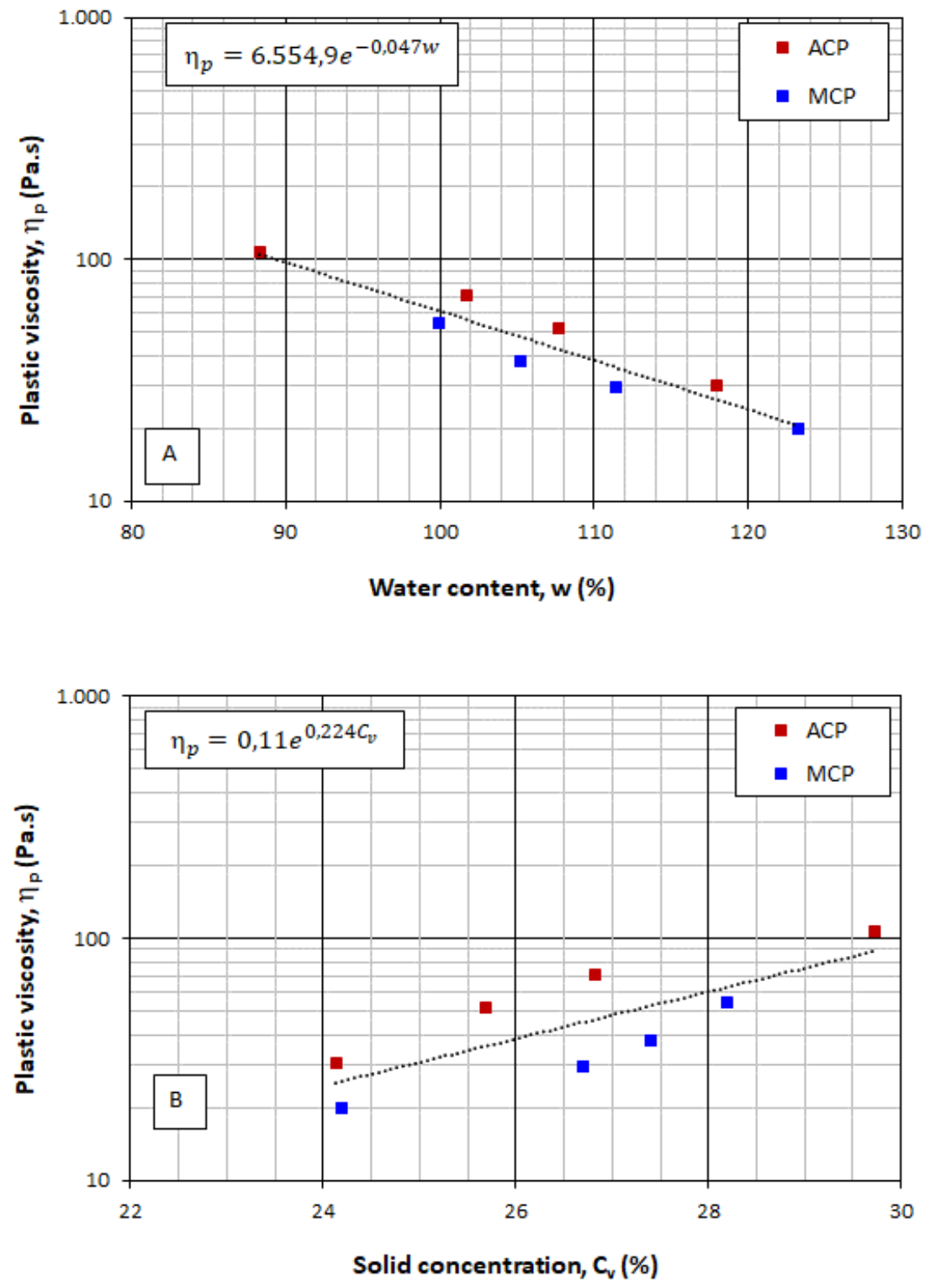

Figure 5.18 - Plastic viscosity variation with physical indexes. (A) Water content. (B) Solid concentration.

It is relevant to notice that, in Figures 5.17 and 5.18, the higher the water content or the lower the solids concentration, the lower the rheological parameters of the materials, appointing to a relevant sensitivity of yield stress and plastic viscosity to water content (or solid concentrations). Exponential functions 
represented quite well the relationships between yield stress/viscosity and water content/solids concentration.

Furthermore, the ACP samples present higher values than the MCP samples, for both yield stresses and plastic viscosities (Figures 5.14 and 5.15, A and B). Considering the particle size distribution of the two materials (see Item 2.2), the ACP soil has a significantly higher sand percentual then the MCP (46.5 and 34.2 $\%$, respectively.

Such finding is in agreement with data gathered from literature. A similar trend was observed in the silty soils tested by Kang \& Kim (2013) and from Jeong (2014). Furthermore, O'Brien \& Julien (1988) mention that the viscosity of claysilt mixtures increases rapidly with volumetric sand concentrations beyond $20 \%$. Moreover, Mangesana et al. (2008) report an increase in viscosity with the size of sand particles in tests on silica sand from tumbling mills. Jeong et al. (2010) stated that clay materials should have higher viscosities than sand materials. Therefore, it is apparent that the particle size distribution by itself may not be taken as indicative of the potential range of viscosities associated with any given soil. Further analyses about grain size influence on rheological parameters are out of the scope of this research.

As data gathered from the literature are associated with solid volumetric concentration, comparisons were made between results from this research and other authors'studies (Fig. 5.19).

Results herein obtained are in quite good agreement with data from other studies, which can be observed in the overlay of regions presented in Figure 5.19. These studies involve predominantly rheometers and viscometers devices. Di Santolo et al. (2011) analysed the yield stress of three pyroclastic soils in a rotation rheometer using a vane geometry. O'Brien \& Julien (1988) studied natural mudflow materials in a concentric cylindrical rotational viscometer. Coussot \& Piaut (1994) investigated different debris flow materials in a parallel plate rotational rheometer. Kang \& Kim (2013) refer to a silty soil (more than $80 \%$ silt) with variable sand content.

Analysing the plastic viscosity graphs (Fig. 5.19 B), it is seen that results from this study are in agreement with data from Galindo (2013). The author studied 
the viscosity of the same soils herein evaluated throughout a modified set-up of the slump test with an Abraham's cone, and found a region variation for the viscosity solid concentration relationship. Results from the present work show to be in the centre of such variation region, indicating an improvement for the evaluation of rheological parameters of tropical soils.

Indeed, this conclusion indicates that the cylindrical slump test is an efficient and cheap alternative methodology for soils viscosity and yield stress measurement, once the test leads to similar results compared to expensive rheometric equipment, such as rheometers and viscometers.
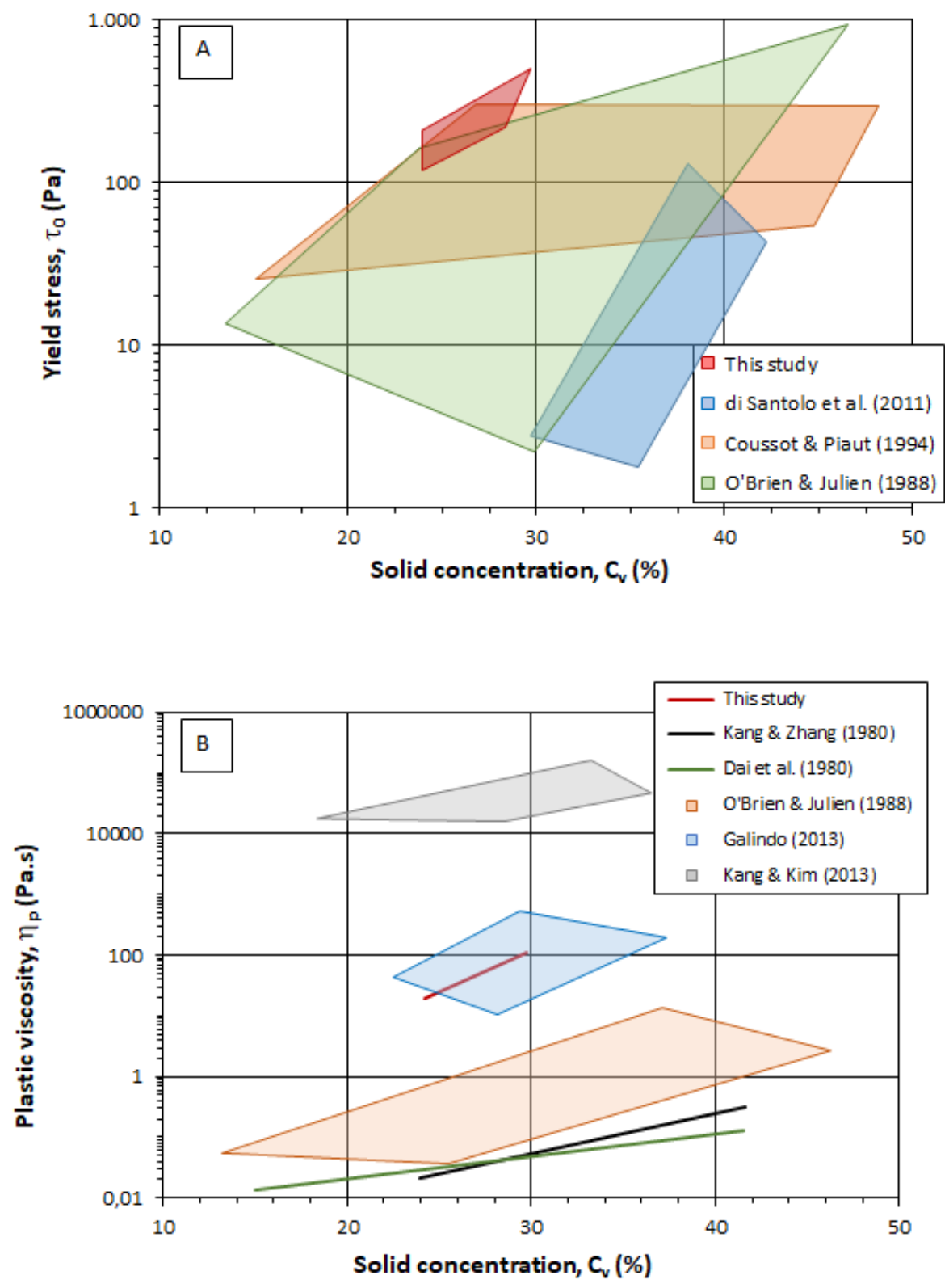

Figure 5.19 - Comparison between results from this research and other studies. 


\section{6 \\ Conclusions and further investigations}

\section{1 Summary and Conclusions}

This study presented the development of an equipment and an alternative methodology to be used for the determination of soil viscosity and yield stress, rheological parameters associated to flow resistance. The main conclusions are presented below.

\subsection{1 \\ Cylindrical tube slump test}

The equipment developed tried to: verify an appropriate geometry for yield stress and viscosity determination; minimize vibrations due to the shocking of the counter weight against the stand in which tests were performed; reduce the lateral and horizontal friction between the soil and, respectively, the inner wall of the cylindrical tube and the flow basin, and develop a methodology for horizontal displacements measurement.

These objectives were respectively achieved through: comparing the yield stress results obtained within three different tubes geometry, with an analytical solution; the use of a damping system consisted in supports to reduce the rising cable displacements and a series of springs to absorb the shock; employment of low friction materials (Teflon and silicone, respectively), and use of a camera and a Digital Image Processing routine.

As a consequence, a new methodology for shear rate determination was developed: a unique equation was put forward to compute shear rates as a function of the sample's water content. 


\subsection{2 Rheological behavior: viscosity and yield stress analyses}

The combined results obtained from the rheometer tests, performed at a shear rate range observed in flow events, and with shear rates obtained in cylindrical slump tests, showed to be a good methodology for yield stress and viscosity determination. Indeed, the average shear rate interval observed in the slump tests is related to the plastic flow regime of the materials, which was observed in the rheometer. As a consequence, slump test shear rates are representative of yield stress and plastic viscosity.

The shear stress flow curves obtained in the rotational plate-plate rheometer indicates a low hysteretic behaviour of the flow of the studied soils, which can lead to flow instability throughout a debris flow event.

Results obtained for two different tropical soils indicated that exponential curves provide fairly good relationships between water content and both yield stress and viscosity, for the tested materials. However, grain size distribution seems to affect these relationships concerning to yield stress. Hence the need for further investigations into the primary effects of sand content in the determination of soil rheology was observed.

Given the wide variety of existing soils and their complexity, new tests should be carried out in order to calibrate the equations proposed herein. Also, with the aim to better understand and simulate real debris flow events, the effects of gravelsized particles embedded in a silt-clay soil matrix are still to be investigated.

Finally, the good correspondence between the experimental results and the results of analytical analysis provides a validation to the assumption that average shearing rates obtained from cylindrical slump tests can be directly related to those used in rheometer tests and indicates that the use of the methodology put forward in this study can provide adequate input parameters for debris flow analysis.

Such findings indicate that the use of a fairly simple and cheap testing technique can provide a direct estimate of soil viscosity and yield stress. 


\section{2}

\section{Suggestions for Future Research}

- Perform tests with materials with different liquidity limits from those presented here, comparing the obtained viscosities and yield stresses experimentally and analytically;

- Find correlations between the shear rate and other quantities related to already consolidated tests in the Soil Mechanics, such as the vane test;

- Perform a numerical modelling of the test to verify the suitability of the proposed analytical method;

- Check the influence of the granulometry of the material on the rheological parameters. It is suggested to repeat all tests performed using the total material, without passing through any sieve. 


\section{References}

ABNT - ASSOCIAÇÃO BRASILEIRA DE NORMAS TÉCNICAS. Solo - Análise granulométrica - NBR-7181, 1984a.

ABNT - ASSOCIAÇÃO BRASILEIRA DE NORMAS TÉCNICAS. Solo - Determinação do limite de liquidez - NBR-6459, 1984b.

ABNT - ASSOCIAÇÃO BRASILEIRA DE NORMAS TÉCNICAS. Solo - Determinação do limite de plasticidade - NBR-7180, 1984c.

ABNT - ASSOCIAÇÃO BRASILEIRA DE NORMAS TÉCNICAS. Amostra de Solos - Preparação para ensaios de compactação e caracterização. NBR- 6457, 1986.

ABNT - ASSOCIAÇÃO BRASILEIRA DE NORMAS TÉCNICAS. Concreto - Determinação da consistência pelo abatimento do tronco de cone - NM 67, 1998.

ABNT - ASSOCIAÇÃO BRASILEIRA DE NORMAS TÉCNICAS. Grãos de solos que passam na peneira de 4,8 mm - Determinação da massa específica NBR-6508, 1984d.

Ancey, C. \& Coussot, P. (1999). Frictional-viscous transition for concentrated suspensions. C.R. Acad. Sci., Paris 327, 515-522.

AUGUSTO FILHO, O.; VIRGILI, J.C. Estabilidade de taludes. In: OLIVEIRA, A.M.D.S.; BRITO, S.N.A.D. (Eds). Geologia de Engenharia, São Paulo: ABGE, 1998, p. 243-269.

BAGNOLD, R.A. Experiments on a gravity free dispersion of large solid spheres in a Newtonian fluid under shear. Proceedings of the Royal Society of London, series A, 1954, 225, p. 49-63.

BARNES, H.A.; HUTON, J.F.; WALTERS, K. An introduction to rheology. Amsterdam: Elsevier Science, 1989, 199 p.

Baudez, J. C., Ayol, A., Coussot, P. (2004) Practical determination of the rheological behavior of pasty biosolids, Journal of Enviromental Management, 72, 181-188.

BENEVELI, R. M. Estudo dos efeitos de umedecimento e secagem na resistência ao cisalhamento de um solo compactado em laboratório. Dissertação de mestrado. Pontifícia Universidade Católica do Rio de Janeiro, PUC-Rio, Rio de Janeiro-RJ, 2002, 182 p. 
BINGHAM, E.C. Fluidity and plasticity. New York: McGraw-Hill, 1922, 463p. BIRD, R.B.; ARMSTRONG, R.C.; HASSAGER; O. Dynamic of polymeric liquids. New York: Johnson Wiley \& Sons, 1977, 458p.

BIRD, R.B.; DAI, G.C; YARUSSO, B.J. The rheology and flow of viscoplastic materials. Rev Chem Eng, 1983, p. 1-70.

Boniello, M. A., Calligaris, C., Lapasin, R. \& Zini, L. (2010). Rheological investigation and simulation of a debris flow event in the Fella watershed. Nat. Hazards Earth Syst. Sci. 10, No. 5, 989-997.

BRITO, A. T. A. Estudo químico e mineralógico de um perfil de alteração de gnaisse migmatítico do campo experimental II da PUC-RJ, Gávea, Rio de Janeiro. Dissertação de mestrado. Pontifícia Universidade Católica do Rio de Janeiro, PUCRio, Rio de Janeiro-RJ, 1981, 312 p.

Chen, H. \& Lee, C. F. (2000). Numerical simulation of debris flow. Can. Geotech. J. 37, No. 1, 146-160.

CORREIA, D. Z. Estudo de Misturas Poliméricas para Recuperação de Petróleo. Tese de doutorado. Universidade Federal do Rio de Janeiro, UFRJ, Rio de Janeiro-RJ, 2006, 222 p.

Coussot, P. \& Meunier, M. (1996). Recognition, classification and mechanical description of debris flows. Earth-Sci. Rev. 40, Nos 3-4, 209-227.

Coussot, P. (1997). Mudflow rheology and dynamics, IAHR Mono- graph Series. Rotterdam: A. A. Balkema.

Coussot, P. (2005). Rheometry of pastes, suspensions and granular materials: Application in industry and environment. New York: John Wiley \& Sons.

Coussot, P., Nguyen, Q. D., Huynh, H. T. \& Bonn, D. (2002). Avalanche behavior in yield stress fluids. Phys. Rev. Lett. 88, No. 17, 175501.

Coussot, P., Tabuteau, H., Chateau, X., Tocquer, L. \& Ovarlez, G. (2006). Aging and solid or liquid behavior in pastes. J. Rheol. 50, No. 6, 975-994.

COUSSOT, P.; NGUYEN, Q. D.; HUYNH, H. T.; BONN, D. Avalanche Behavior in Yield Stress Fluids. Physical Review Letters, v. 88, n. 17, april 2002b.

COUSSOT, P.; NGUYEN, Q. D.; HUYNH, H. T.; BONN, D. Viscosity bifurcation in thixotropic, yielding fluids. Journal of Rheology, v. 46, n. 3, p. 573589, may/june, 2002a.

DAY, K. W. Equivalent slump. International Rilem conference: Production methods and workability of concrete, Paisley/Scotland. In: Proceedings... London: E \& FN Spon, 1996, p 357-364. 
De CAMPOS, L.E.P. Influência da sucção na estabilidade de taludes naturais em solos residuais. Dissertação de mestrado. Pontifícia Universidade Católica do Rio de Janeiro, PUC-Rio, Rio de Janeiro, 1984, 192 p.

De CAMPOS, T.M.P. Relatório técnico do projeto Tinguá. 2012, 113p.

DUARTE, A. P. L. Avaliação das propriedades termo-hidráulicas de solos requeridas na aplicação da técnica de dessorção térmica. Tese de doutorado. Pontifícia Universidade Católica do Rio de Janeiro, PUC-Rio, Rio de Janeiro, 2004, $290 \mathrm{p}$.

DYLAC, R. Desenvolvimento e utilização de uma célula para medição de K0 com controle de sucção. Dissertação de mestrado. Pontifícia Universidade Católica do Rio de Janeiro, PUC-Rio, Rio de Janeiro-RJ, 1994, 180 p.

ESPINOZA, L.H. Avaliação do potencial de liquefação de solos coluvionares do Rio de Janeiro. Dissertação de mestrado. Pontifícia Universidade Católica do Rio de Janeiro, PUC-Rio, Rio de Janeiro-RJ, 2010, 146 p.

Fakher, A., Jones, C. J. F. P. \& Clarke, B. G. (1999). Yield stress of super soft clays. J. Geotech. Geoenviron. Engng 125, No. 6, 499-509.

Fall, A., Bertrand, F., Ovarlez, G. \& Bonn, D. (2009). Yield stress and shearbanding in granular suspensions. Phys. Rev. Lett. 103, No. 17, 17830.

FERNANDES N. F.; GUIMARÃES R. F; GOMES R. A. T.; VIEIRA B. C.; MONTGOMERY D. R.; GREENBERG H. Condicionantes geomorfológicos dos deslizamentos nas encostas: avaliação de metodologias e aplicação de modelo de previsão de áreas susceptíveis. Revista Brasileira de Geomorfologia, v. 2, n. 1, 2001, p. 51-71.

Fernandes, N. F., Guimarães, R. F., Gomes, R. A. T., Vieira, B. C., Montgomery, D. R. \& Greenberg, H. (2004). Topographic controls of landslides in Rio de Janeiro: field evidence and modeling. Catena 55, No. 2, 163-181.

FERRARIS, C. F.; De LARRARD, F. Testing and modeling of fresh concrete rheology. National Institute of Standards and Technology. NISTIR 6094, Feb. 1998, $71 \mathrm{p}$.

FOX, R. W.; McDONALD, A. T. Introduction to fluid mechanics. New Youk: John Wiley \& sons, 1998, 762 p.

Galindo, M. S. V. (2013). Development of a methodology for the experimental determination of soil viscosity. MSc dissertation, Pontifícia Universidade Católica do Rio de Janeiro, Brazil (in Portuguese).

Gomes, R. A. T., Guimarães, R. F., Carvalho, O. A. Jr, Fernandes, N. F. \& Vargas, E. A. Jr (2013). Combining spatial models for shallow landslides and debris-flows prediction. Remote Sensing 5, No. 5, 2210-2237. 
GOMES, R.A.T. Modelagem e previsão de movimentos de massa a partir da combinação de modelos de escorregamentos e corridas de massa. Tese de doutorado, Universidade Federal do Rio de Janeiro, UFRJ, Rio de Janeiro-RJ, 2006, $102 \mathrm{p}$.

Gram, A., Lagerblad, B. (2013) Obtaining Rheological Parameters from Slump Flow Test for Self-Compacting Concrete, Proceedings of Third International Conference on Sustainable Construction Materials e Technologies, SCMT3, Tokyo, Japan.

Houlsby, G. T. (1982). Theoretical analysis of the fall cone test. Géotechnique 32, No. 2, 111-118, http://dx.doi.org/10.1680/ geot.1982.32.2.111.

Huang, N., Ovarlez, G., Bertrand, F., Rodts, S., Coussot, P. \& Bonn, D. (2005). Flow of wet granular materials. Phys. Rev. Lett. 94, No. 2, 028301.

Hungr, O., Evans, S. G., Bovis, M. J. \& Hutchinson, J. N. (2001). A review of the classification of landslides of the flow type. Environ. Engng Geosci. VII, No. 3, 221-238.

Hungr, O., Morgan, G. \& Kellerhals, L. (1984). Quantitative analysis of debris hazards for design of remedial measures. Can. Geotech. J. 21, No. 4, 633677.

Hutchinson, J. N. (1988). Morphological and geotechnical par- ameters of landslides in relation to geology and hydrogeology. Proceedings of the 5th international symposium on landslides, Lausanne, Switzerland, vol. 1, pp. 3-36.

Iida, K. (1938). The mud flow that occurred near the explosion crater of Mt Bandai on May 9 and 15, 1938, and some physical properties of volcanic mud. Tokyo Imperial Univ. Earthquake Res. Inst. Bull. 16, No. 1, 658-681.

Imran, J., Parker, G., Locat, J. \& Lee, H. (2001). 1D numerical model of muddy subaqueous and subaerial debris flow. J. Hydraulic Engng 127, No. 11, 959968.

Iverson, R. M. (2010). The physics of debris flows. Rev. Geophysics 35, No. 3, 245-296.

Jakob, M. \& Hungr, O. (2005). Debris-flow hazards and related phenomena, Chichester, UK: Springer-Praxis Books in Geophysical Sciences.

Jeong, S. W. (2010). Grain size dependent rheology on the mobility of debris flows. Geosci. J. 14, No. 4, 359-369.

Jeong, S. W. (2013). The viscosity of fine-grained sediments: a comparison of low-to-medium-activity and high-activity clays. Engng Geol. 154, No. 1, 1-5.

Jeong, S. W. (2014). The effect of grain size on the viscosity and yield stress of fine-grained sediments. J. Mountain Sci. 11, No. 1, 31-40. 
Jeong, S. W., Locat, J., Leroueil, S. \& Malet, J. P. (2010). Rheological properties of fine-grained sediments: the roles of texture and mineralogy. Can. Geotech. J. 47, No. 10, 1085-1100.

JOHNSON, A. Physical process in Geology. Freeman, Cooper \& Company, San Francisco, California, 1970, 576p.

Julien, P. Y. \& León, C. A. (2000). Mudfloods, mudflows and debris flows: classification, rheology and structural design. Proceedings of international workshop on mudflows and debris flows, Caracas, Venezuela, pp. 1-15.

JULIEN, P.Y.; LEÓN C. A. Mudfloods, mudflows and debris flows: classification, rheology and structural design. International Workshop on Mudflows and debris flows, Caracas, Venezuela, 2000.

Kang, H. S. \& Kim, Y. T. (2013). Rheological caharacteristis of fine-grained soil with sand contente. J. Korean Soc. Civ. Engrs 33, No. 5, 1897-1905 (in Chinese).

Kang, X., Cheng, Y. \& Ge, L. (2015). Radial strain behaviours and stress state interpretation of soil under direct simple shear. J. Testing and Evaluation, ASCE 43, No. 6, 1594-1601.

Kang, Z. \& Zhang, S. (1980). A preliminary analysis of the characteristics of debris flow. Proceedings of the 1st international symposium on river sedimentation, Beijing, China, pp. 213-220 (in Chinese).

Klein, B. (1992). Rheology and stability magnetite dense media. DSc thesis, University of British Columbia, Vancouver, BC, Canada.

Kokado, T., Hosoda, T., Miyagawa, T., Fuji, M. (1998) Study on a method of obtai- ning yield values of fresh concrete from slump flow test, Proceedings of JSCE 578(37), 29-42.

Komamura, T. \& Huang, R. J. (1974). A new rheological model for soil behaviour. J. Geotech. Engng Div. ASCE 100, No. 7, 807-824.

Koumoto, T. \& Houlsby, G. T. (2001). Theory and practice of the fall cone test. Géotechnique 51, No. 8, 701-712, http://dx.doi.org/ 10.1680/geot.2001.51.8.701.

L. (1998). Direct determination of rheological characteristics of debris flow. J. Hydraul. Engng ASCE 124, No. 8, 865-868.

LINS, H. A. P. Resistência e poro-pressões desenvolvidas em um solo compactado não saturado em laboratório. Tese de doutorado, Universidade Federal do Rio de Janeiro, UFRJ, Rio de Janeiro-RJ, 1991, 363 p.

Locat, J. (1997). Normalized rheological behavior of fine muds and their flow properties in a pseudo-plastic regime. In Proceedings of the 1st international 
conference on debris-flow hazards mitigation, San Francisco (ed. C. L. Chen), pp. 260-269. New York, NY, USA: American Society of Civil Engineers (ASCE).

MACHADO, J. C. V. Reologia e escoamento de fluidos: ênfase na indústria do petróleo. Rio de Janeiro, Interciência: Petrobras, 2002, 257 p.

Macias, J., Amaral, C. \& Vargas, E. Jr (1997). Back-analysis of the mechanical behaviour of the 1996 debris flow in Rio de Janeiro: displacement rate and viscosity determination of the soils. Proceedings of the 2nd pan-American symposium on landslides and 2nd Brazilian conference on natural slopes stability, Rio de Janeiro, Brazil, vol. 1, pp. 243-251 (in Portuguese).

MACIAS, J.; AMARAL, C.; VRGAS JR. E. Retroanálise do comportamento mecânico das corridas de massa de 1996 no Rio de Janeiro: determinação da velocidade e da viscosidade dos materiais envolvidos. In: $2^{\circ}$ Pan-American Symposium on Landslide (II PSL)/ $2^{\text {a }}$ Conferência Brasileira sobre Estabilidade de Encostas ( $2^{\circ}$ COBRAE), Rio de Janeiro, vol.1, 1997, p.243-251.

Macosko, C. W. (1994). Rheology: principles, measurements and applications. New York, NY, USA: John Wiley \& Sons.

Mahajan, S. P. \& Budhu, M. (2009). Shear viscosity of clays using the fall cone test. Géotechnique 59, No. 6, 539-543, http://dx.doi. org/10.1680/geot.7.00114.

Major, J. J. \& Pierson, T. C. (1992). Debris flow rheology: experimental analysis of fine-grained slurries. Water Resour. Res. 28, No. 3, 841-857.

MARINHO, F. A. M. Características de deformabilidade do solo residual do campo experimental II da PUC/Rio obtidas a partir de ensaios triaxiais axissimétricos. Dissertação de mestrado. Pontifícia Universidade Católica do Rio de Janeiro, PUC-Rio, Rio de Janeiro-RJ, 1986, 215 p.

MATTOS, C.C.L.V. Mesoclima da cidade do Rio de Janeiro. Floresta e Ambiente (Série Técnica), 2006, p. 1-22.

Mewis, J. \& Wagner, N. J. (2009). Thixotropy. Adv. Colloid Inter- face Sci. 147-148, 214-227.

MOTHÉ, M. G. Estudo do comportamento de ligantes asfálticos por reologia e análise térmica. Dissertação de mestrado. Universidade Federal do Rio de Janeiro, UFRJ, Rio de Janeiro-RJ, 2009, 204 p.

Nguyen, Q. D. \& Boger, D. V. (1983). Yield stress measurement for concentrated suspensions. J. Rheology 27, No. 4, 321-329.

Nguyen, Q. D. \& Boger, D. V. (1985). Direct yield stress measurement with the vane method. J. Rheology 29, No. 3, 335-347. 
O’Brien, J. S. \& Julien, P. Y. (1985). Physical processes of hyperconcentrated sediment flows. Proceedings of the ASCE specialty conference on the delineation of landslides, floods and debris flow hazards, Logan, UT, USA, pp. 260-279.

O’Brien, J. S. \& Julien, P. Y. (1988). Laboratory analysis of mudflow properties. J. Hydraulic Engng 114, No. 8, 877-887.

O’Brien, J. S. \& Julien, P. Y. (2000). Flo-2D user's manual, version 2000.01. Nutrioso, AZ, USA: Flo Engineering.

ONU. Working party on world landslide inventory. Bulletin of the IAEG, vol.41, nº1, 1993, p. 5-12.

Osano, S. N. (2012). Direct shear box and ring shear test comparison: why does internal angle of friction varies. J. Engng Indian Centre for Adv. Sci. Technol. Res. 5, No. 2, 77-93.

Ovarlez, G., Bertrand, F. \& Rodts, S. (2006). Local determination of the constitutive law of a dense suspension of noncolloidal particles through MRI. J. Rheol. 50, No. 3, 259-292.

Pashias, N., Borger, D. V., Summers, J., Glenister, D. J. (1996) A fifty cent rheometer for yield stress measurement, Journal of Rheology, 40(6), 1179-1189.

Pastor, M., Blanc, T. \& Pastor, M. J. (2009). A depth-integrated viscoplastic model for dilatant saturated cohesive-frictional fluidized mixtures: application to fast catastrophic landslides. J. Non-Newtonian Fluid Mech. 158, No. 1-3, 142-153.

Phillips, C. J. \& Davies, T. R. H. (1991). Determining rheological parameters of debris flow material. Geomorphology 4, No. 2, 101-110.

Pierre, A., Lanos, C., Estellé, P. (2013) Extension of spread-slump formulae for yield stress evaluation Applied Rheology, 23.

Pipe, C. J., Majmudar, T. S. \& Mc Kinley, G. H. (2008). High shear rate viscometry. Rheologica Acta 478, No. 5, 621-642.

Prime, N., Dufour, F. \& Darve, F. (2014). Solid-fluid transition modelling in geomaterials and application to a mudflow interacting with an obstacle. Int. J. Numer. Analyt. Methods Geomech. 38, No. 13, 1341-1361.

Redaelli, I., di Prisco, C. \& Vescovi, D. (2015). Avisco-elasto-plastic model for granular materials under simple shear conditions. Int. J. Numer. Analyt. Methods Geomech. 40, No. 1, 80-104.

Rickenmann, D. (1999). Empirical relationships for debris flows. Nat. Hazards 19, No. 1, 47-77. 
Rickenmann, D., Laigle, D., McArdell, B. W. \& Hubl, J. (2006). Comparison of 2D debris flow simulations models with field events. Comput. Geosci. 10, No. $2,241-264$.

Roussel, N., Coussot, P.(2005) "Fifty-cent rheometer" for yield stress measurements: From slump to spreading flow Journal of Rheology, 49(3), 705-718.

Schatzmann, M., Bezzola, G. R., Minor, H. E., Windhab, E. J. \& Fischer, P. (2009). Rheometry for large-particulated fluids: analy- sis of the ball measuring system and comparison to debris flow rheometry. Rheol. Acta 48, No. 7, 715-733.

Schramm, G. (1998). A practical approach to rheology and rheometry, 2nd edn. Gebrueder HAAKE GmbH, Karlsruhe, Germany.

Scotto di Santolo, A., Pellegrino, A.M., Evangelista, A. \& Coussot, P. (2012). Rheological behaviour of reconstituted pyroclastic debris flow. Géotechnique 62, No. 1, 19-27, http:// dx.doi.org/10.1680/geot.10.P.005.

SERTÃ, H. B. C. Aspectos geológicos e geotécnicos do solo residual do campo experimental II da PUC/RJ. Dissertação de mestrado. Pontifícia Universidade Católica do Rio de Janeiro, PUC-Rio, Rio de Janeiro-RJ, 1986, 206p.

Shieh, C. L., Jan, C. D. \& Tsai, Y. F. (1996). A numerical simulation of debris flow and its application. Nat. Hazards 13, No. 1, 39-54.

SOARES, A. P. A. L. Avaliação do mecanismo de ruptura da encosta em solo residual não saturado da Vista Chinesa. Dissertação de mestrado. Pontifícia Universidade Católica do Rio de Janeiro, PUC-Rio, Rio de Janeiro-RJ, 1999, 156p.

SOARES, R. M. Resistência ao cisalhamento de um solo coluvionar não saturado da cidade do Rio de Janeiro. Dissertação de mestrado. Pontifícia Universidade Católica do Rio de Janeiro, PUC-Rio, Rio de Janeiro-RJ, 2005, 172p.

Sosio, R. \& Crosta, G. B. (2009). Rheology of concentrated granular suspensions and possible implications for debris flow modeling. Water Resour. Res. 45, W03412.

Spira, Y., Lackner, R., Pichler, C. H. \& Mang, H. A. (2005). Viscoplastic material models for soil: new insight into the soil-support interaction in NATM tunnel excavations. Archs Mech. 57, No. 2-3, 209-240.

Staron, L., Lagree, P-Y., Ray, P., Popinet, S. (2013) Scaling laws for the slumping of a Bingham plastic fluid, Journal of Rheology, 57(4), 1265-1280.

Takahashi, T. (2007). Debris flow: mechanics, prediction and countermeasures. Rotterdam, the Netherlands: Taylor \& Francis/ Balkema.

Tanigawa, Y. \& Mori, H. (1989). Analytical study on deformation of fresh concrete. J. Engng Mech. 115, No. 3, 493-508. 
Tanigawa, Y., Mori, H. \& Watanabe, K. (1991). Analytical and experimental studies on casting of fresh concrete into modeled wall form. Trans. Japan Concrete Inst. 13, No. 1, 33-40.

TANNER, R. I. Engineering Rheology. Ed. Rev. New York: Oxford University Press, 1988, 451p.

TONELI, J. T. C. L.; MURR, F. E. X.; PARK, K. J. Estudo da reologia de polissacarídeos utilizados na indústria de alimentos. Revista Brasileira de Produtos Agroindustriais, Campina Grande, Especial, v.7, n.2, 2005, p.181-204.

Torrance, J. K. (1987). Shear resistance of remoulded soils by viscometric and fall-cone methods: a comparison for Canadian sensitive marine clays. Can. Geotech. J. 24, No. 2, 318-322.

Tsai, M. P., Hsu, Y. C., Li, H. C., Shu, H. M. \& Liu, K. F. (2011). Application of simulation technique on debris flow hazard zone delineation: a case study in the Daniao tribe, Eastern Taiwan. Nat. Hazards Earth Syst. Sci. 11, No. 11, 3053-3062.

VAN WAZER, J. R.; LYONS, J.W.; KIM, K.Y.; COLWELL, R.E. Viscosity and flow measurement: a laboratory handbook of rheology. New York: Interscience Publisher, 1966, 406p.

VIDAL-BEZERRA, J. R. M. B. Comportamento reológico da polpa de manga. Tese de doutorado. Universidade Estadual de Campinas, Campinas-SP, 2000, 159p.

Vliet, T. V. \& Lyklema, H. (2005). Rheology. In Fundamentals of interface and colloid science (ed. J. Lyklema), vol. 4, pp. 6.1-6.88. Amsterdam, the Netherlands: Elsevier.

Vyalov, S. S. (1986). Rheological fundamentals of soil mechanics. Amsterdam, The Netherlands: Elsevier. 


\section{Appendix A: LVDT calibration}

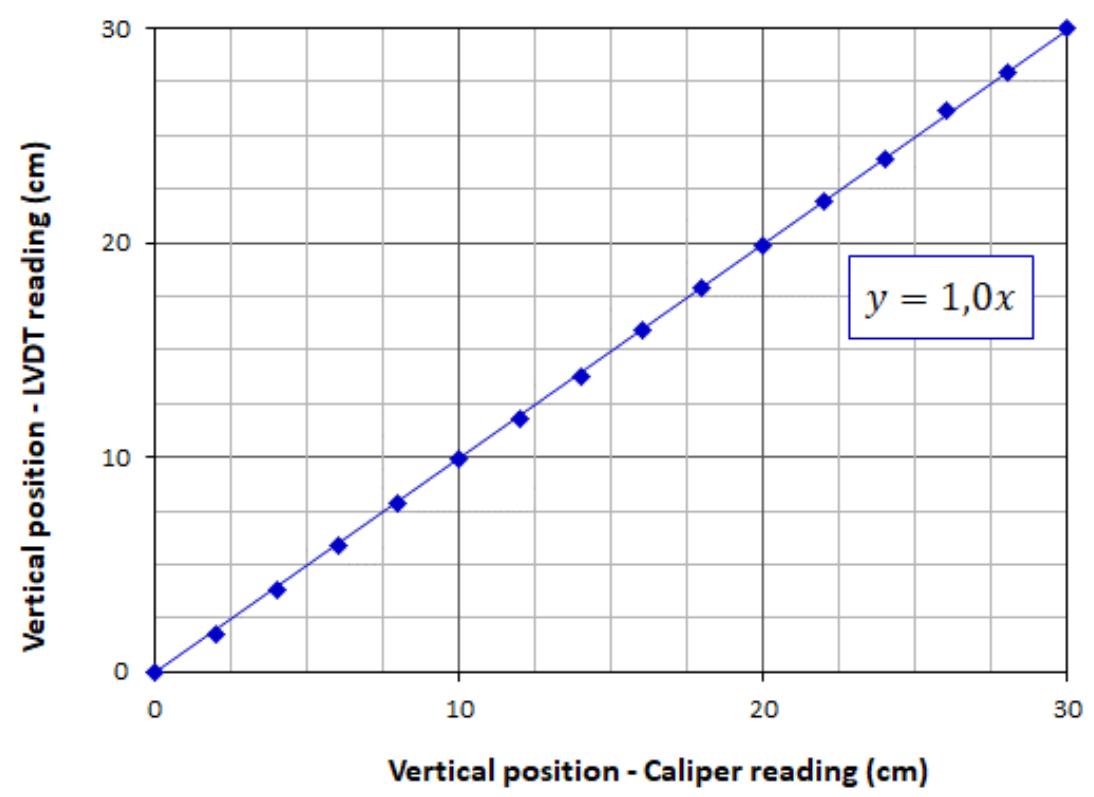

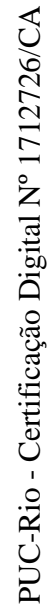

\begin{tabular}{c|c|c|}
$\begin{array}{c}\text { Time } \\
\text { (hh:mm:ss) }\end{array}$ & $\begin{array}{c}\text { Caliper reading } \\
\text { (cm) }\end{array}$ & $\begin{array}{c}\text { LDVT reading } \\
\text { (cm) }\end{array}$ \\
\hline $19: 34: 40$ & 30,0 & 30,0 \\
\hline $19: 35: 04$ & 28,0 & 27,9 \\
\hline $19: 35: 38$ & 26,0 & 26,1 \\
\hline $19: 36: 05$ & 24,0 & 23,9 \\
\hline $19: 36: 28$ & 22,0 & 22,0 \\
\hline $19: 36: 52$ & 20,0 & 19,9 \\
\hline $19: 37: 09$ & 18,0 & 17,9 \\
\hline $19: 37: 28$ & 16,0 & 15,9 \\
\hline $19: 37: 39$ & 14,0 & 13,8 \\
\hline $19: 38: 04$ & 12,0 & 12,0 \\
\hline $19: 38: 17$ & 10,0 & 9,9 \\
\hline $19: 38: 29$ & 8,0 & 7,9 \\
\hline $19: 38: 42$ & 6,0 & 5,9 \\
\hline $19: 38: 54$ & 4,0 & 4,0 \\
\hline $19: 39: 12$ & 2,0 & 1,9 \\
\hline $19: 39: 24$ & 0,0 & 0,0 \\
\hline
\end{tabular}




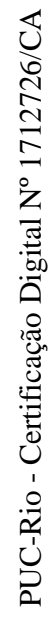

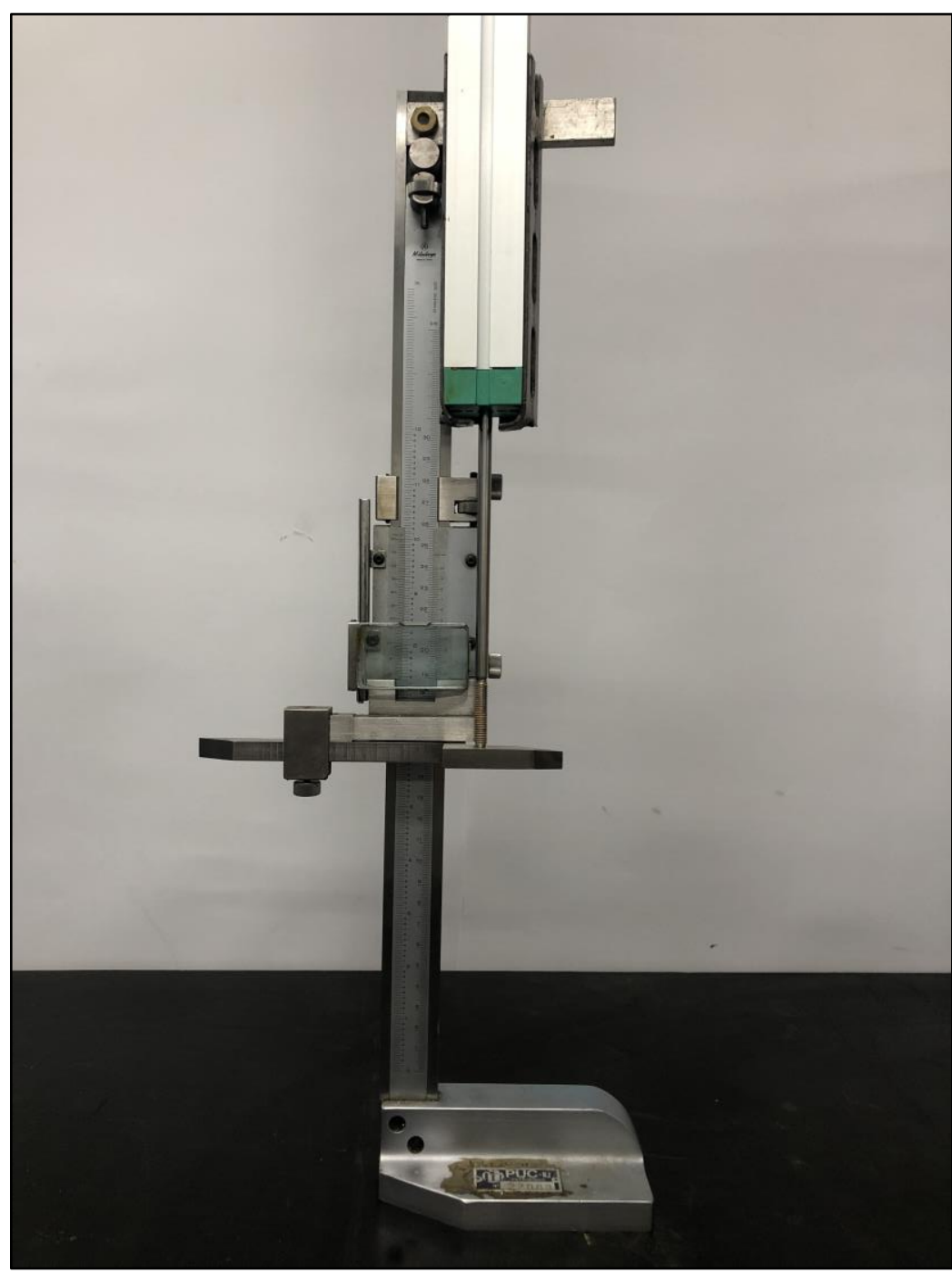




\section{Appendix B: Camera calibration}

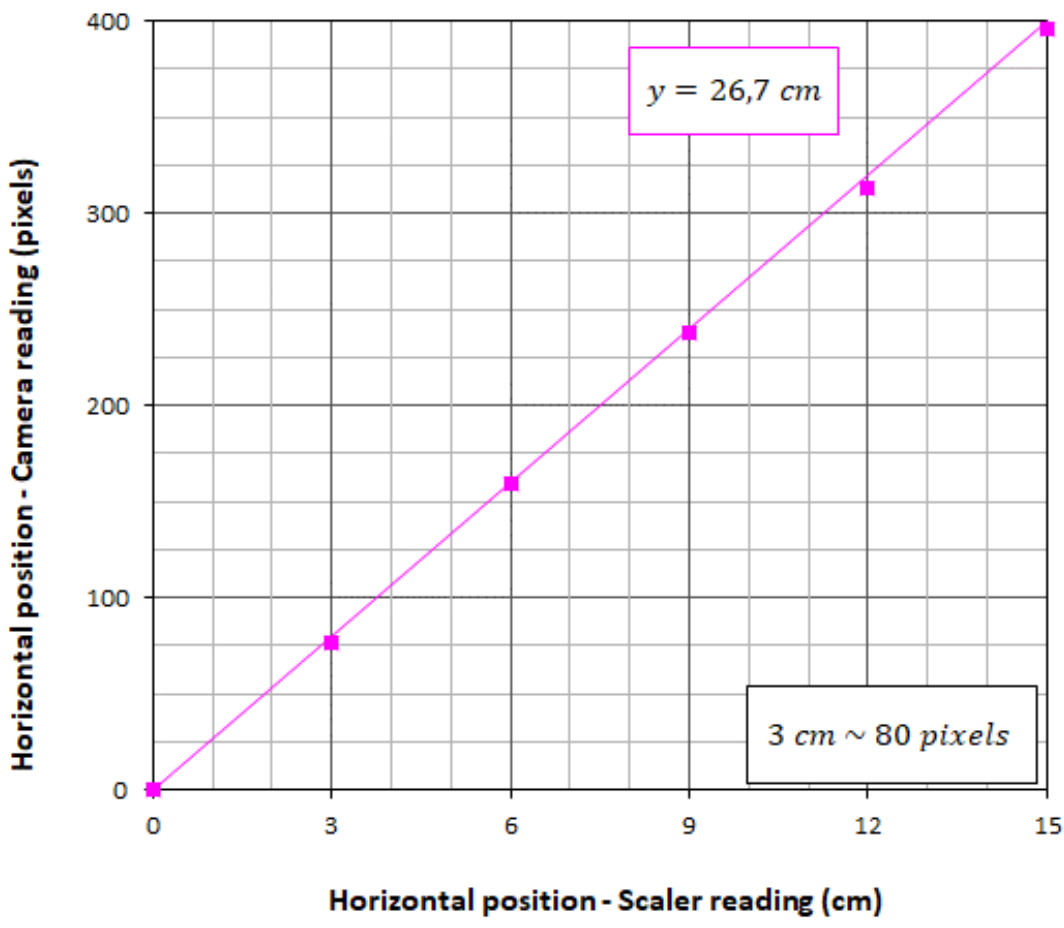

\begin{tabular}{c|c|c|}
$\begin{array}{c}\text { Time } \\
\text { (hh:mm:ss) }\end{array}$ & $\begin{array}{c}\text { Scaler reading } \\
(\mathrm{cm})\end{array}$ & $\begin{array}{c}\text { Camera reading } \\
\text { (pixels) }\end{array}$ \\
\hline $11: 27: 10$ & 0,0 & 0,0 \\
\hline $11: 27: 21$ & 3,0 & 76,9 \\
\hline $11: 27: 33$ & 6,0 & 159,4 \\
\hline $11: 27: 43$ & 9,0 & 238,1 \\
\hline $11: 27: 54$ & 12,0 & 313,1 \\
\hline $11: 28: 06$ & 15,0 & 395,6 \\
\hline
\end{tabular}



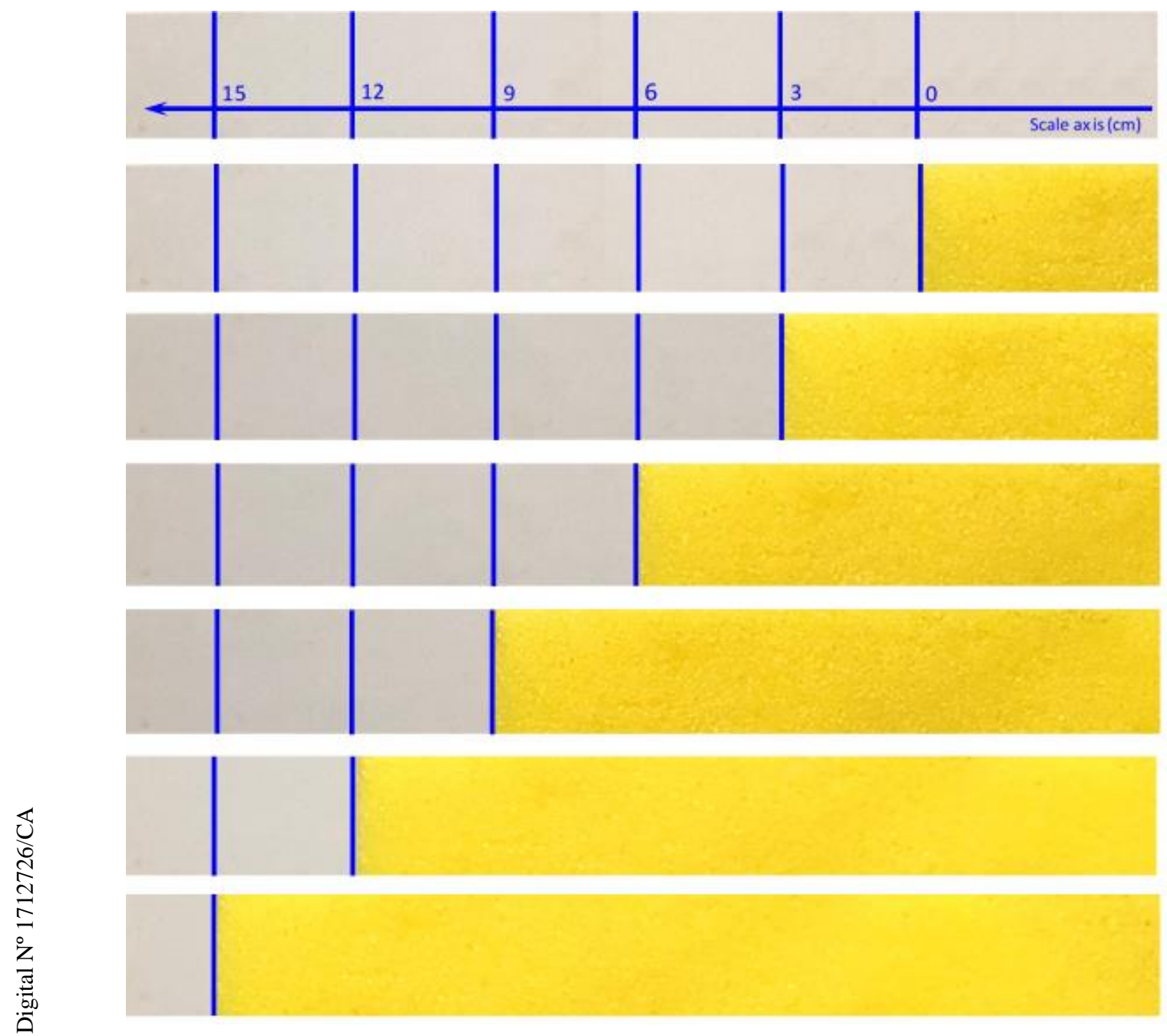

ن'

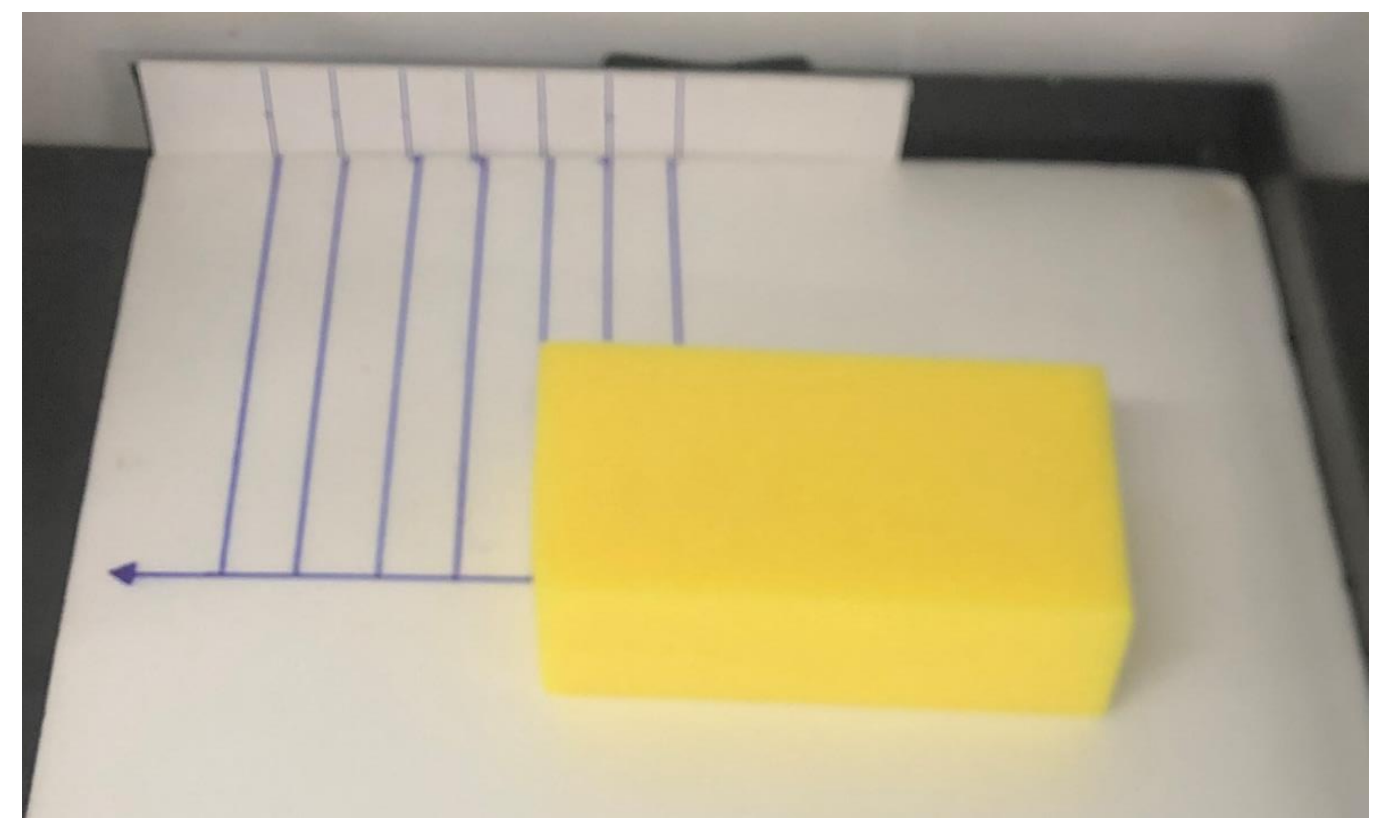




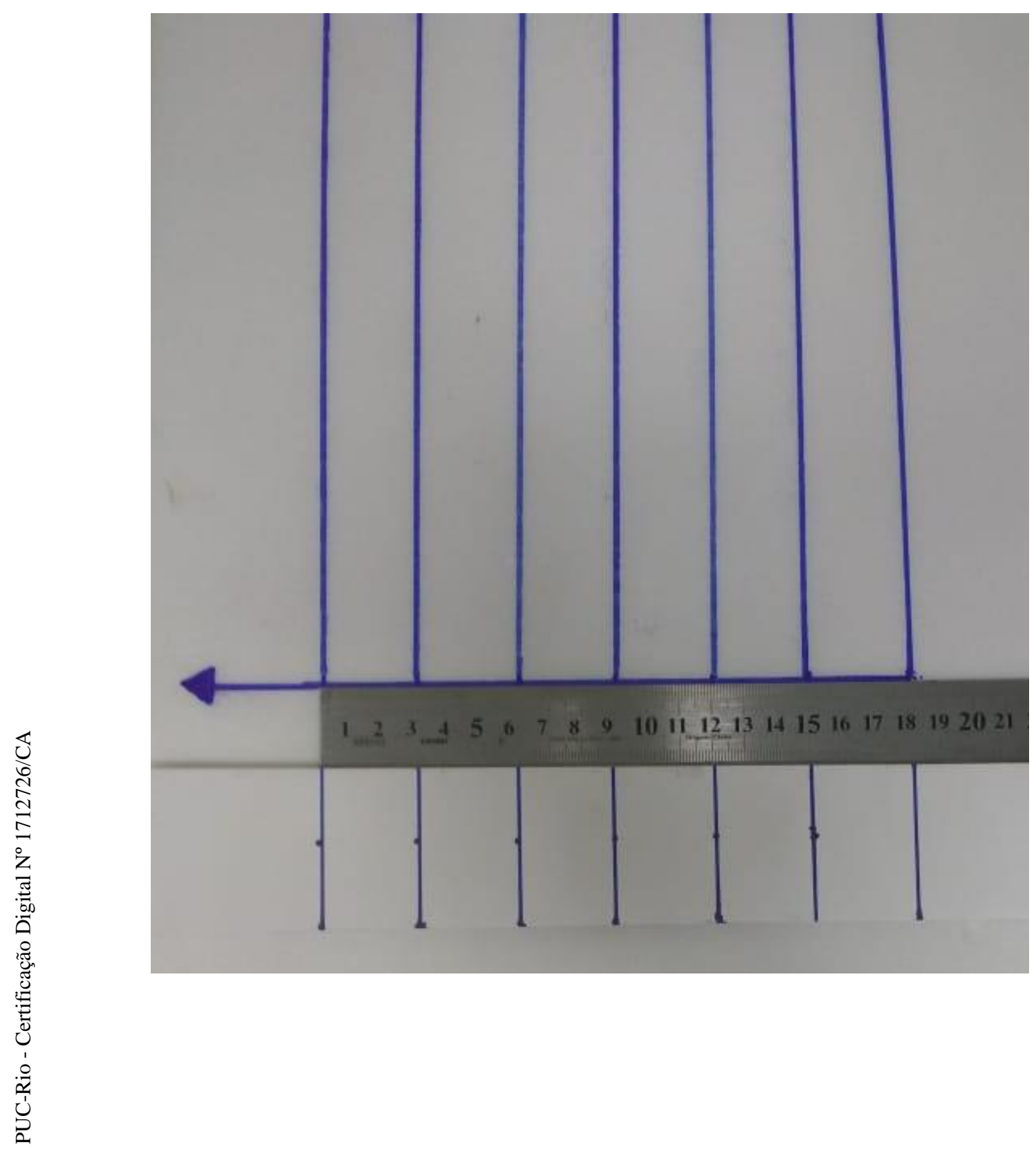

